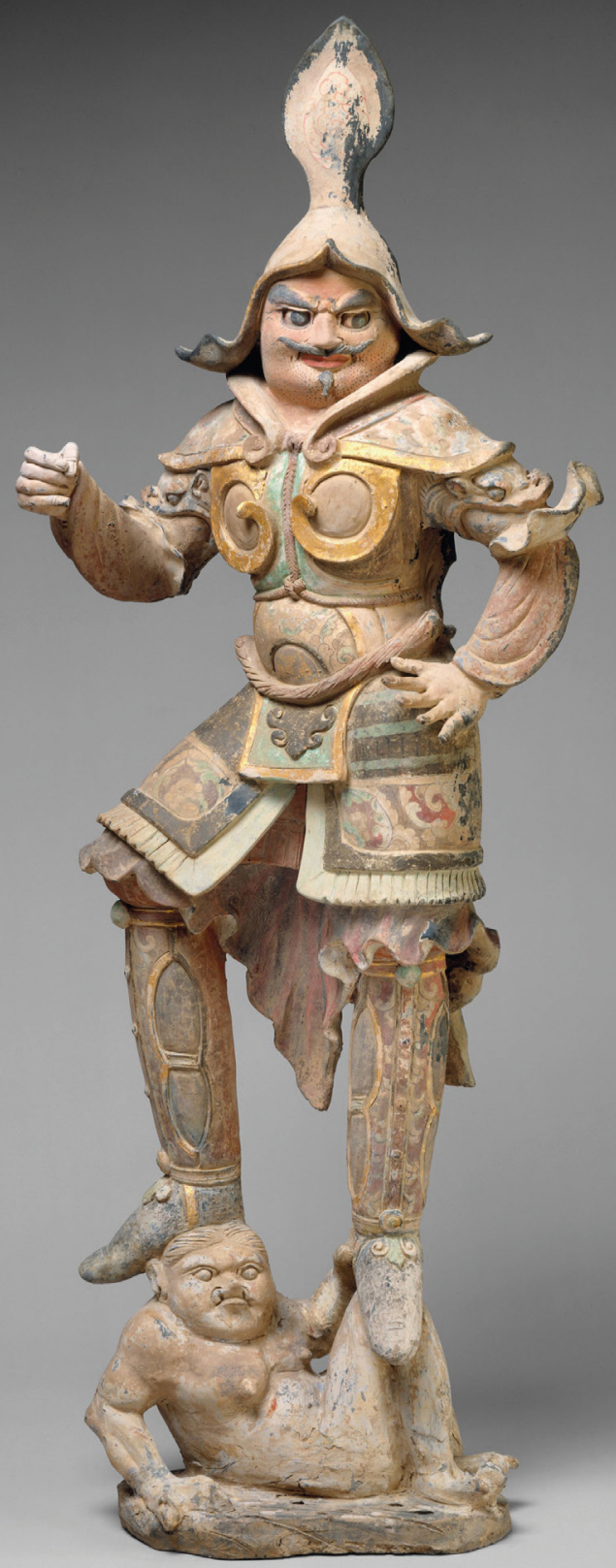

CONCEPTUALISING COMPARATIVE POLITICS

\title{
POLITICS AS A SCIENCE
} A Prolegomenon

(2) Philippe C. Schmitter and Marc Blecher 密 
"Insight and parsimony permeate this analytic road map. Schmitter and Blecher provide readers with a bold and ambitious tour d'horizon showing essential linkages among dozens of concepts integral to comparative politics and international relations. Readers will return to it regularly for insights and examples."

T.J. Pempel, Jack M. Forcey Professor, Political Science, University of California, Berkeley

"Schmitter and Blecher provide a great overview of bringing politics back into political science, with a high-level overview of the main building blocks for a science of politics that is sensitive to the uncertain and dynamic nature of the contemporary world while remaining attentive to the enduring features of what makes politics political."

Todd Landman, Professor of Political Science, University of Nottingham

"This book offers a compelling reflection on the essence of the study of politics, or politology, and on its importance. It puts power and its exercise squarely in the center and, in jargon-free language, develops a comprehensive view of their foundations and consequences."

Evelyne Huber, Distinguished Professor of Political Science, University North Carolina 

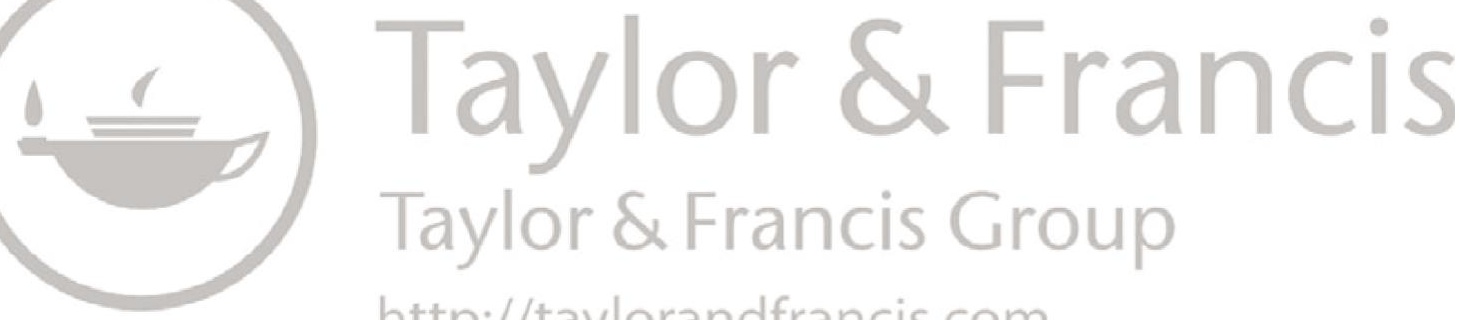

http://taylorandfrancis.com 


\section{POLITICS AS A SCIENCE}

\section{A Prolegomenon}

In Politics as a Science, two of the world's leading authorities on comparative politics, Philippe C. Schmitter and Marc Blecher, provide a lively introduction to the concepts and framework to study and analyze politics.

Written with dexterity, concision and clarity, this short text makes no claim to being scientific. It contains no disprovable hypotheses, no original collection of evidence and no search for patterns of association. Instead, Schmitter and Blecher keep the text broadly conceptual and theoretical to convey their vision of the sprawling subject of politics. They map the process in which researchers try to specify the goal of the trip, some of the landmarks likely to be encountered en route and the boundaries that will circumscribe the effort. Examples, implications and elaborations are included in footnotes throughout the book.

Politics as a Science is an ideal introduction for anyone interested in, or studying, comparative politics.

Philippe C. Schmitter is Emeritus Professor of the Department of Political and Social Sciences at the European University Institute. Since 1967 he has been successively assistant professor, associate professor and professor of political science at the University of Chicago, then at the European University Institute (1982-1986 and 1997-2005) and at Stanford (1986-1996). He has published widely on comparative politics, European and Latin America regional integration, transitions from authoritarian rule and democratization processes and the intermediation of class, sectoral and professional interests. Schmitter won the Johan Skytte Prize in Political Science in 2009, the ECPR Lifetime Achievement Award by the European Consortium for Political Research in 2007, the EUSA Award for Lifetime Achievement in European Studies by the European Union Studies Association in 2009 and the Mattei Dogan Prize 
awarded by the International Political Science Association (IPSA) to a scholar of high international reputation in recognition of their contribution to political science in 2009.

Marc Blecher is James Monroe Professor of Politics and East Asian Studies at Oberlin College. He has also served as a Senior Research Fellow at the UC Berkeley Center for Chinese Studies, Visiting Professor of Political Science at the University of Chicago and Visiting Fellow at the Institute of Development Studies of the University of Sussex (UK). His specialty is Chinese politics, on which he has published five books and dozens of articles on local politics, popular participation and political economy. His research has been supported by the American Philosophical Society, the Ford Foundation and the National Endowment for the Humanities. Blecher teaches about Chinese and Asian politics and political economy, Marxian theory, the politics of class, and politics and theatre. His ongoing research focuses on workers' politics in contemporary China. 

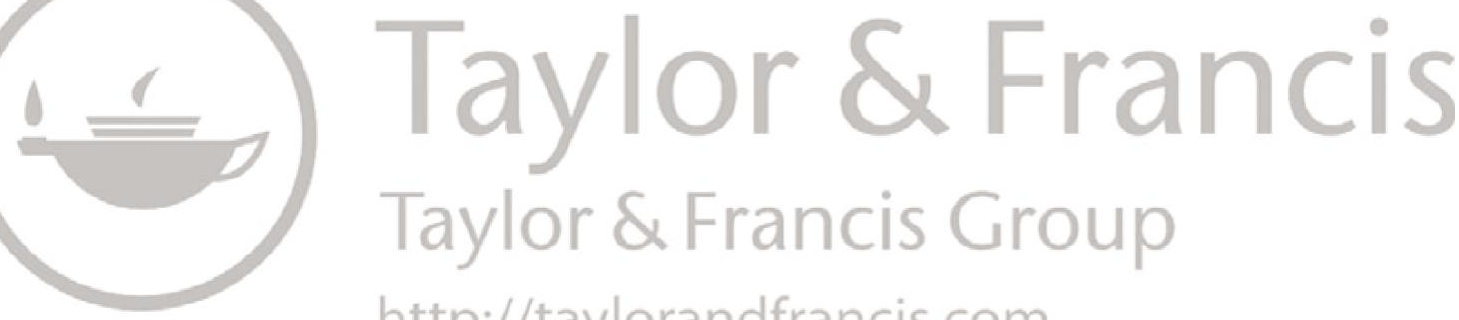

http://taylorandfrancis.com 


\section{Conceptualising Comparative Politics: Polities, Peoples, and Markets}

Edited by Anthony Spanakos (Montclair State University) and

Francisco Panizza (London School of Economics)

Conceptualising Comparative Politics seeks to bring a distinctive approach to comparative politics by rediscovering the discipline's rich conceptual tradition and inter-disciplinary foundations. It aims to fill out the conceptual framework on which the rest of the subfield draws but to which books only sporadically contribute, and to complement theoretical and conceptual analysis by applying it to deeply explored case studies. The series publishes books that make serious inquiry into fundamental concepts in comparative politics (crisis, legitimacy, credibility, representation, institutions, civil society, reconciliation) through theoretically engaging and empirically deep analysis.

\section{Manipulating Political Decentralisation}

Africa's Inclusive Autocrats

Lovise Aalen and Ragnhild L. Muriaas

\section{Shaping Citizenship}

A Political Concept in Theory, Debate and Practice

Edited by Claudia Wiesner, Anna Björk, Hanna-Mari Kivistö

and Katja Mäkinen

10 The End of Communist Rule in Albania

Political Change and The Role of The Student Movement

Shinasi A. Rama

\section{Authoritarian Gravity Centers}

A Cross-Regional Study of Authoritarian Promotion and Diffusion

Thomas Demmelhuber and Marianne Kneuer

\section{Politics as a Science}

A Prolegomenon

Philippe C. Schmitter and Marc Blecher

For more information about this series, please visit: https://www.routledge.com 


\section{POLITICS AS A SCIENCE}

A Prolegomenon

Philippe C. Schmitter and Marc Blecher 
First published 2021

by Routledge

52 Vanderbilt Avenue, New York, NY 10017

and by Routledge

2 Park Square, Milton Park, Abingdon, Oxon, OX14 4RN

Routledge is an imprint of the Taylor E Francis Group, an informa business

(C) 2021 Philippe C. Schmitter \& Marc Blecher

The right of Philippe C. Schmitter \& Marc Blecher to be identified as authors of this work has been asserted by them in accordance with sections 77 and 78 of the Copyright, Designs and Patents Act 1988.

The Open Access version of this book, available at www.taylorfrancis. com, has been made available under a Creative Commons AttributionNon Commercial-No Derivatives 4.0 license.

Trademark notice: Product or corporate names may be trademarks or registered trademarks, and are used only for identification and explanation without intent to infringe.

Library of Congress Cataloging-in-Publication Data

A catalog record for this title has been requested

ISBN: 978-0-367-46949-8 (hbk)

ISBN: 978-0-367-46469-1 (pbk)

ISBN: 978-1-003-03214-4 (ebk)

Typeset in Bembo

by codeMantra 
To Terry who not only understands politics, but also practices it. - PCS

For Hannah, and for Jacob, Aria, Naomi and Solomon, who carry her brilliant torch. $-M J B$ 

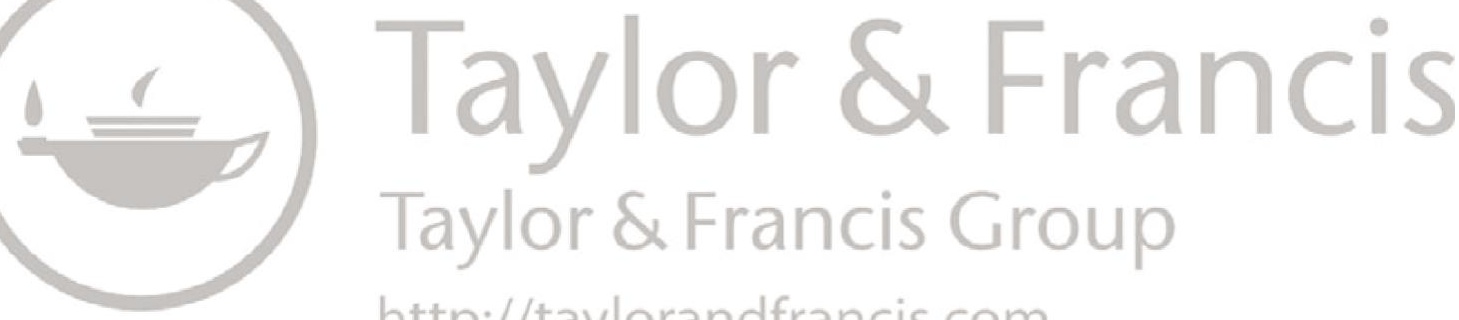

http://taylorandfrancis.com 


\section{CONTENTS}

The Cover xiii

Preface and Acknowledgments xv

1 The Subject Matter 1

1.1 The Core: Power and Politics 1

1.2 The Exercise of Power 9

2 The Foundations 14

2.1 The Concepts 19

2.2 The Agents 22

2.3 The Cleavages 37

2.4 The Motives 41

2.5 The Processes 44

2.6 The Mechanisms 47

2.7 The Temporalities 51

2.8 The Units 56

2.9 The Régimes 58

3 The Consequences $\quad 67$

3.1 Order 68

3.2 Production and Distribution 70 
xii Contents

3.3 Recognition and Respect 71

3.4 Externalities 73

3.5 Legitimacy 74

4 The Discipline

4.1 The Theoretic Trajectory 79

4.2 The Liberal Bias 82

4.3 The Methods 85

5 The Design of Research

5.1 Choice of Topic 93

5.2 Conceptualization 94

5.3 Formation of Hypotheses 96

5.4 Selection of Cases 97

5.5 Proposal Writing 102

5.6 Operationalization of Variables 103

5.7 Measurement 105

5.8 Test for Association 106

5.9 Causal Inference 108

5.10 Evaluation of Results 111

Conclusion 111

6 The Purpose

7 The Promise

References

Index 


\section{THE COVER}

Our cover depicts an Eighth Century Tang Dynasty figurine of a Samurai imperial tomb guardian vanquishing an attacking demon. It was unearthed on the site of what is now the Northeastern College of Politics and Law in Xi'an, China's ancient capital. In 2004, it traveled to the Tokyo National Museum, where Schmitter was lucky enough to see it. The concatenation of its imagery of a battle to the death, to protect the dead no less, with its discovery at an institute for the study and advancement of politics and law encapsulates the core theme of our book: politics as the effort to domesticate raw, destructive power struggle in favor of civilized, even peaceable management of conflict, without which society would be impossible. 

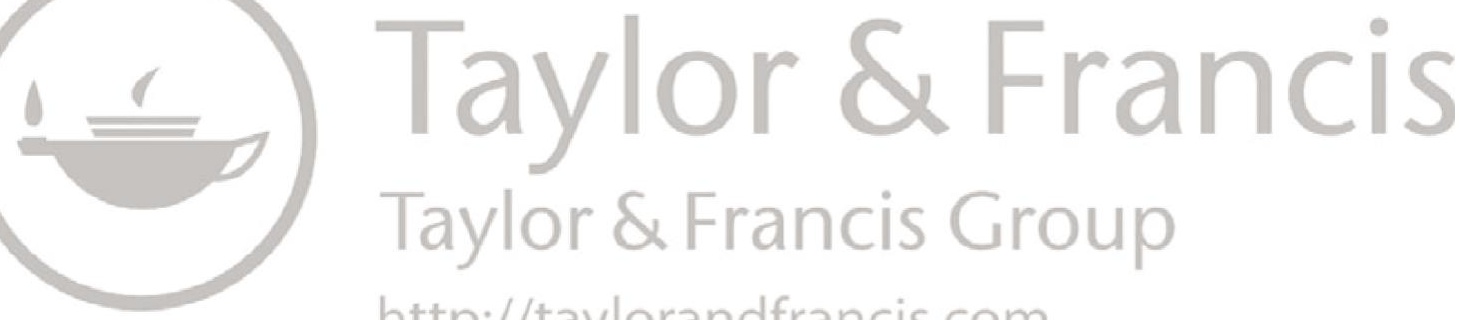

http://taylorandfrancis.com 


\section{PREFACE AND ACKNOWLEDGMENTS}

These are the reflections of two professors who have had lengthy careers researching and teaching "the politics of others" - known in the profession as "comparative politics." Always being on the outside looking in has its advantages and disadvantages. It should make one less susceptible to presuming that the rules and practices of one's own polity are normal and, therefore, should provide a more objective standard for observing and evaluating the politics of others. As a Chinese saying puts it, "Those up close are lost; onlookers see most clearly." 2

1 We write "of others," rather than "of other countries," for two reasons. First, we will argue infra. that the units within which politics takes place - polities, if you will - are not limited to countries (or national states). Second, we wish to highlight the human context of politics which was and still is missing in much research in the field. Comparing polities involves the analysis of at least one unit and group of persons that is "other" to the investigator. The potential bias - ranging from subjective distortion across cultures and languages, as well as the stretching of concepts across time and space - remains an under-explored (and potentially treacherous) subject. See Peregrine Schwartz-Shea and Dvorah Yanow, Interpretive Research Design: Concepts and Processes (New York: Routledge, 2012); Frederic C. Schaffer, Elucidating Social Science Concepts: An Interpretivist Guide (New York and London: Routledge, 2016); and Edward Schatz, Political Ethnography: What Immersion Contributes to the Study of Power, ed. Edward Schatz (Chicago, IL: University of Chicago Press, 2009) for a discussion of this issue. Thanks to Tony Spanakos for the second point.

2 当局者迷,旁观者清. The best testimony to this advantage of comparative politics comes from Blecher's Chinese students. Every time he has expressed his sheepishness about teaching Chinese politics to them, they have responded - au contraire - that analyzing their own country through the comparative lenses of a foreigner has profoundly opened their eyes. 
However, the comparative approach also means that the necessarily short exposure to other people's politics - and it gets shorter and shorter as one gets older - deprives the researcher of the depth of observation and, yes, feeling that is needed to capture all of the subtleties and secrets of their behavior. ${ }^{3}$ Indeed, even years of immersion cannot fully bridge the gap. Of course, one can always take refuge in statistical manipulations of data that can be gathered at one's deskwithout having to go to some exotic locale. ${ }^{4}$ But, as we shall see, data often produce significant distortions when they travel. Our experience has suggested that there is no substitute for living among and talking with the subjects of one's research - and preferably in their own language - for as long as possible. ${ }^{5}$

The authors also have something else in common: the University of Chicago where they met when Schmitter was a very beginning assistant professor and Blecher a very beginning doctoral candidate. From this point, our careers have diverged in ways that we hope will be of benefit to the reader. Isaiah Berlin once said that there were two kinds of scholars: "foxes and hedgehogs" and that both were equally valuable for the creation of knowledge. ${ }^{6}$ Schmitter, an incorrigible and unrepentant "fox," knows a little bit about many things; Blecher, an area specialist "hedgehog," knows more about fewer things and, therefore, was able to benefit from his teacher's greater range. ${ }^{7}$ Schmitter has spent his career teaching only doctoral students at a wide variety of sites: mainly Chicago, Stanford and the European University Institute - not to mention shorter "gigs" at various universities and institutes in Latin America, Western, Southern and

3 Although we have always been on the outside, many students of comparative politics do so from the inside, i.e., by working on their own country. Presumably, the requirement that they do so by applying generic concepts and exogenous theories protects them from the potential nativist bias.

4 If the reader agrees with our assumption that comparison is the best design for understanding politics, he or she may wish to apply Giovanni Sartori's test, namely, when considering reading an article or book, calculate how many of its footnotes and references were written by foreigners or, even better, are in foreign languages. Discount both indicators if the country in question is an autocracy that does not permit the domestic practice of political science or allow foreigners to conduct research there.

5 Like most political scientists, we see the move beyond the Western (European and North American) tradition which prioritized single-case research and formal - often only constitutional - institutions as beneficial to the discipline. To be a true comparativist, a scholar must be prepared to "live comparatively." The vernacular employed by natives, local academics or ruling elites conveys a distinctive knowledge about the "realexisting" practices occurring within a political community. Students of politics should learn the phrases, quirks and languages spoken by persons and communities within each country of study. (Thanks to Mishella Romo for emphasizing this to us.)

6 Isaiah Berlin, The Hedgehog and the Fox (London: Weidenfeld and Nicoloson, 1933).

7 Indeed, Blecher remembers a seminar in which Schmitter confessed to "crass eclecticism," a sin against which graduate students were, for the most part, strenuously warned, in part because they were told that they would be punished in the job market if they could not be identified as card-carrying members of some fashionable "school" in the discipline - usually, of course, the one of which the instructor was a follower. 
Eastern Europe, Africa, the Middle East and Asia. Blecher has been more of a hedgehog in his scholarship and location, but has also taught very bright, inquisitive, mainly American but also increasingly international, undergraduates at Oberlin College who, like scholarly foxes, love to ask big, synthetic questions as they begin their quest to make sense of a complex world. Hence, the shamelessly broad brush of this book and its attempt to appeal to a broad range of students, scholars and citizens.

When we started this project, our purpose was relatively simple: to demonstrate that comparison across units of action (national, sub-national and supranational) was the best method for advancing scientific knowledge about politics, and that this was the case regardless of the many sub-fields into which the academic field of political science has been divided. Granted that there is only one "planet" of international relations, but it too is divided into numerous subcomponents ("regions") and time-periods ("epochs") that can be compared.

But as we advanced, we discovered many other objectives: (1) the most obvious is the crucial importance of conceptualization - choosing the right words and associations to capture the similarities and differences in politics across space and time; (2) the desirability of breaking through the geographic and cultural boundaries (East and West, North and South) that have separated the discipline and to attempt, at least, to take a universalistic approach to the study of politics; (3) but also the importance of eschewing any notion of universal laws or generalizations about how politics actually operates, stressing instead its complexity, historicity, contingency, human subjectivity and, because of all this, its uncertainty, unpredictability and variability; (4) the imperative of recognizing that the exercise of power and its consequences - whenever and wherever - has distinctive properties - its own logic - that cannot be captured by simply borrowing assumptions and concepts from other social science disciplines; (5) the paradox that, while politics is a continuously changing subject matter, it is very important for researchers to connect their own contemporary work with the enduring tradition of inquiry - both objective and normative that has been dedicated by our forerunners to almost every aspect of it; (6) the study of politics is the most challenging of the social sciences - not only because of the nature of the topic but also because of the passions and interests inevitably associated with it and unavoidably affecting its students; (7) the focus of acquiring knowledge about politics should be first and foremost on substance, and the method chosen should depend on that choice ${ }^{8}$; and (8) the greatest appeal

8 Abraham Kaplan once wisely observed that: "Give a small boy a hammer, and he will find that everything he encounters needs pounding." Abraham Kaplan, The Conduct of Inquiry: Methodology for Behavioral Science (San Francisco, CA: Chandler Publishing Co., 1964), 28. American political scientists (perhaps, because of the unusually competitive marketplace that surrounds them) seem particularly adept at wielding the latest statistical 
for choosing to study politics is precisely that which makes it so difficult to do so: the intrinsic uncertainty and contingency of the subject matter.

This lengthy essay-cum-short book makes no claim to being scientific. It contains no disprovable hypotheses, no original collection of evidence, no search for patterns of association and certainly no conclusive inferences about causality. It is self-consciously "pre-scientific." 9 Before one can do any science, and especially any social science, one must identify and label what it is that one is trying to understand or explain. Without the "right" words (and the "right" theory surrounding them), researchers could not even begin their task, much less gather the relevant evidence. In the case of political (or any social) research, "Que dire?" (What should I say?) comes before "Que faire?" (What should I do?). In academic jargon, this indispensable first stage is called "conceptualization." It is a sort of mapping process in which the researcher tries to specify the goal of the trip, some of the landmarks likely to be encountered en route and the boundaries that will circumscribe his or her effort. ${ }^{10}$

For those readers who are already in the business of explaining politics to others, we hope you will find this effort useful later, when generating explicit hypotheses that can be tested and, if verified, allow you to make reasonable inferences about why specific forms of power are exercised and what their effects are likely to be. ${ }^{11}$

Our book also contains only a few novelties. Most of its assumptions and concepts have been borrowed from our forerunners in what has been a lengthy effort to understand the reality of politics. We are convinced that

hammer to pound whatever data can be found, regardless of the nature or significance of the topic chosen.

9 Hence, our sub-title, prolegomenon, defined as an "introduction or preliminary observation on the subject of a book," The Compact Edition of the Oxford English Dictionary (Oxford: Oxford University Press, 1971), vol. II, p. 1446. In short, this is not a comprehensive and definitive "how-to do-it manual," but an exploration of what to do before doing it.

10 We are not suggesting that conceptualization is just a single phase that is surpassed once hypotheses have been drafted and empirically tested. By recognizing the pre-scientific nature of much of the discipline, we wish explicitly to keep open the question of conceptualization which may have to be re-visited "serendipitously" once the actual data-gathering and analysis has taken place. Thanks to Tony Spanakos for this point; see Anthony P. Spanakos, "Conceptualising Comparative Politics: A Framework," in Anthony P. Spanakos and Francisco Panizza, eds. Conceptualising Comparative Politics (New York: Routledge, 2015), 1-14.

11 Consistent with our epistemological position, which is suspicious of approaches that claim to produce Truth, our proposed goal when making inferences is more modest: "reasonableness." In this reading, unlike Truth, which corresponds invariably to "the facts" and is part of an intersubjective understanding rooted in the naturally observable world, reasonableness is the tentative byproduct of the gathering of largely artifactual data and the imperfections in communication that are intrinsic to the human condition and, especially, to its politics. Thanks again to Tony Spanakos for seeing this in our work. 
almost everything generically meaningful about politics has already been said somewhere by someone, and often a long time ago. It is just a matter of finding it and assembling it in a novel manner. This is what we have tried to do here. ${ }^{12}$

To those who are long or recently gone, we can only apologize for not having explicitly cited their eternally valid work. Doing so would have made this essay excessively academic - and much too long. ${ }^{13}$ Schmitter does, however, want to acknowledge formally the multiple contributions of his wife, colleague and muse, Terry Lynn Karl. Without her support (and not infrequent disagreements), none of his contribution would have been possible. Or, if still possible, it would have been decidedly inferior. Blecher wishes to single out Schmitter and Tang Tsou, his two most important teachers - who shared an office suite, no less! - at the University of Chicago. More than once, he has subsequently discovered the humbling truth that ideas he thought his own in fact originated from their scholarship and teaching.

Tony Spanakos and Mishella Ramo served as steadfast supporters of the project, and contributed sage advice on key questions about how to do politology. Wise critique from two referees helped us improve the manuscript. At Routledge we benefited from cooperative, professional help from Charlie Baker, Natalja Mortensen and Assunta Petrone.

We have tried to write this essay without excessive professional jargon. Like all social scientists, political scientists - whom we will suggest might better call themselves "politologists" - have developed a vocabulary of their own. As the reader shall discover, this poses a serious problem of communication in part since some of their concepts are identical to those used by the political agents they are studying but can have a different meaning. Other concepts are unique to their discipline. These can seem esoteric and confusing to the non-specialist. Thus, in an effort to avoid these complications and obfuscations, we have made frequent use of boldface to indicate key concepts and tried to convey their (often exotic) meanings.

12 Here, we wish to share a comment we received from Tony Spanakos: "Contemporary reviewers of manuscripts usually look for the 'value added' or what is 'innovative' in a submitted piece of scholarship - and reward the authors accordingly. Like Isocrates (in Against the Sophists), Schmitter and Blecher attribute less value to novelty than to continuity and accumulation. They also stress the potential contribution of putting together a meta-vision of the sub-field by identifying key concepts, suppositions and approaches. Most students of comparative politics follow the advice of King, Keohane and Verba, and attribute little value to such a synthesis or macro-vision. Schmitter and Blecher's reference to "a long time ago" is implicitly a critique of the sub-field's loss of a sense of its own history." Tony Spanakos, personal communication. See Gary King, Robert Keohane and Sidney Verba, Designing Social Inquiry: Scientific Inference in Qualitative Research (Princeton, NJ: Princeton University Press, 1994).

13 We have eschewed inserting empirical references in footnotes that would cite the work of others to bolster our credibility - not just to reduce the length of this book, but also because our purpose is primarily conceptual and methodological. 
Finally, we have kept the main text spare, and broadly conceptual and theoretical, in the interests of conveying as crisply and clearly as possible our vision of the sprawling subject of politics. But, because we don't want all that to hang in thin air, we have punctuated our discussion with footnotes that introduce concrete examples, explore implications and offer elaborations. We are sad, but not surprised, at the decline of such "substantive" footnoting in all of the social sciences - a development we chalk up to authors, referees and editors having fallen for the "professional" drive for specialization that impoverishes the wider connections, side-points and implications that could so enliven what we do. ${ }^{14}$ Consistent with our earlier admission (in footnote 7) of "crass eclecticism" to counterbalance "narrow empiricism," we have moved in the opposite direction by reviving the substantive footnote, and we urge our readers to cast their eyes occasionally to the bottom of the page. If this does not add to their enlightenment, it may at least help prevent them from closing their eyes altogether.

14 In academic practice, substantive remarks are located at the bottom of the page; references are usually bunched together as endnotes. We have overdosed on the former and more or less eschewed the latter. 


\title{
THE SUBJECT MATTER
}

\begin{abstract}
Politics is a (if not the) quintessential human activity - the "master science" of the sphere within which all other human activities must take place. Its goal is to domesticate the inevitable conflicts that arise from our need to live together in communities under conditions of scarcity. This requires coordination, which, in turn, necessarily involves the controlled exercise of power. Politics involves the development of mutually agreed upon rules, norms, institutions and/or reliably applied practices that permit conflicts to be resolved pacifically to preclude the resort to violence. Yet, it also produces constant contestation, which makes politics inherently dynamic and always unbalanced. It also involves units that are not equivalent, and that are conscious and themselves transformed as they interact. They do so through highly imperfect processes of communication. Politics is also inherently historical, since humans are always affected by their experiences and institutions. For all these reasons, politics is a very different kind of realm from the natural world, with its predictable regularities and objective processes. So is the "science" that studies it. Thus, it would be appropriate to give the study of politics its own name that captures its uniqueness as a science: politology.
\end{abstract}

\subsection{The Core: Power and Politics}

Politics is a (if not the) quintessential human activity. ${ }^{1}$ It brings to bear on the relations between persons many of the qualities that are unique to the human species. Ever since they have lived together in communities large enough to

1 Should politics be singular or plural? In this text, we have tried consistently to use the former when referring to its generic properties and the latter when referring to its diverse practices. 


\section{The Subject Matter}

require interdependent action in order to survive, human beings have, even when just hunting and gathering, had to do so in a social context. Often (and increasingly often, as they moved into more complex processes of production), they have had to coordinate their efforts and, therefore, to make decisions about what, how and how much to produce and how to distribute it. Just the existence of scarcity, not to mention innate differences in individual preferences and resources, has compelled them to attempt to resolve the inevitable conflicts of interest and sentiment that this requires. If all such decisions were so-called "Pareto Optimal" - i.e., benefitted everyone without harming anyone - politics would be unnecessary. They are very rarely so, and this means that some persons will have to either convince or compel others to contribute or to conform.

Power is what we commonly call this process - the capacity to make others do what we want them to do which they would not otherwise wish or choose to do. ${ }^{2}$ It always has at least "two faces." The one that is easier to observe and eventually to measure involves coercion - the use or threat of physical force to bring about an intended outcome. The second is much less visible and, hence, potentially more insidious. It involves the multifarious ways in which the powerful manipulate the knowledge, preferences and patterns of thought of the less powerful in order to convince them to conform "voluntarily" to the "legitimate" demands of those in power. The study of politics is dedicated to making sense of both of these - and any of the other - faces of power. ${ }^{3}$

2 In a recent book, Stefano Bartolini has dedicated 27 pages in an effort to define what politics is. (Stefano Bartolini, The Political (London: ECPR Press/Rowman and Littlefield International, 2018), ch. 5.) The definition he proposes

(a) the process through which ordinary citizens unite their wills in the form of authority fields and constitute politically relevant actors (the politics of participation and collective action); (b) the process in which authority fields as politically relevant actors exchange support resources with factions of the elite competing for authority positions (the politics of support and pressure); and (c) the process in which these factions struggle among themselves for public authority (the politics of competition).

is not incompatible with our more parsimonious focus on the exercise of power and its consequences. Nevertheless, there is at least one way in which our approaches differ quite significantly. Bartolini focuses exclusively on politics in what we have called "real-existing" democracies (hence, the reference to citizens, participation and competition). We are equally concerned with politics in "real-existing" autocracies, as well as a large number of "hybrids" of the two. He is also much more preoccupied with probing the ambiguity of the very concept of power itself:

$[\mathrm{T}]$ here is a world of difference whether bindingness over others is applied via a direct utilisation of power/resources in dealings with other actors or whether compliance is stabilised over time and generalised to the entire membership of a system, including those against which no 'power' has been used and no conflict has been waged (p. 125).

We raise the same questions in the rest of this paragraph and infra, but much more summarily.

3 Antonio Gramsci recognized as much when he focused on the dyad of dominio and direzione (coercion and consent). See his Selections from the Prison Notebooks, eds. Quintin Hoare and Geoffrey Nowell Smith (New York: International Publishers, 1971). Since then, scholars have been competing to discover the most "faces" of power. For the original 
All of those involved in politics - be they politicians or ordinary citizens/ subjects $^{4}$ - are agents of some kind or another. ${ }^{5}$ Their actions are not completely pre-determined by the physical or social contexts in which they find themselves. They have, or at least believe they have, choices to make among alternative courses of action. Moreover, they are intrinsically "restless" with regard to their environment. ${ }^{6}$ Some agents are dissatisfied with their existing situation and, hence, willing to try to change it. In so doing, they are very likely to provoke a response from those who are not so dissatisfied. The latter will react to defend the status quo and, therefore, also become agents. ${ }^{7}$ To effect

two, see Peter Bachrach and Morton S. Baratz, "Two Faces of Power," American Political Science Review 56, no. 4 (December 1962): 947-952. For three, see Steven Lukes, Power: A Radical View (New York: Macmillan, 1973); for four, see Peter Digeser, "The Fourth Face of Power,' Journal of Politics 54, no. 4 (November 1992): 977-1007; for all five, see Iris M. Young, Justice and the Politics of Difference (Princeton, NJ: Princeton University Press, 1990). By now, there may be a sixth that we have not yet encountered.

4 What concept should be used when referring to the political behavior of the vast majority of people who are not self-declared politicians or political activists? This genotype (i.e., generic concept) requires immediate specification into observable phenotypes (i.e., sub-types) that vary according to régime. Politologists usually refer to people who live in democracies in which people have political rights as citizens, and those living in those kinds of régimes which do not have such rights as subjects. We have adopted here the somewhat awkward term "citizens/subjects" when we have to refer to the genotype. (Even "subject," with its connotation of those living under a royal sovereign, is not quite right - and somewhat ideologically loaded - when referring to "the people" of nonmonarchical autocracies, especially state socialist ones.) We are convinced that a central objective of politology should be to focus more on the phenotypes, i.e., what they have in common. For further discussion of the problem of genotypes and phenotypes, and of its specific application to the problem of how to conceptualize and analyze politics involving ordinary people, see page $21 \mathrm{ff}$. and especially footnote 26 there.

5 N.b. Agents are not actors. They do not perform exclusively according to roles established by others beforehand. They are potentially capable of writing their own scripts, even though many politicians and citizens/subjects may in routine practice behave as they are told, trained or induced to do.

6 This encapsulated description of the generic nature of the political agent combines the very well-known observation of Aristotle that human beings are zoon politikon (political animals) and, therefore, intrinsically disposed to use power over others to realize their goals (or to protect themselves from the efforts of others to do so) with the much less well-known observation of the philosophical anthropologist, Arnold Gehlen, that human beings are distinctively "incomplete" with regard to their environment and, thus, intrinsically disposed to being dissatisfied with it and seeking to change it - by institutions if possible, by force if necessary. A. Gehlen, Der Mensch: Seine Natur und seine Stellung in der Welt, ed. Karl-Siegbert Rehberg (Frankfurt: Verlag Vittorio Klosterman, 2016). The fact that Gehlen was a convinced and unrepentant Nazi no doubt has contributed to the reluctance to attribute this important observation to him. It also probably did not help that his brother, Reinhard, was a Nazi general in charge of intelligence on the Eastern Front who subsequently became a US intelligence asset and later the founder of the West German equivalent of the CIA.

7 Some would argue that those who passively support the status quo are also agents in that they contribute to the imposition of a system of domination that generates dissatisfaction 
change or prevent it, both types have to be able to imagine future conditions and the alternative actions that might improve or threaten the quality of that environment and their existence within it. ${ }^{8}$

If these generic characteristics of agents are true, politics as a form of human behavior is likely to be in almost permanent violation of two of the foundational principles of the physical sciences: the First and Second Laws of Thermodynamics. First, the agents involved will not normally be able to contain their actions and reactions within a closed homeostatic system and, hence, will be continuously subjected to exogenously induced changes in their relative power resources to which they will have to respond by changing their behavior or preferences. Second, given that entropy - the tendency toward disorder - is inevitable in any system, even if agents do succeed in isolating, controlling and/or satisfying these disturbing outside influences, they will never be completely successful in sustaining an equilibrium between conflicting and competing forces. Proponents of change - whom we will call "progressives" in a generic sense ${ }^{9}$ - may tire of "the costs of politics" and be tempted to withdraw from the struggle. ${ }^{10}$ Their opponents - "conservatives," by which we mean simply opponents of change - may welcome the stability of the institutions and policies that brought them to power and that protect their resources. But this does not prevent the latter from inventing new motives for being dissatisfied, not to mention the perpetual presence in politics of progressives who are, by definition, dissatisfied with the magnitude or distribution of collective goods.

In other words, politics is an intrinsically dynamic and unbalanced process. The quest for stability has been an eternal component of its practice (not to mention the principal objective of conservative agents), but even when it has seemed to prevail, the result has been either illusory or momentary in the

in others. Even if their contribution is unintentional or unnoticed, they could be considered agents even before they react overtly to the actions of their dissatisfied fellow members. Thanks to Tony Spanakos for this point.

8 The implication here is that politics is never purely immediate and material, but is always affected by the capacity of individuals and groups to imagine different potential futures. The Chilean social scientist, Norbert Lechner, wrote similarly that politics involve not only the conduct of administration, the protection of life and the maintenance of economic security, but also "the common sense [notion] that politics is above all a project of the future, the design of a referential horizon which makes the present intelligible." See Norbert Lechner, Obras Escogidas de Norbert Lechner: Volume II (Santiago: LOM Ediciones, 2007), 331. Thanks to Tony Spanakos for this point.

9 See page 29. In this usage, "progressives" can come from any direction and have widely divergent objectives. All they have in common is opposition to the existing rules and practices and some conception of what they think are "better" alternative ones. Likewise, "conservatives" can hail from the left, center or right, depending on the prevailing power relations produced by the outcome of previous conflicts.

10 For a consequential example, see page 26, footnote 40. 
grand scheme of things, and is likely to remain so. Unlike other animals, humans are condemned to be repeatedly dissatisfied with their individual and collective accomplishments. There is no finite status or outcome that can induce them to remain inactive. That may well be the first principle of political thermodynamics.

Despite dealing with a subject matter that is a constantly moving target, students of politics are still expected to produce reliable and reasonable findings of causality and consequence - like all scientists. Unlike the physical sciences where cause and effect are usually invariant in direction and magnitude (after controlling for all other factors), the social sciences (and political science more than the others) face two unavoidable problems of inference: (1) different antecedent conditions can, nevertheless, produce the same outcome (equifinality); and (2) the same conditions can lead to different outcomes (polyfinality). Moreover, researchers are almost never capable of controlling for all of those other potentially intervening factors. Just think of the different historical trajectories that eventually led to the establishment of relatively similar liberal, parliamentary democracies in Western (and now, even, some of Eastern) Europe. Or, to the different trajectories followed by the component republics of the former Soviet Union since 1989. Or, to the survival of state socialism ${ }^{11}$ in Asia and Cuba in the face of its collapse in Eastern Europe and Russia.

Moreover, the units of politics - even the irreducible ones such as members of the species homo sapiens - are not homologous. $\mathrm{H}_{2} \mathrm{O}$ will always form water, and its component atoms have no choice in or views about the matter. But even identical twins reared together who manage to share historical, social and physical characteristics cannot be expected to have the same politics. Humans cannot but reflect on their experiences, environment and makeup. They bring their own will to bear on politics in unpredictable ways that cannot be completely reduced to the material of which they are made and the histories and structures in which they find themselves.

And, if this were not enough, to be effective, political agents have to communicate their complex thoughts to other human beings through a shared spoken and (usually also) written language. Numerous problems arise here.

11 The conceptual coin of the realm for Leninist régimes such as the USSR and those in Eastern Europe, East Asia and Cuba has been "communist." Yet for all of them, communism was mainly an aspiration which they generally admitted they had not yet reached in which property itself, rather than just private property, and, with it, most forms of inequality, had disappeared. Moreover, in the West, it became an ideologically charged epithet. For more strictly analytical purposes, then, we prefer, when referring to actual régimes, the more neutral and analytically precise concept of "state socialism." We have retained "communism" when referring to the overarching ideology that produced state socialism, and to Western (mis)perceptions of the Leninist, state socialist régimes. 
Language is naturally full of ambiguities. ${ }^{12}$ And politicians can intentionally take advantage of this. ${ }^{13}$

Political communication is also subject to corruption, increasingly so as it moves online. Candidates for office have been distorting their descriptions of "reality," and both their own and their opponents' records and positions, since the dawn of public campaigning. The problem grew more serious and impactful with the rise of mass media and advertising and, more recently, when campaigns developed the capacity to micro-target voters with distorted and downright false messages online.

Turning to autocratic political régimes, ${ }^{14}$ effective political communication is often blocked by the state. Political leaders in Iran, Syria, North Africa, China, Eastern Europe and many other countries, not to mention politologists, have puzzled over the ways that massive protests can materialize often literally overnight without the slightest prior organization or signals. One explanation is that a critical mass of people prepared to rise up existed all along, but no one knew it because almost everyone was too frightened to talk about politics, much less to act politically. ${ }^{15}$

Moreover, in order to formulate and communicate the as yet unrealized conditions they desire to satisfy, political agents must possess sufficient analytical acuity about other human beings to be able to anticipate their responses and to seek their approval - and they regularly make miscalculations in these respects. Empathy is a particular problem, given the vast and, in recent decades, ever-increasing economic, social and cultural segmentation and inequality. ${ }^{16}$ The problem has been made worse by the decline of in-depth humanistic

12 Schmitter was reminded of this linguistic ambiguity when he interviewed the leader of an ultra-conservative civic association in São Paulo. When asked about their political activities, she responded: "We are completely apolitical. So apolitical that we ran our own candidate for mayor in the last election." She did not have to worry about the immediate future since an ensuing military coup in 1964 (which her apolitical organization enthusiastically supported) abolished all elections in large Brazilian cities.

13 In the US, Joseph Lieberman and Barack Obama were famous for crafting utterances that could persuade voters with widely contradictory preferences that they agreed with them. In a series of essays in the London Review of Books, David Bromwich, a professor of English at Yale, marveled angrily at President Obama's talent for obfuscation and contradiction. See, for example, David Bromwich, "The Fastidious President," London Review of Books 32, no. 22 (18 November 2010); and “The World's Most Important Spectator," London Review of Books 36, no. 13 (3 July 2014). During the Chinese Cultural Revolution, warring factions all claimed their linguistic fealty to Mao Zedong Thought, even as they proceeded from radically opposed aspects of his writings and historical practice.

14 For our definition of régimes, see page 58. "Authoritarian" and "autocratic" are often used interchangeably, but we prefer the latter; see pages 59-60.

15 Timur Kuran, "Now Out of Never: The Element of Surprise in the East European Revolution of 1989," World Politics 44, no. 1 (1991): 7-48.

16 Mao Zedong worried about this both before and after the victory of the Chinese Revolution, and developed an innovative set of practices that forced party cadres to spend significant time and energy working at the grassroots. 
narrative - in literature or oral traditions - which can foster empathy. ${ }^{17}$ Even professionals in political communication and strategy have major problems understanding what will work. Finally, large bureaucracies - be they government departments, political parties or civil society organizations - are prone to suffering significant failures of effective communication both upward and downward. Messages become garbled over long chains of transmission - as in the parlor game of "telephone." Or they can be blocked by political pressures and crises. $^{18}$

If political agents do manage to avoid these myriad problems and communicate effectively, they still can rarely achieve their goals alone. Politics is inherently social, after all, and all political agents must work with other humans. At least three broad categories come into play here. They can do so by deploying or threatening coercion, which is all too common; Weber's view that the sine qua non of the state is its monopoly on violence reflects as much - even if very few states have ever completely managed to suppress private political violence. They can also try to contract with others, which usually requires mutual trust, and which, in turn, can emerge either from strong affective social bonds or from ethical norms grounded in long historical practice or, most commonly, from robust institutions resting on mutually recognized norms and respect for the rule of law. Finally, agents can act strategically to create a situation in which other agents face no alternative. ${ }^{19}$

Human political agents are also collectively capable of committing acts of malice, cruelty, vengeance and violence on a scale of which no other species seems capable. This generates memories of past treatment that persist and can impede present and subsequent agreement - even when the conditions for a mutually satisfactory outcome and, hence, some degree of institutional stability do objectively exist. ${ }^{20}$

17 Jade Schiff, Burdens of Political Responsibility: Narrative and the Cultivation of Responsiveness (Cambridge: Cambridge University Press, 2014).

18 Perhaps the most stunning example in human history was the massive famine induced by the Chinese Great Leap Forward, whose scope remained hidden for a disastrously long time because local officials were under intense pressure to produce wildly exaggerated positive reports.

19 A classic work on such "boxing in" of one's interlocutors is Thomas Schelling, The Strategy of Conflict (Cambridge, MA: Harvard University Press, 1960). Of course, the efficacy of such a strategy depends on how much the listener is dependent upon the more powerful caller.

20 This is not to say that all aspects of politics are unique to homo sapiens. Most primates are capable of physically coercing others of their species to comply with their demands, and some of them also seem to have the capacity to command obedience without using force. While elaborate language seems to be beyond their comprehension, they can "read" the meanings of gestures and sounds. And some animal species can form mutually beneficial alliances that may be based on implicit contracts. 


\section{The Subject Matter}

Finally, all these problems iterate continuously and always under changing conditions. ${ }^{21}$ Politics is nothing if not historical. It is in constant flux, and each move and moment re-shapes the potentialities for and constraints upon the next. The common search in political science for repeating patterns is always subject to being frustrated by the possibility that each instance in which one appears can "contaminate" its replication in the subsequent one.

To sum up, politics as a sphere of human activity has very specific characteristics, dynamics and a logic all its own, and its study ought to reflect that.

- It is, as Aristotle claimed, the "master science" in that it is the practice of politics that sets the preconditions for all but the narrowest forms of human activity.

- Political agents are irreducible to their own physical, social or historical characteristics, much less to wider structures. They are reflective about and reflexive to their endogenous makeup and their exogenous worlds.

- They possess the capacity for forming and exercising will in their efforts to control the behavior of others.

- Thus, what political agents do is almost never completely pre-determined and always contingent upon the (often unpredictable) response of others.

- Political agents are restless, constantly seeking to change the outcomes of politics and, not infrequently, often the very processes by which they are produced.

- Their agency is also indeterminate because it depends on the pursuit of or defense against imagined future conditions, not just the existing ones.

- Hence, politics always takes place in non-homeostatic contexts in which the appearance of stability is illusory and unlikely to persist.

- Politics is beset with all manner of communicative problems and dysfunctions, even when it is conducted among persons who share the same language and culture.

- Therefore, it always involves the problem of acting conjointly or contracting voluntarily (which includes but is certainly not limited to the rationalist dilemma of "collective action"). ${ }^{22}$

21 Tony Spanakos has observed that

The ontology implied here necessarily sees human motivation and action in an indeterminate range between the desirable and the 'good' and the undesirable and the 'evil.' Rather than standing with authoritarians who see 'man as sinful and in need of community' or with liberals who see 'man as good and whole in himself,' they regard human beings as incomplete and in need of communication with each other which can lead to a variety of only partially predictable political outcomes.

(Personal communication)

22 The notion that collective action in pursuit of public goods is intrinsically irrational unless conducted in small groups where everyone contributes to the success of the 
- Because politics is centrally about power, and because power has a corrupting influence upon those who exercise it, it is particularly prone to mobilizing homo sapiens's capacity for insensitivity and brutality toward others.

- It is always historical, with each instance of political action inevitably producing new conditions, memories and forms of conflict that cannot be easily ignored or eliminated.

- Politics always occurs in "open systems" and, therefore, is always subject to random effects generated by exogenous forces.

- All this makes politics a human activity that is particularly uncertain, dynamic and consequential.

Other spheres of human activity share some of these characteristics. But it is the complex set of them that imparts a specific logic all its own to politics. Thus, we argue that the study of politics might usefully be renamed: politology. ${ }^{23}$

\subsection{The Exercise of Power}

What we think of as politics rests on the exercise (or the threat of the exercise) of power and the resistance to it. What is also unique to human beings is their capacity to "domesticate" this activity by inserting conditions that serve to channel the actions and reactions of agents according to mutually agreed upon

collectivity is associated with the work of Mancur Olson; see The Logic of Collective Action: Public Goods and the Theory of Groups (Cambridge, MA: Harvard University Press, 1971). The very existence of many such large groups - historically and contemporarily is self-evident proof that factors other than individualistic marginal calculation must be at work in politics.

23 Literally, the study of the logic of politics. In proposing "politology," we are not launching a presumptuous campaign to rename our field. Whether it gains any currency is for our colleagues - especially our younger ones - to decide. Rather, we deploy it in this book to emphasize our core point that politics as a human activity possesses characteristics all its own that are distinct from and irreducible to the other forms of behavioral activity studied by social scientists and, even more, by physical scientists. We argue that, if the assignment of labels to scholarly specializations and academic departments, institutes or faculties followed some consistent logical-linguistic principle, the study of politics should not in the first place have been called "political science," but "politology" - following the examples of anthropology, psychology and sociology, whose names convey the appropriate message that each of these subject matters has its own logic of explanation, and, even, more importantly, that these are distinct from those of the physical sciences. Actually, in French, Italian, Russian, Spanish and German, one does increasingly find references to "politologie," "politologiya" (политология) or "politologia," and their practitioners have been called "politicologues," "politistes," "politologi," "politologisti" e cosi via. This labeling is even further complicated in some Latin languages when the subject matter itself has been pluralized: "les sciences politiques" or "le scienze politiche." In China, our profession is generally called, literally, "political studies" (zhengzhi xue [政治学]), which is closer to politology (the logos of politics) since it eschews the word for "science" (ke xue [科学] ) that could easily have been adopted by adding the single character ke [科]. 
rules, norms and/or reliably applied practices. ${ }^{24}$ These regulated exchanges, negotiations, deliberations and decision-making processes permit conflicts to be resolved pacifically and, thereby, preclude the resort to violence that could otherwise be needed to resolve the differences in resources and preferences that give rise to political activity in the first place. Needless to say, the effort is not always successful, hence the long list of atrocities in human history. Put differently, the "quality" of politics can be measured at least in part by the extent to which it has succeeded in domesticating the exercise of power - i.e., preventing the use of individual or collective violence to resolve disputes - without removing citizens/subjects from participating by killing them, torturing them, violating them, incarcerating them or forcing them into exile.

Power, in turn, rests on the uneven distribution of resources and returns among human beings living within a given unit (usually a demarcated geographic space whose definition itself may become contested). Some of these asymmetries may be "natural," given the different physiological endowments that human beings receive upon birth, but most will be "social" and rooted in subsequent accomplishments (or non-accomplishments) during their respective life-cycles, the unequal inheritance of previously acquired social, economic and political privileges, and/or the institutions of market exchange that systematically generate and perpetuate inequality. ${ }^{25}$

24 The attentive reader will note our repeated references to "rules, norms and practices." This is our attempt to indicate that politics always involves different combinations of formally enacted rules, informally recognized norms and empirically established practices. All three can serve to domesticate the exercise of power - although rules are usually more reliable (perhaps, because they are backed up by a set of specialized juridical and penal institutions). The latter two have only custom, convenience and mutual advantage going for them. In some polities, the informal element has been especially prominent. Brazilians even have an expression for this: "um jeito" - an unorthodox and ingenious way of solving problems and avoiding conflicts that cannot be accomplished through legal procedures, but only by relying on "inconfessable," but often well-known, consensual arrangements that usually shift the burden to others. Italians have taken this notion further and made it into an alternative régime form: il sottogoverno. In both of these countries, the public scrutiny and competitiveness built into "real-existing" democracy eventually led to a major institutional crisis over corruption that, in the Italian case, destroyed its party system and, in the Brazilian case, to a profound challenge to the government in power. In China, informal banfa - literally, "ways to make something happen" - have been indispensable responses for the operation of politics within the country's highly formalized and rigid institutions from time immemorial. The term connotes creative and often widely understood ways to skirt but not flout the rules in the interest of efficiency and that do not necessarily involve or connote corruption. It has a positive normative loading - of cleverness and effectiveness.

25 Huge debates swirl here. Perhaps the most controversial one pits those who believe that unequal social and economic (and therefore political) outcomes are the result of systematically unequal birth endowments among groups against those who see only socially random ones among individuals. Herbert Spencer argued that inequalities throughout history developed because some people were less "fit" at birth. Blecher has 
Agents seeking to change the status quo - "progressives" in the generic sense of those seeking change, whether of the left or right and whether individuals or organizations - will be tempted to exploit asymmetries when they try to compel others to conform to their preferences. The former may threaten to deprive the latter of resources, promise to reward them with greater resources, take advantage of a crisis, mobilize new participants as supporters or allies, raise new issues, make new kinds of appeals, put social or political pressure on them and/ or organize themselves and their supporters in new or more effective ways. The defenders of the status quo - "conservatives" - will resist these efforts and will usually have an intrinsic advantage due precisely to their incumbency. They will try to control the agenda of public disputation, reinvigorate arguments for the status quo, influence the course of decision-making, suppress and/or de-legitimate demands for change, undermine the organization and alliances of the "progressives," offer tactical compromises that do not shift the strategic balance, and/or alter the preferences of the challengers and their allies. The "normal" outcome of these challenges and conflicts should be a reaffirmation (or, in some cases, a revision) of the status quo ante. This is especially likely if (1) they are contained within a pre-established set of rules and norms that the opponents also respect as legitimate and that are enshrined in institutions which, going still further, are woven together into a coherent régime; and (2) the incumbents have come to and remained in power by observing those rules and norms and by working within those institutions. ${ }^{26}$

often wondered whether, when the gates are closed in the evenings at London's Highgate Cemetery, where Spencer is buried just opposite Karl Marx, furious battles still break out between them. Marx, of course, chalked up the biggest cleavages in history to the operations of successive modes of production - especially the capitalist one. Social Darwinism has lived on, drawing liberal as well as radical critics. In our time, it has reappeared in the work of Richard Herrenstein and Charles Murray, who have argued that African-Americans are intellectually, psychologically and morally inferior to white Americans. See Richard Herrenstein and Charles Murray, The Bell Curve: Intelligence and Class Structure in American Life (New York: Free Press, 1994). In 2017, a nocturnal debate about this work at Middlebury College led to a punch-up. Less dramatic but more serious arguments have proliferated among center leftists (known in the US as political "liberals") and radicals of various stripes. The former generally seek the roots of inequality in social discrimination and/or government policies, while the latter look for deeper roots (the actual meaning of "radical") in underlying forces such as capitalism, patriarchy or racism.

26 A recent example is the fact that in 2016, no one in the US advocated refusing to seat Donald Trump in the White House, notwithstanding his loss of the popular vote, his palpable unfitness for the job and the profound threat he posed to the very institutions that put him there. Indeed, even Trump, who did not expect or, arguably, want to win the election still followed the rules of the game and took up office even as he had to know that doing so posed enormous personal and financial risks for him. 
Yet, of course, there are also many "abnormal" outcomes in politics. As we have argued, ${ }^{27}$ the logic of action-reaction that underlies the exercise of power is not "thermodynamic." Politics tends to produce reciprocal interactions, but the conflicting agents are rarely equal in their power or effect; the conflicts may be more oblique than strictly opposite; and the eventual outcome may not produce a stable equilibrium, just a temporary arrangement; institutions are not always self-enforcing, and require periodic injections of energy - in political rather than thermodynamic terms, adaptations - from other sources in order to survive any change. Incumbents may well have resisted these, because their incumbency blinds them to the need for change, renders them ideologically rigid, or because they believe that even minor "reform" may invite further demands that would endanger the core of their power. ${ }^{28}$ In other words, incumbents do not always prevail. The "institutional paths of dependency" they claim everyone should rely upon are not always followed. Not only may the decision rules and the means for coming to power be ambiguous in specific instances, but also the prior conditions presumed by these rules may have changed in ways that incumbents have not discerned or responded to adequately - especially if they involve unfamiliar and surprising crises and/or exogenous shocks. Incumbents' performance once in office may have alienated their supporters and/or those previously indifferent, by not doing what was expected of them, by pursuing policies that backfired or by political missteps they committed in order to ramp up their leadership, organization and participation. Most importantly, the rules themselves may turn out to have embodied only a temporary compromise that proves vulnerable to contestation. For opponents to win, it will help if these clusters of rules have not become institutions that are valued for themselves by most agents even above the political outcomes they produce; if they are not protected in power by the legitimacy of the institutions they govern; and especially if these institutions are not clustered together into a coherent régime. ${ }^{29}$

This is one reason why power has proven so elusive to observe and difficult to measure. It is most effective when those who have it do not have to exercise or even display it, i.e., when their power is so overwhelming that it intimidates

27 Page 3.

28 They may have read Samuel Huntington - many did - who famously observed: "In some circumstances... reform may well exacerbate tensions, precipitate violence, and be a catalyst of rather than a substitute for revolution." Samuel P. Huntington, Political Order in Changing Societies (New Haven, CT: Yale University Press, 1968), 6-7.

29 See page $58 \mathrm{ff}$. This reminds Schmitter of an Austrian expression he once heard: die Rute im Fenster ("the Whip in the Window"). It referred to the fact that, while the negotiations between social partners (capital and labor) were ostensibly between private (or, in the Austrian case, semi-public) institutions, the participants were fully aware that the state, i.e., the whip, was always present, and if agreement could not be reached or if it exceeded anticipated limits, someone would break the glass and the state would intervene. In other words, in normal, "domesticated" political situations - regardless of appearances - public authority (and potential coercion) is never far away. 
or pre-empts any response by subordinates, and, even more so, when it is accepted by subordinates as legitimate. Nevertheless, the entropy embedded in such relations may not remain manageable when threatened by significant exogenous transformations in the power resources of conflicting agents or by the endogenous emergence of new expectations, preferences or sources of discontent among them. Yet, incumbents may also remain in place for a long time in the absence of such conditions, due to sheer inertia - i.e., the failure of challenges and challengers to produce enough pressure to reach the reforming point. It is, then, easier to observe or measure the absence or insufficiency of power at critical moments (also known as "crises") when incumbent leaders and régimes have succumbed to political entropy than when they remain in place, whether on strong or weak foundations. 


\title{
2
}

\section{THE FOUNDATIONS}

\begin{abstract}
Most fundamentally, politology seeks to explain two qualitatively different kinds of politics (the explicanda): "normal" (Type One), which takes place within established rules, norms, practices and institutions; and "abnormal" (Type Two), which takes place when such "dams and dikes," as Machiavelli called them, have broken down, and politics shifts to the task of creating them anew. It does so with three different categories of explicans: necessità, or the imperatives to make decisions and the built-in conditions (similar to what are now called "structures") that come into play in doing so; virtú, or the capacities, inclinations and choices rulers make (similar to what is now called "agency"); and fortuna, or the unforeseen and unforeseeable (similar to what is now called "contingency").

Like any science, politology must begin with concepts, and it is best to be clear and self-conscious about what they are. The most fundamental ones are power (what is it?) and the generic dynamics of its exercise (how is it deployed?). Other central ones are agents (who exercises it?). Next come discussions of cleavages (what differences shape their activity?), motives (why do they do it?), processes (through what means do they do it?), mechanisms (how do they do it?), units (where and together with whom do they do it?), temporalities (when do they do it?), régimes (within what state institutions do they do it?) and, finally, consequences (who benefits or suffers from their doing it?).
\end{abstract}

Every scientific study - whether of physical or human subjects - rests on micro-foundations. These are the basic assumptions shared by its practitioners. 
They shape the way in which topics are identified and transformed into projects worthy of teaching or researching. Normally, they are invisible - as befits most foundations - and are usually accepted implicitly and without controversy. However, the visible structures of a science - its concepts, hypotheses, methods, data, patterns of association and modes of inference - are only as valid as these foundations. The study of politics is no exception to this maxim, even if it is exceptional in the extent to which its micro-foundations have been and still are visible and subject to dispute.

Let us begin with the venerable advice of Aristotle, "It is the mark of an educated man to look for precision in each class of things just so far as the nature of the subject admits." 1 Therefore, those who would study politics should be resting their research on a set of assumptions that are as "precise" as their subject matter is distinctive. Their problem begins with the intrinsic imprecision and indeterminacy of that subject matter.

To start with, there are two quite different "classes of things" that students of politics have historically tried to explain (which we prefer to call explicanda) ${ }^{2}$ : (1) "normal" politics that takes place within a context of stable rules, practices, norms and institutions, and (2) "abnormal" politics that takes place in their absence. In this, we follow the advice of Niccolò Machiavelli, whose micro- (or, better, meso- ${ }^{3}$ ) foundations of politics consisted of a mixture of three explanatory elements (which we prefer to call the explicans): (1) necessità: the imperative of taking costly and consequential decisions under conditions of scarcity of resources, threat of violence and/or ambition of persons; (2) virtù: the capacity of rulers to understand the political context and to exploit it in order to create order and security; and (3) fortuna: the ever-present likelihood of unforeseen events and imponderable processes. ${ }^{4}$ For Machiavelli, when fortuna becomes the dominant element, the very nature of politics is different. Without "prudent men, when times are quiet, (to) provide themselves with dikes and dams," the necessary exercise of power leads to unexpected (and usually unwanted) results. Since Machiavelli found himself in "a country without dams and without dikes," he had to "enter upon a new way, as yet trodden by anyone else," 5 i.e., to invent a new science of "Type Two" politics. In normal times Machiavelli implied, "Type One" politics takes place within established units, i.e., states,

1 Aristotle, The Nichomachean Ethics, trans. W. D. Ross (Digireads, 2009), 2.

2 See page 86, footnote 17.

3 Like most foundational concepts, they, in turn, rest on a number of prior assumptions.

4 Today, social scientists would probably conceptualize these as instances of structure, agency and contingency - the latter a fancy word for what Blecher's snarkier students have been known to refer to as "shit happens."

5 Niccolò Machiavelli, The Prince, ed. and trans. David Wooton (Indianapolis, IN: Hackett, 1995), ch. 25. 
and between established institutions, i.e., within régimes, that circumscribe the options of agents and make their behaviors more predictable ${ }^{6}$ and peaceful. ${ }^{7}$

Until recently, this line of demarcation between Type One ("normal") and Type Two ("abnormal") politics was supposed to run between domestic politics and international relations, and was used to justify their separate status as sub-disciplines within politology (or, if you insist, political science). The latter was broadly anarchic, with no higher authority or predictably binding rules above its (supposedly) unitary and sovereign agents - the nation-states ${ }^{8}-$ that were expected to do whatever was necessary to further their particular interests and to defend themselves from predation by others. ${ }^{9}$ The former took place within a political space pre-defined by formal (if not always constitutional) rules and informal norms, ordered by a supreme (and sometimes legitimate) authority over a specific territory - again, a nation-state - in a social setting that possessed a distinctive common identity.

This distinction within the discipline of politology is no longer valid. International (or, better, inter-state) relations have become clogged with a myriad of conventions, treaties, "régimes," inter- and non-governmental organizations, and even (especially in the case of Europe) regional supra-national governments, agencies and courts. Sovereignty has become more and more of a formality (though still a most consequential aspiration); nationality is less and less exclusive. Even well-established states have been coming apart for some time, raising the

6 Machiavelli gave these two classes of political things labels that would be "politically incorrect" today. The normal and more predictable one, he called "male times," and the abnormal and less predictable one, he called "female times," and he lamented having to live in the latter.

7 Machiavelli's opera magna, The Prince, has often been misinterpreted in this regard. Nowhere does he advocate the use of violence indiscriminately, but only when it can contribute to the eventual domestication of politics. His expression for this objective is "per fare lo Stato" (Schmitter's translation would be "in order to do what is necessary to produce stateness"). Politicians ("Princes") who succeed in doing this have virtù. Only once they have constructed these "dikes and dams" can politics follow its "normal" course and can agents peacefully resolve their conflicts within predictable and mutually acceptable limits.

8 We adopt this term since it is the coin of the politological realm, even though, as we point out just below, not all states are founded on or bounded by nations (groups of people with a common identity).

9 The distinction is foundational and regarded as common sense by the so-called "realists" in the sub-discipline of international relations; see, inter alia, Hans Morgenthau, Politics Among Nations: The Struggle for Power and Peace (New York: Knopf, 1948); John Mearsheimer, The Tragedy of Great Power Politics (New York: W.W. Norton and Company, 2001). There are scholars in this field with quite different presumptions, such as Hedley Bull, The Anarchical Society: A Study of Order in World Politics (London: Macmillan, 1977). This distinction can be traced back to Plato; see The Republic, trans. G. M. A. Grube (Indianapolis, IN: Hackett, 1992), Book. V, ch. 16. Thanks to Tony Spanakos for this elaboration. 
most fundamental political and constitutional questions. ${ }^{10}$ Meanwhile, the number of putatively sovereign and national states has proliferated, and many of them have little or none of the orderly qualities described earlier. The list of outright "failed states" is getting longer, and there is a growing waiting list of "defective" ones. Some "countries" or "nations" are not even states at all, though they aspire, often violently, to become so. ${ }^{11}$ For decades, it has been statistically more likely that residents of a given country would be more likely to be killed in a civil war by one of their co-nationals than in an international war with foreigners. ${ }^{12}$

The fact that the empirical loci of these two generic types of politics - the normal and the abnormal - have shifted does not invalidate the difference in terms of micro-foundations. Both are still very much present in our world and they definitely still require contrasting, not to say antithetic, sets of basic assumptions and concepts.

What, then, are the generic components of a solid and well-balanced microfoundation for the study of politics? These should be a priori assumptions that are more or less isomorphic with the situations involving power that are usually faced by politicians - whether of Type One or Type Two - and presumably justifiable with regard to the agents (and maybe also the publics) involved. Basing one's science upon conditions that do not exist or values that cannot be satisfied may be useful for constructing formal models or for exhorting people to change their behavior, but both are, at best, of marginal utility as foundations for building a "realistic" science of politics. ${ }^{13}$

The indispensable elements of such a foundation are discussed in the following sections. They begin with an assertion of the critical importance of concepts (how should we think, talk or write about politics?). Having raised this briefly earlier, ${ }^{14}$ we have already moved to the most important and contested of all concepts, namely, power (what is it?) and the generic dynamics of its exercise (how, most generally, is it deployed?). Then will follow a lengthy disquisition about agents (who exercises it?). Next come discussions of cleavages (what differences shape their activity?), motives (why do they do it?), processes (through what means do they do it?), mechanisms (how do they do it?), units (where and together with whom do they do it?), temporalities

10 The UK is the current poster child here, but one could also look to the former USSR or Yugoslavia for more perverse consequences.

11 For example, Palestine, Abkhazia, Kurdistan, Somaliland, Catalonia e cosi via. See Joshua Keating, Invisible Countries (New Haven, CT: Yale University Press, 2018).

12 Although, to be sure, many of these "civil wars" were, to a significant degree, proxy wars in which the opposing sides were acting with the support of, or even at the behest of, existing nation-states.

13 As Mishella Romo has pointed out to us, our proposal to build a realistic science of politics must involve the identification of the underlying elements that shape the conflicts that leaders must endure, either in extraordinary or ordinary moments, regardless of where they occur. In practical terms, this would mean eliminating the distinction between domestic and international politics.

14 Page xvii-xviii. 
(when do they do it?); régimes (within what state institutions do they do it?) and, finally, consequences (who benefits or suffers from their doing it?).

One item will be conspicuously absent, namely, the telos of politics (where is it going?). It used to be routinely assumed that politics was heading in a predictable (and usually benevolent) direction - that the entire structure of power and authority was moving somewhere over time, however erratically and unevenly, across different units. The Will of God, the power of human rationality, natural selection by social evolution, the greater normative appeal of liberal democracy or the inexorable dialectic of historical "progress" have at various times been candidates for explaining why certain values and institutions would eventually win out, or why the ones that have won out were the better ones. ${ }^{15}$ More recently, we have been told that we have fortunately reached "the End of History," thanks to the spread of more and more liberal democracies. ${ }^{16}$ None of these seems sufficiently plausible to us to include them among our microfoundations of political research. ${ }^{17}$ As we shall see, there is plenty of movement in the contemporary world of politics, but it is not definitively headed in a predestined direction - least of all, a benevolent one. ${ }^{18}$

15 Schmitter's former student Nicholas Guilhot has problematized this in The Democracy Makers: Human Rights and the Politics of Global Order (New York: Columbia University Press, 2005).

16 Francis Fukuyama, The End of History and the Last Man (New York: Avon, 1992). As Mishella Romo reminds us, Fukuyama does not posit an end to politics as such. Rather, he argued that politics will move away from the "big questions" (such as which régime is best) and become confined to narrower, more pedestrian ones. Regrettably, this has not happened - even in the case of some of the most established of liberal democracies.

17 Maurice Duverger, the noted French analyst of political parties, claimed to have discovered a distinctive law of historical development driven by the electoral process that he called "the Leftward Bias." Assuming that there usually existed two parties or coalitions of parties: (1) "those of stasis" (the Right) who are normally in power; and (2) "those of movement" (the Left). The latter would gradually increase its strength on the basis of the appeal of its novel proposals and the sclerosis of its opponents' performance. Correspondingly, the Right would come reluctantly to accept these Leftist reforms and the game would start again. Maurice Duverger, Les Partis Politiques (Paris: Armand Colin, 1951). In the world of contemporary democratic politics, one could well argue the inverse: what on page 11 we have called the "progressives" - those with new ideas and challenges - have been coming from the neo-liberal and neo-fascist Right, while the Left has proven incapable of doing anything except eventually to accept them.

18 Mishella Romo observed to us that this is not the first time Schmitter has been reluctant to assert a telos to politics. In fact, when discussing Transitions from Authoritarian Rule: Tentative Conclusions about Uncertain Democracies (1986), he emphasized that he and Guillermo O'Donnell did not seek to make a teleological argument, and that this has been a consistent misinterpretation of this work. They did not posit that there would be a consistent (least of all, an irreversible) turn toward democratization. Guillermo O'Donnell was even reluctant to consider himself a "transitologist," much less a "consolidologist." See his interview in Gerardo Munck and Richard Snyder, Passion, Craft, and Method in Comparative Politics (Baltimore, MD: Johns Hopkins University Press, 2007), 294. 
The exploration we have undertaken below is a personal one, not a doctrinal affirmation valid for everyone who wishes to study politics. Each of these elements has involved and continues to involve controversial choices. Those made by any one student will be a complex function of the fads and fashions present in the discipline at the moment, the politologist's theoretical pre-disposition and the nature of the research topic - perhaps seasoned with some of his or her own normative preferences. Whatever these choices are and however implicit they may often be, they cannot be avoided when conducting research on any political topic.

\subsection{The Concepts}

Concepts are the building blocks for studying politics. "If you cannot name it, it does not exist" should be the maxim for all politologists. ${ }^{20}$ The deeper foundations of their work are provided by theories, and all concepts are either taken from or inspired by prior theories, out of which, in turn, the latter are built. ${ }^{21}$

Concept formation is a difficult but unavoidable obstacle when conducting political research. For most students, it will be easily removed when they choose a particular "school of thought" or "fashionable approach," adopt its conceptual apparatus and apply the methods typically associated with it. Not infrequently, however, students will find themselves deprived of such guidance or convenience - especially if the topic they have chosen is novel or out of fashion. One answer suggested earlier ${ }^{22}$ is simply to listen carefully to the

19 Concepts give rise to conceptualists, those within the discipline who devote concentrated attention to the meaning of concepts and their application. Often, they more or less passively accept the theory that has generated specific terms and concentrate their attention on the ambiguities and misapplications that may be associated with them. This has not been a prestigious specialization. We have never heard of anyone getting a job for practicing it. Yet, ambitious politologists also do strive to invent a new concept to name an empirical phenomenon or even a theoretical approach they have encountered - which, when it gains currency (and footnotes), can indeed bring him or her some notoriety.

20 Perversely, "if you can put a label on it, it must exist - everywhere." A striking example of this has been the recent diffusion of the concept of "governance." It was a French term that had been completely unknown and unused for over 400 years when it was picked up for opportunistic reasons in 1989 by the author of a World Bank Report on the problems of development in Africa. Since the Bank is prohibited by its statutes from intervening in the internal affairs of its member governments, the author had to invent a new concept rather than refer to the real problem, which was corruption in African governments. Once the IGO, NGO and academic communities had taken hold of the concept, it has been found and applied everywhere - usually with the prefix "good" attached to it.

21 The fancy word for this is that all theories have their ontology, a set of prior assumptions about what exists and what it is capable of becoming, and these are then translated into concepts that are presumed to be relevant with regard to these assumptions.

22 See page $x v i$, footnote 5 and passim. 
language of those he or she is studying - and then to search for its affinity with pre-existing (and more academically respectable) theories. ${ }^{23}$

Another trick, once the principal components of a potential explanation have been identified inductively, is to work with agonistic dichotomies, i.e., to identify and label the extreme versions of the phenomenon or process being researched. The real world of politics is filled with them: Left-Right, CenterPeriphery, Urban-Rural, Insiders-Outsiders, Civilian-Military, CapitalistCommunist, Centripetal-Centrifugal, Dispersed-Cumulative, Winners-Losers, Unitary-Federal, Presidential-Parliamentary, Pluralist-Corporatist, e cosi via. Granted that most of the relevant behaviors to be observed will lie between these extremes, nevertheless, having nailed them down with antonymic ideal types should still facilitate subsequent identification and measurement. Often, this will mean proceeding per genus et differentiam as the research advances, i.e., by identifying and labeling sub-types that lie between the extremes that serve to define the continuum. ${ }^{24}$

23 In the event that concepts identified do not fit or cannot be easily re-conceptualized, we encourage researchers to search for an alternative by expounding on what it is not (so long as they do not include too many variables which may make eventual operationalization more difficult). In effect, we suggest "thinking in polarities." There is nothing new about this strategy. The great social and political theorists of the nineteenth century all comparativists - used it in their efforts to capture the complexities of their time, e.g., Benjamin Constant with la démocratie des anciens and la démocratie des modernes, Karl Marx with capitalism and socialism, Ferdinand Tönnies with Gemeinschaft and Gesellschaft, Emile Durkheim with mechanical and organic solidarity, Max Weber with types of legitimate authority and bureaucracy. What is distinctive of many of the contemporary ones is their reference to relations between levels of social and political power, rather than relations at the same level of aggregation. We also encourage comparativists to talk to "real people" who - through their ordinary language - may reveal hidden or otherwise ineffable relationships. To formalize this practice, Schmitter has been the editor of the Italian section of the Les Intraduisibles: The Dictionary of Untranslatable Political Terms (Mexico City: Centro de Investigación y Docencia Económicas). Thanks to Mishella Romo for this point. Blecher has built most of his scholarship - starting from his dissertation, which Schmitter helped nurture - on interviews with ordinary Chinese, on the basis of which he developed both quantitative and qualitative analyses. In terms of the current point, he found particularly useful Dryzek and Berejikian's "reconstructive methodology," in which the researcher constructs a survey instrument (and then undertakes a factor analysis on it, no less) based on close reading and listening in the discursive world of the subjects themselves rather than the researcher's own ideas. See John S. Dryzek and Jeffrey Berejikian, "Reconstructive Democratic Theory," American Political Science Review 87, no. 1 (March 1993): 48-60; and Marc Blecher, "What - and How Have Tianjin Workers Been Thinking?" Journal of Chinese Political Studies 13, no. 3 (October 2008): 249-267.

24 Conceptualization also has its practical side. One temptation is to conceptualize as operative variables or enabling conditions only those phenomena that the researcher knows ex ante that he or she can measure empirically. Another is to rely on the tradeoff between the number of potential cases (the "universe") and the number of variables. When the $\mathrm{N}$ is small, even as little as one, the temptation is to pile on as many variables as can be imagined to be relevant - most of them with upper-case labels. When it is large and extends not only across many cases but also time periods, the concepts 
Like other kinds of scientists, conceptualizing politologists have to distinguish between phenotypes and genotypes. The former are concepts produced by political activity itself; the latter are generated by the practice of politologists (or the various adjacent disciplines from which they have regularly stolen their concepts) in the process of abstracting from the former in order to get at the underlying dynamics by revealing commonalities among the differences - in a different lexicon, "finding the signal amidst the noise." Politologists are usually drawn to the genotype, interested as they are in explaining generic classes of events or processes occurring (at least potentially) in several places and/or different time periods. ${ }^{25}$ The relationship between the two lies at the core of politology, and the reciprocal dynamics between them can be most productive not just of better concepts but also of political knowledge. ${ }^{26}$

are much more likely to be given lower-case labels from an upper rung on the ladder of abstraction. For example, in the study of Chinese politics, long an arena of "comparative" politics that, grounded in Sinology, eschewed actual comparison, much ink has been spilled about the best broad-gauged conceptual moniker for no less grand a subject than the state itself: totalitarian, totalistic or authoritarian? (As mentioned on page 6, footnote 14 , and on pages 59-60, we prefer "autocratic.") In a necessary response to the shortcomings of so high a level of abstraction, politologists of China resorted to inserting inevitable adjectives such as "fragmented authoritarianism" and "authoritarian resilience" into the analytical process.

25 Historians, by contrast, are usually focused on understanding specific events or processes in bounded time periods. They tend, therefore, to be more phenotypical in their choice of concepts.

26 One good example is corporatism. Blecher remembers very clearly the seminar in which Schmitter first floated his new-fangled and still embryonic concept. As a genotype of interest representation distinct from pluralism, before long it came to require phenotypical elaboration - into "state" and "societal" forms - as it confronted the challenge of analyzing actual political processes in various cases. This, in turn, prompted a refinement of the genotype itself from "representation" to "intermediation." In Schmitter's experience, this was also especially significant when he was working on regional integration in Europe. This process was (and still is) unprecedented and barely resembled that of the previous processes of national integration in its member states all of which had relied on differing degrees of coercion and violence. Precisely because of this, the agents involved in trying peacefully and consensually to bring about a supra-national level of political authority in the region had to invent a specialized lexicon - Euro-speak, he called it - to describe what they were doing. And learning it alerted him to aspects of their behavior he might have otherwise ignored. Charles de Gaulle made the same discovery, although he called it "Volapük intêgrê" in contrast, of course, to his own elegant (and pompous) French. Blecher has encountered a similar conceptual problem when trying to deploy the proper term to describe individual Chinese persons in political terms. From time immemorial, the imperial Chinese state's term was "people" ( $\min$ 民). The Communist Party continued to use it alongside "the masses" (qunzhong 群众). Neither spoke of “citizens” (shimin 市民). With the birth of the post-Mao structural reforms, the latter began to come into limited use by Westerninfluenced Chinese politologists who began to study the handful of embryonic political organizations emerging out of society rather than from the state by deploying the concept of civil society. The Chinese adjective for "civil" (shiminde 市民的) contains the noun for "citizen," but its use remains problematic and, therefore, rare in China, 
Here, politologists have a special problem with concepts because the ones they seek to develop and use are often already being used by those whom they have chosen to study. What the natives are saying about who they are, what they are doing and why are they doing it often provides vital clues to what the analyst should be looking for. ${ }^{27}$ Yet, students of politics also tend, appropriately, to be skeptical about the overt protestations of politicians and the public. ${ }^{28}$ For this reason, they need a conceptual vocabulary that captures the generic features of actions and intentions. ${ }^{29}$

And, finally, although it is rare, politicians and the public can even pick up concepts from scholarly works and use them for their own purposes. ${ }^{30}$

\subsection{The Agents}

This is the most distinctive feature of a human as opposed to a natural or physical science. Agency begins with the assumption that the objects of research

where its Western connotation of a person with political rights does not fit well. Yet, as in Schmitter's case of Euro-speak, the conceptual disconnect has revealed something very important about the underlying elements and assumptions of the political relationship between the Chinese people and the state that rules them.

27 Welcome developments in this regard include the growing use by politologists of ethnographic methods and of the "reconstructive" approach to survey methodology. Historians have been more accustomed to this issue, since the words that agents use are $e o$ ipso important subjects of their inquiry - especially for intellectual and political historians but even for the newer generation of social historians, for whom ordinary language provides rich evidence.

28 As usual, the Italians have a word for this intrinsic skepticism: dietrologia, or the science of capturing and understanding what lies behind (dietro) the public statements and manifestations of politicians. The implication is clear: politologists should be skeptical and practice dietrology in their research.

29 A related issue concerns the so-called "ladder of abstraction" - the level of generality built into a given concept. See Giovanni Sartori, "Concept Misformation in Comparative Politics," American Political Science Review 64, no. 4 (December 1970): 1033-1053. At the bottom are those upper-case words that are only intended to denote some specific instance; at the top are those lower-case ones that are presumed to connote the complete range of whatever empirical phenomenon is being referenced. Most works of politology are based on concepts that occupy some middle-rung of the ladder. How far up or down to range from that middle is a strategic choice the analyst must make and will vary with the temporal and spatial characteristics of the outcome he or she is working on - as well as the pretentiousness of the theory from which the concept is drawn.

30 Schmitter remembers being buttonholed in a magnificent Milanese palazzo by Norberto Bobbio, the doyen of political thought in Italy, who then said: "Interesting your work, but why did you call it corporatism?" Bobbio was a notorious opponent of Fascism and simply could not imagine separating the concept from its use by Mussolini. Nevertheless, the label stuck and generated a mini-growth industry in the 1970s and 1980s, although wildly different meanings and normative implications were attached to it by both scholars and politicians. In 1980s China, important political leaders and ideologists ushering in structural economic reform developed a theory of "new authoritarianism" to convey and justify shunning political reform in the face of growing social tensions. To this end, they promoted the translation and study of Samuel Huntington's famous and controversial Political Order in Changing Societies, op. cit. 
are also subjects. In the case of politics, this means that agents can make choices that are not completely determined by the conditions in which they find themselves. ${ }^{31}$ It also inevitably introduces significant elements of innovation and unpredictability into political analysis. ${ }^{32}$

It further implies that the subjects have the capacity for reflexivity. Political agents are historical in at least two senses: (1) their past actions can become valued traditions that are difficult to break when presented with new opportunities; and (2) their present actions can be influenced by reflections ("memories") from the past and, hence, by learning they may alter their responses to similar situations in the future. These two observations assume that agents do not change their preferences in the course of trying to satisfy them - which itself is highly improbable. Whether by their own experience or by observing the efforts of others, they may conclude that what they thought they wanted is no longer so desirable. Learning by doing and from diffusion are integral parts of the political process through which preferences are routinely altered. If that were not enough, the very process of outsiders researching the power relations among agents can produce changes in the behavior or expectations of the persons and organizations one is studying.

Albert Hirschman, in a very influential book, has identified the fundamental alternatives offered to political agents: exit, voice and loyalty. ${ }^{33}$ Confronted with the necessity of taking a consequential decision involving the exercise of power: (1) they can choose to leave the unit entirely (or to stay and try to avoid being affected by it and avoiding its politics); (2) they can take a position in favor of or against and try to influence the outcome to their favor; or (3) they can give up on agency altogether by sitting back and accepting whatever decision is taken on the grounds that it has been or will be taken legitimately. ${ }^{34}$

Elaborations and qualifications to this trichotomy immediately begin to appear. Both exit and voice can lead eventually to a change (and, we can hope, an improvement) in the performance of the unit or at least a reduction in entropy. However, voice, if a valid representation of the agents' views, conveys a great deal more information than exit about the nature and strength of agents' discontent. And, if agents express themselves not just with criticisms but also by

31 Not all politologists would agree with this affirmation of our basic human capacity to think and act with some level of self-determination. The discipline has periodically been invaded by "determinists" who claim to have identified the forces that determine why and how agents behave - whether it is "the mode of production" (Marxists); "the political socialization of infants" (behaviorists); "the national political culture" (area and country specialists); or "the individual calculation of marginal advantage" (rationalists). Each of these deterministic claims has made some positive contribution to the discipline; all have failed, however, in their ambitious effort to overcome the intrinsic uncertainty of political behavior - even to explain such routine behavior as voting, not to mention the still more unpredictable ones of régime change and revolution.

32 See the discussion on pages 8-9.

33 Albert O. Hirschman, Exit, Voice and Loyalty (Cambridge, MA: Harvard University Press, 1970).

34 Yet, loyalty can also motivate agency. See page 42. 
suggesting alternatives, that may prove even more constructive. Finally, voice can be and, in stable institutional contexts, usually is grounded in loyalty; it only rarely reflects or portends the public's sense of the régime's illegitimacy. We should also not expect, even in theory, that "loyal voice" needs to restrict itself to real-existing democracies $\left(\mathrm{REDs}^{35}\right){ }^{36}$ Indeed, if too many loyalists in the public do nothing, there will be much less pressure for the system to change. Given the general assumption of entropy, politics, policies and institutions will correspondingly "deteriorate.",37

To these three generic types of response, we suggest adding a fourth: sufferance. Potential agents may stay and choose to remain silent, not out of loyalty to their rulers or conviction of their legitimacy, but simply because they perceive that the costs of speaking out and acting are too great, that the chances of their being heard are too slim, or that no viable alternative seems available. Like the loyalists, they will suffer the consequent injustices and injuries, but they remain in the system and presumably accumulate resentments that at some future point could contribute to entropy and lead them to exercise voice often unexpectedly and stridently. ${ }^{38}$ Their very existence is a sure sign of dysfunctional political institutions and politics. Moreover, the difference between "loyalists" and "sufferancers" will generally be clearer in conceptual-cumtheoretical terms than empirical ones. After all, both eschew agency in the here-and-now. One of politology's greatest challenges is to explain "the dog that has not been barking and then suddenly starts to do so." In addition, quiescent "loyalists" can easily turn into quiescent "sufferancers" if they begin to

35 Throughout this essay, we will refer to what are generally called "democracies" or "liberal democracies" as "real-existing" ones in order to stress how different their institutions and practices are from the Greek etymological ideal of "rule by or of the people."

36 Sadly, Italian Fascism and German Nazism both drew considerable nourishment from the voices of large numbers of enthusiastic loyalists. And, in 1989, Chinese protesters at least initially remained loyal to the Party (see footnote 40).

37 We have added "scare" quotes because there is a normative assumption built into this theory, i.e., that order is preferable to disorder. Whether that is so depends on one's preferences and standpoint. For "progressives" who are unable otherwise to exercise power in the interests of change, disorder may create new opportunities and/or weaken the position of the "conservatives" protecting the status quo. Mao Zedong famously championed this normative and political view when he said: "Things are really chaotic; the situation is excellent." More recently, Slavoj Žižek has championed this position. See his In Defense of Lost Causes (London: Verso, 2017).

38 Presumably, this is the group to which Calvin Coolidge and Richard Nixon were appealing when they invoked the expression "the silent majority." Whether or not they constitute a majority, which is hard to measure precisely because of their silence, "sufferancers" do represent a potentially disruptive element in all types of régimes, especially when they are able finally to express themselves at very little cost by the simple act of voting. In recent years, they have wrought electoral havoc in Hungary, Poland, the UK and the US, to name just a few. 
feel that their loyalty has not been rewarded and, worse, if it has created the conditions for their situations to deteriorate. Thus, it may only be possible to distinguish loyalty from sufferance in practice after the destabilizing consequences of the latter have come to the surface.

The vast majority of politologists presume that agents are individual and autonomous human beings faced with and capable of making deliberate choices between alternative and consequential actions. While scholars tend to agree that people are uniquely capable of exerting political agency (compared either with other species or with a strictly deterministic theory of human behavior), they differ considerably about the properties that humans are capable of bringing to bear on their choices. We have been told by economists (and the political scientists who imitate them) that individuals have pre-established and relatively fixed preferences, are able to assign to them a specific intensity and to rank them consistently, possess adequate information about alternative courses of action and theories about their effects, will predictably choose the one that (they think) best realizes those preferences at the least cost and still have the same preferences once they have experienced the consequences of their choice. Even with the insertion of caveats such as "bounded rationality," "limited or asymmetric access to information," "intransitive preferences," "transaction costs" and "logics of appropriateness or habit," this generic conception of the capacities and roles of agents accords not only with currently fashionable theories of rational choice, but reflects the much deeper ideological commitment of modern social and political thought to liberal individualism and utilitarian social progress. Shifting to a different micro-foundation would seem to many participants and observers to be equivalent to declaring that politics is just a "passionate" rather than a "rational" activity rooted in raw emotion, blind faith, naïve gullibility, mindless imitation, instinctual tradition, collective stupidity and/or random events - and, hence, depressingly and dangerously incapable of collectively improving the world in which we live. ${ }^{39}$

Our research has supplied three kinds of reasons for calling this time-worn foundation into question. The first has to do with the sheer complexity and contingency that surrounds contemporary individuals. They cannot possibly know what are the "real" (or, even, all of the available) alternatives and, even less, what all of their eventual consequences will be. For them even to approximate these search conditions in the real world would require so much time

39 Mishella Romo reminds us that other scholars have questioned the ability of rational choice theory to account for significant empirical developments in contemporary politics. Martha Nussbaum has emphasized "emotions" and their role in shaping the political order; see her Political Emotions: Why Love Matters for Justice (Cambridge, MA: Harvard University Press, 2013). Ian Shapiro and Donald Green have identified and articulated a number of "pathologies" within rational choice theory, in Pathologies of Rational Choice Theory: A Critique of Applications in Political Science (New Haven, CT: Yale University Press, 1994). 
and resources that little would be left to subsequently pursue their interests, which would allow someone capable of shortcutting the whole process by simply accepting the solutions proposed by pre-existing institutions or ideologies to prevail. In short, it would be irrational from a political perspective to act "rationally" in this fashion!

Moreover, these individuals are very likely to discover upon such complicated and time-consuming reflection that they have many conflicting interests, passions or even convictions - especially over different time horizons - and, hence, cannot possibly pursue them consistently according to rank and intensity.

And, if those reasons were not enough, these agents are typically acting within a multi-layered, polycentric and "nested" set of institutions - some public and some private - all of which are potentially capable of making or influencing binding collective decisions. Acting as rational individuals, they would have not only to discover which of these institutions is relevant but also, in the likely event that several are involved, to distribute and adjust their calculations accordingly.

Agent preferences, then, are not fixed, but contingent upon which policies and political actions are proposed and by whom, and upon which "others" they are observing. In other words, preferences, and political agency in pursuit of them, will probably change during the course of political exchange as it moves unpredictably across the various layers and centers of domestic power and as agents reflect on and react to their efforts and experiences, as well as those of foreigners. ${ }^{40}$ Rationalists have attempted to recognize as much by devel-

40 An apposite case, and one that is especially well documented, concerns the attitudes of the British public to membership in the EEC/EU. In 1973 in a national referendum, they voted $67.2 \%$ to join. In 2016, they voted $51.9 \%$ to leave. Admittedly, 43 years is a long time for them to change their collective mind but it does suggest that experiencing the costs and benefits of a choice can make a difference across generations. As one deadline for leaving actually approached (March 2019), public opinion polls suggested that, just three years later after witnessing the chaos and misrepresentation that this choice had entailed, if there were to be a another referendum on leaving or staying, they had changed their minds again and would probably have chosen to stay.

Another illustration might be the attitude of propertied and professional groups the stalwarts of liberal democracy according to modernization theory - in various Latin American countries during the 1960s and 1970s, when they encouraged and welcomed military coups that promised to protect their interests. Some decades later, after experiencing the human, material and reputational costs of this form of autocracy, it is almost unthinkable that they would still do so. The region has been unusually free from the plague of golpes that used to characterize it - although definitely not immune from the prospect of decensos (backslidings) that would gradually transform their nascent democracies into some form of democradura or, even, dictablanda (see page 62).

One more: during just a few short weeks in the Chinese spring of 1989, the political calculations and actions of agents driving massive protests moved through several momentous iterations from voice (inflected with loyalty) to exit or at least sufferance, then back to voice before making a final exit. Students of the capital's top universities initially felt emboldened to occupy the center of Beijing. The 
oping complicated theories of "iterative games." These only produce highly stylized and formalized pictures of real politics that themselves depend on the profoundly limiting and problematic micro-foundations discussed immediately earlier. Real politics is far more complex than the capacity of such theorizing to grasp and elucidate it, much less prognosticate on the basis of it.

Moreover, agents' "rational choices" among their modal strategies of exit, voice, loyalty and sufferance are likely to differ systematically as they are played out in different kinds of political units and régimes (to which we will turn in Sections 2.8 and 2.9). For example, in units whose boundaries map onto salient historical and cultural affinities (such as nation-states), loyalty may be more likely to trump exit. Or, it is often thought, in REDs, citizens may find voice more rational (and less risky), and sufferance less necessary, than do subjects in autocracies, though, given the bluntness of such régime types as concepts, these broad (and often ideological) generalizations are probably less useful than more textured analyses of the politics of specific times and places. ${ }^{41}$

The second (and more compelling) reason for resetting one's microfoundations is even more subversive of the prevailing orthodoxy. What if most of the significant agents engaged in normal politics were collectivities - including but not limited to formal organizations - rather than individual persons? Of course, they are composed of individuals, but the latter may play little or no meaningful role in shaping the formers' agency. Moreover, while some may depend on the contributions and compliance of their constituent persons, many do not, and have developed elaborate rules and sources of support that cannot be reduced to the individuals who comprise them or whom they claim to represent. They often embody collective choices made long ago, and have acquired a reputation and legitimacy of their own. In other words, they are not merely the arithmetic sum of independent and individual

ensuing protest quickly produced political dynamics that shifted the political situation dramatically several times. After a few weeks of tolerance, the leadership found its own tough voice in a declaration of martial law. But that only emboldened the number of protesters to swell and raise their voices still higher. Yet after a few more weeks, the protesters naturally wearied of their 24-hour-a-day protests. (Recall our mention of political exhaustion on page 4.) Many now switched to a different but equally "rational" choice and exited. Yet, they were soon replaced by new recruits fresh from the provinces, whose preferences and inclinations for noisy voice at that very same moment were much more like those of their Beijing "classmates" initial ones. Meanwhile, the passage of so much time created an opportunity for the hard-liners to gain the upper hand at the highest levels of the government, leading to a crackdown. Ultimately, the surviving protesters lost their initial sense of loyalty, and were forced into resentful, disillusioned sufferance.

41 For example, over the past several decades, aggrieved Chinese workers have, quite rationally (as well as passionately), "chosen" voice far more than their aggrieved fellow proletarians in the REDs of North America and Western Europe. And "loyalty" grounded in resurgent nationalism has come to the fore in both. 
preferences. Moreover, political parties, interest associations, non-governmental organizations, business firms, government agencies, private foundations, social movements and even ad hoc crusades are often in the business of teaching these potential individual agents what their preferences should be and committing them to participating in politics they lead and obeying policies made in their name. $^{42}$

As we have just argued, very few individuals can determine alone what their interests, passions or convictions are or should be, much less act alone as effective agents. Thus, they require stimuli from their social environment in order to discover what these motives are, and coordination with and support from others in order to act with any chance of success. We can array these collectivities along a continuum from spontaneous and informal at one end to institutionalized and organized at the other. The former would include episodic congeries such as clusters of like-minded voters or spontaneous demonstrators; the latter continuous, often highly bureaucratized, organizations which have existed before being joined by their individual members and will survive after they are gone. In general, autocratic régimes tend to breed the former. REDs encourage, sponsor and tolerate the latter in the space known as "civil society." For our present discussion, the most important implication is that the agency of these intermediaries between state and society cannot be reduced to the mere sum of the choices and preferences of their members or followers. These intermediaries - whether leaders of peasant uprisings or of modern political parties - have interests of their own related both to their distinctive needs as formal or informal agents and to their role in coordinating the diverse interests, passions or convictions of their followers or members. As historical agents, even the spontaneous, informal collectivities may develop standard operating procedures and in-house ideologies, especially if they can observe each other. ${ }^{43}$ Some, especially in REDs, ${ }^{44}$ are able to morph into more organized, institutionalized and continuous agents, though the latter may also come about through more top-down, planned initiatives. In either event, more organized, institutionalized and continuous collective agents are better able and more likely to extend their time horizons when calculating their interests, passions or convictions beyond what individuals are likely to

42 They could include a wide range of groups from an ad hoc collection of angry people mobilized by political activists, on the one end, to formal organizations such as labor unions in REDs or the Chinese Communist Party both in their internal relationships with their own officials and in their "external" ones with their members or the people they govern.

43 For example, in China, disaffected workers are unable to organize formally, and the country's plentiful strikes are all wildcat affairs put together on the fly either without any organization or by wildcat "unions" that only arise in the course of the current struggle and then disappear as soon as it ends. Yet by learning through informal channels about previous disputes, they have come to develop a remarkably similar set of repertoires and tactics.

44 See pages 49-50. 
do. Moreover, they can also enter into longer-term arrangements with other organized interlocutors and state agencies. The latter may even extend to them rights by which they are guaranteed access to public decision-making and participation in policy implementation.

When one adds to these distinctive qualities the fact that very few of these intermediary organizations have competitive internal processes for choosing their leaders or staff, their autonomous contribution to the political process should be abundantly clear - and, therefore, included in any "model" of how contemporary polities operate, whether democratic or autocratic. In a different lexicon, contemporary politics in both types of régime is all about representation about the extent to and manner in which collective intermediaries can act in lieu of individual persons by intervening between them and their rulers by "re-presenting" their ideas (if necessarily in an altered form). ${ }^{45}$

Even autocracies rarely rule directly. In extreme (so-called "totalitarian") cases in which the state occupies all the space for public decisions and allows none for society, it usually fills that space with its own intermediary organizations and institutions, many of which prove to be key agents not just in maintaining its rule but also by suppressing or coopting "progressives" demanding change. ${ }^{46}$ In REDs, freedom of association, assembly and petition - coupled with the diffusion of organizational skills from the private to the public realm has made it almost mandatory for individuals to resort to permanent collective bodies if they are to have any impact upon rulers and their policies.

Collectivities, whether organized or not, have transformed the nature of politics. By definition, they have solved the dilemma of rational collective action by individuals and, in some cases, they may even have addressed some of the issues involved in the inequality of power resources by combining large numbers of weakly endowed individuals to countervail the concentrated influence of smaller, privileged groups. ${ }^{47}$ Their preferences do not have to be inferred or indirectly revealed; they have been articulated publicly, whether through spontaneous or organized activity. Granted, there are bound to be some elements of dissimulation, strategic action and hypocrisy in these activities, but these are minor when compared to those of less well-informed and publicly committed

45 On the general problem of representation (including "re-presentation"), see Hannah Fenichel Pitkin, The Concept of Representation (Berkeley: University of California Press, 1972).

46 In China, the state rules better by establishing its own labor federation rather than simply by banning any independent labor organizing - see Eli Friedman, Insurgency Trap: Labor Politics in Post-socialist China (Ithaca, NY: ILR Press, 2014) - and by creating its own elaborate urban neighborhood organizations (Luigi Tomba, The Government Next Door: Neighborhood Politics in Urban China (Ithaca, NY: Cornell University Press, 2014).

47 For example, the disorganized but persistent machinations of Chinese workers have, arguably, accomplished more for the country's disenfranchised than the lone protestations of China's brave political dissidents. 
individuals. As we have noted earlier, organized collectivities in particular are also capable of extending the time horizon for political calculations because they usually outlive their members (and sometimes even the social category they claim to represent). Both they but, as also noted earlier, sometimes even the less well-organized ones tend to develop standard operating procedures and official ideologies that greatly facilitate their members' calculation of preferences, and they "package" these preferences into justified and possibly broadly acceptable demands, making it much easier for authorities to consult and negotiate with them. In autocracies, where individual agency hardly exists, formal intermediary organizations do not have much if any power. Their raison d'être is to enable those with power, who created them, to rule. Nevertheless, disorganized and spontaneous collectivities have been able to exercise some real power - despite official control of these intermediate spaces. ${ }^{48}$

In REDs, individual agency through the ballot box is often crucial in bringing about changes in policy and rules of the game, but who and what is on the ballot is shaped almost entirely by organizations (especially parties, of course), of which even the individual political candidates are creatures. Most political agency, therefore, remains collective, and a mirror-image of that in autocracies: the betterorganized and more institutionalized collectivities are the key players, even as they are increasingly constrained or upstaged by the more spontaneous ones. ${ }^{49}$

The power of collectivities depends upon their credibility, which, in turn, depends on their capacity to deliver the conformity of their members, followers or fellow travelers in the event of a given conflict or decision - before, during or after it occurs. But even when better-organized and institutionalized collectivities lose power because they can no longer command obedience or even just support, the beneficiaries tend to be less-organized, more spontaneous outfits rather than individuals, no matter how charismatic.

All in all, it does not seem exaggerated to describe these collectivities whether more or less organized and institutionalized - as "secondary citizens/ subjects" with their own political capacities and, in REDs, rights, obligations and channels of access to authorities independent of the electoral one.

\subsubsection{The Political Parties}

It has become customary to distinguish among three generic types of organized intermediaries. Political parties are by far the most studied by politologists.

48 Examples abound: "Colored revolutions" in Eastern Europe, the 1978 Islamist Uprising in Iran, the "Arab Spring," the popular revolts that brought about the "Third Wave" of democratization in Latin America and East Asia, e cosi via.

49 Here, key examples include the Civil Rights, Anti-Vietnam War and far-right movements in the US, anti-corruption campaigns in South Korea, the independence movement in Taiwan, recalcitrant French unions perennially opposed to neo-liberal "reform," e cosi via. 
They are the institutions which claim exclusive political power on behalf of all the people in the country on the basis of having been elected, won a revolution, commanded overwhelming popular support in a peaceful régime transition or by virtue of appointment by themselves or by God. Their most distinctive functions (which they monopolize in most REDs, not to mention in those autocracies which rule partly through parties) are to nominate candidates, conduct elections, organize legislatures and form governments. They usually do this by developing a distinctive ideology or image that offers to their members and voters more generally a convincing (and sometimes alternative) set of policies that will benefit them, and then promise to use this program to order their priorities when ruling.

But, as Peter Mair has argued in connection with Western European REDs (though his analysis can "travel" quite widely), political parties inevitably face a serious dilemma in their role as the embodiment of the political will of the governed. ${ }^{50}$ On the one hand, those who placed them in power expect them be responsive to their specific interests, passions and convictions. However, since party politicians also represent territorial constituencies with citizens who have not voted for them, and since they, once elected, have to enter into compromises with other parties, associations, movements, government agencies and other institutions, they also have to behave responsibly in accord with a broader set of interests, passions and convictions. The problem is even worse in federal systems in which citizens often find themselves simultaneously governed by multiple parties claiming power at different "nested" levels within a territory. If that were not difficult enough, many of the constraints to act responsibly are increasingly being generated by supra-national agents - regional (e.g., the European Union (EU)) and even global (e.g., the International Monetary Fund (IMF)) - with no claim whatsoever to legitimate power within the country the party is governing.

Of course, many autocracies also rule in part through parties. Some politologists have tended to dismiss them as not "real" parties like their RED cousins because they do not face electoral competition and because they are often the "top-down" creatures of rulers rather than "bottom-up" organizations who put politicians into ruling positions. Yet, there are good reasons to treat such parties in autocratic systems in some of the same terms. First, if lack of competition were a fatal problem, we would also have to dismiss dominant parties in REDs even though they regularly win elections which are genuine tests of their popularity despite the victor never being in question. ${ }^{51}$ Second, even in REDs, single parties form governments claiming exclusive legitimacy to rule,

50 Peter Maier, Ruling the Void (London: Verso, 2013).

51 Examples abound: the Indian National Congress for the first three decades of independent India, or the Japanese Liberal Democratic Party for almost all of the post-war period, to name just two. Social Democrats in Scandinavia, Christian Democrats in 
albeit with the crucial caveat that their time in power may be limited by the electoral cycle. Third, single parties in autocratic régimes also claim, often credibly and effectively, a legitimating intermediary role between the rulers and the ruled. They do so on bases that are often not so different from their RED cousins: having won a revolution, having led a broad popular movement that inherited power from a previously unpopular interloper or despot, or having acceded to power thanks to their own charisma (in the strictly religious sense or not) or, simply, for having "provided the goods" to their constituents. In autocratic régimes whose dominant parties arose historically out of revolutions or broad, peaceful social movements led by parties, the autocrats can legitimately claim that their power rests on a popular (if non-competitive) base, and the ruled may often share that view. Whatever their origins, elections in autocracies obviously do not lie anywhere near the core of parties' significance (which is why politologists focused on REDs have often dismissed them). That such régimes may hold elections at all is a minor puzzle, since, presumably, they are little more than window-dressing that is unlikely to fool the ruled, and may be unnecessary if the ruled do indeed regard their rulers as legitimate for other, non-electoral reasons.

Taking seriously single parties in autocracies opens up analysis of them to some of the same conundrums that Peter Mair identified as plaguing parties in REDs. A prominent one has to do with the cross-pressures of ruling in polities with significant territorial subdivisions (which is a common feature of most if not all of them). Even in autocracies, insofar as people expect anything from the ruling party, they generally look to party officials to work on behalf of their local interests even when that means pursuing policies or seeking resources in ways that put them in competition or even conflict with their fellow party officials in other places and/or with those at higher levels of the nested jurisdictional and political hierarchies. While much of this is the ordinary, manageable stuff of politics, such factional conflict among fellow politicians in the same, single autocratic party has led to significant crises and even régime collapse. ${ }^{52}$

Germany and Liberals in Switzerland have long dominated their electoral systems without anyone questioning the democratic credentials of these countries.

52 The most stunning example is the way in which the cleavage between Communist Party leaders in the various republics of the USSR, who shared strong national bonds with each other that produced conflicts with both neighboring enemy nationalities and the center, contributed heavily to the centrifugal breakup of the Union. See Ronald Grigor Suny, The Revenge of the Past: Nationalism, Revolution, and the Collapse of the Soviet Union (Stanford, CA: Stanford University Press, 1993). In China, by contrast, something of the reverse has actually sustained the régime. Local party organizations are often prone to high-handed and/or corrupt political practices (as they surely were in the USSR too), but they are not able to take advantage of shared bonds of nationality to protect themselves from discontent about their misrule. Malcontents have frequently taken their grievances to their provincial capitals or even to Beijing. Thus, in China, 
In short, then, among the various types of intermediary collectivities that stand between individual agents and their rulers, parties are probably the most salient and politically important. That is why politicians rarely switch parties, and they strenuously resist fundamental changes in the existing party system. To put it the other way around, successful efforts to form new parties are extremely rare in established régimes. ${ }^{53}$ When autocrats face serious challenges to their power, they tend to rely most heavily on consolidating the power of their parties in order to stay in office (provided that they care seriously about their legitimacy and that they already have firm control of their armed forces). ${ }^{54}$ The absence of parties is a sign that the polity is probably a failure and has no régime at all.

\subsubsection{The Interest Associations}

The second generic type of organized intermediary is the interest association. Its distinctive claim is to represent some social ("ideational") or economic ("functional") category in its relations with public authorities in such a way as to benefit its own members exclusively, although it is not infrequent that its activities will also benefit "free-riders" - persons or organizations in the category that are not members or contributors. Class, economic sector and occupation are the usual, but not exclusive, functional categories, in addition to which there are many others oriented to ideological concerns, single political issues, identities of all kinds, and even hobbies and leisure activities. If there are competing, overlapping associations claiming to represent the same category, the system of interest intermediation can be described as pluralist. If there is only one or only a single cluster of related associations - and even more so if public authorities recognize such a monopoly and grant it privileged access then the system is called corporatist. ${ }^{55}$ While the number of political parties is relatively limited by the very nature of the electoral process and its constituencies, the number of interest associations and the relations among them is not so limited - or, better, is only limited on the one side by the level of the state's regulation of the freedom of association, and on the other by the division of labor and the social, political, cultural, ideological or leisure-oriented categories with which individual citizens/subjects identify collectively.

If the state - in this case, usually a monopolistic governing party - restricts freedom of association very tightly, permitting only intermediary associations

the cleavage between localities and what Chinese call "the higher levels" has insulated rather than endangered the People's Republic.

53 Which is what makes the recent explosion of "populist" parties of the Left and Right in European REDs so indicative of a generic and serious crisis of this type of régime.

54 Hence, Xi Jinping's overriding focus on corruption in the Chinese Communist Party in order to help assure the survival of the People's Republic.

55 This concept is to be distinguished from any meaning associated with the modern business corporation, despite the shared etymology. 
around each interest that it has singularly organized or coopted, and which it controls, the system is monist. In state socialist régimes, these outfits are not even known as interest associations, but, rather, as "mass organizations." While pluralist and corporatist interest associations are, as generic types, in the business of representing their constituencies to a greater or lesser degree, and also negotiating with the state (hence the term "interest intermediation" rather "interest representation"), monist outfits have much more to do with "appropriated representation" 56 while also serving as "transmission belts" from the state to society. Here, the rulers arrogate the function of "representing" various societal groups and concerns to themselves, ${ }^{57}$ and also use monist organizations to represent themselves to various sub-groups among those they rule.

\subsubsection{The Social Movements}

The social movement is the third generic type of organized intermediary although many of its exemplars are not (or pretend not to be) formally organized and certainly not to be bureaucratized. They engage in public, contentious, often disruptive and direct confrontations with rulers around a "cause" or a "public good," i.e., a declared objective that would benefit not only its members, but also some larger group - if not the society as a whole. In other words, interest associations are self-regarding and social movements are otherregarding. As we have seen, ${ }^{58}$ political parties are usually a peculiar mix of both, aiming to represent specific constituencies but also claiming to govern on behalf of everyone.

Needless to say, the causes that can be represented in this fashion are almost infinite in content and will vary constantly over time from objective to objective. Participation in a movement generally provides a benefit in itself in the form of direct interaction with other like-minded persons. Moreover, in a social movement, the pleasure of such interplay is heightened by the excitement of playing a part in dramatic, disputatious group events, especially public demonstrations - activities that parties and interest associations generally eschew. While participants and even passive members of parties and interest

56 This important and useful concept has only recently been resuscitated from Max Weber (Max Weber. From Max Weber, trans. and ed. H. H. Gerth and C. Wright Mills (New York: Oxford University Press, 1946), 292) by Eli Friedman (Insurgency Trap, 22), who rightly criticized the applicability of "state corporatism" to characterize the AllChina Federation of Trade Unions, pointing out that the federation and its constituent "unions" not only did nothing to "incorporate" workers' interests into Chinese politics, but actually served to prevent any such incorporation.

57 Such a prospect may seem absurd prima facie. But in China, not only does the state do it, but the people understand that the state is doing it. In 2009, a group of protesters in Panyu, near Guangzhou, who were opposing the construction of a toxic waste incinerator, spontaneously began chanting: "We don't want to be represented." Austin Ramzy, "China Environmental Protests Gather Force," Time, November 23, 2009.

58 Page 31. 
associations may also experience victories or defeats with great exhilaration, most of their activities and rewards are more humdrum. By contrast, most of the work of social movements involves real creativity and operates at a higher emotional register. These solidaristic pleasures obtain and may live on even if one's own contribution does not make much of a difference to the outcome. In other words, the self-satisfaction of not having taken a "free ride" is likely to be greater in a social movement than in a party or interest association. Even if the movement fails to reach its goals, the personal experience of having contended with authorities in concert with others can produce new knowledge (including self-knowledge) and collective identities, as well as affective experiences with lasting residues.

Social movements operate outside the institutionalized political processes of the state, and they tend to occur when those processes have failed to address strongly felt political interests or passions of some of the governed. They tend to be more frequent in REDs than in autocratic régimes despite the fact that the former potentially offer better prospects for disaffected "progressives" to seek and achieve at least some of their goals via parties or associations. The reason is that they are easier to organize in REDs, which generally offer legal protections and political environments with higher levels of development of civil society and more open political spaces (literally and figuratively). In autocratic régimes, social movements are far more difficult and dangerous to organize. For this reason, they also tend to arise and operate more spontaneously than in REDs, where they can be more easily and effectively organized by political entrepreneurs, be they experienced activists or novice campaigners. Finally, given the generally draconian constraints faced by social movements in autocratic régimes, their contention often puts them at odds with the régime itself, whereas in REDs, they tend to challenge particular social or political "wrongs" and policies that can potentially be satisfied within or by the régime. That is why, in autocratic régimes, they are more likely to result in severe repression or, more rarely, régime change.

\subsubsection{The Civil Societies}

REDs have some mix of the three types of organized intermediaries, which together may form what has been called a civil society, a first-order definition of which is the sphere of self-organization of society, often but not always for political purposes. As early as the 1760s, this has been identified by Adam Ferguson and, then, in the 1830 s by Alex de Tocqueville as a distinctive and positive component of democratic régimes. ${ }^{59}$

59 Adam Ferguson, An Essay on the History of Civil Society (London: T. Cadell, 1782); Alexis de Tocqueville, Democracy in America (New York: J. and H.G. Langley, 1841). 
In theory, civil society is composed of "intermediate bodies," i.e., formal organizations and some informal groups that have the following characteristics:

1 They are relatively independent of both public authorities and private units of production and reproduction, i.e., of firms and families. That is, they involve the political self-organization of society.

2 They are capable of deliberating about and taking collective actions in defense or promotion of their interests, passions or convictions.

3 They do not seek to replace either state agents or private (re)producers, or to accept responsibility for governing the polity as a whole.

4 They do agree to act within pre-established rules of a "civil" - i.e., mutually respectful and law-abiding - nature. ${ }^{60}$

Autocracies may also have civil societies, depending on the historical processes by which they came to power and their ruling ideologies. Those established on the basis of failed or defeated democracy or a pacted transition from either colonialism or their premodern political institutions may face coming to power in societies which already have had some development of civil society. If so, they may lack the will or capacity to stamp it out, or find it more advantageous to maintain the appearance of "democratic" or "participatory" politics - even while violating it in practice. They may also calculate that tolerating the existence of a pre-existing civil society offers them the prospect of coopting potential opposition. Those autocrats that came to power by social revolutions, especially when led by Leninist parties whose experience with violent class struggle produced a commitment to monopolizing all political space, have generally not subsequently tolerated a civil society. Here too, though, there are variations and exceptions grounded in the multitudinous vagaries of history. ${ }^{61}$

Needless to say, some polities have much richer, more diverse and more active civil societies than others. This variation is often correlated with the level of development of the economy and the length of time the polity has been a RED. The reigning assumption seems to be that the more civil society in a

60 Civil society institutions can also act in decidedly uncivil ways that radically break the pre-established rules, often quite intentionally. Examples include the Nazi and Fascist Parties, which eventually came to power via the ballot box, but only after they had captured interest associations and social movements. Less extremely but still decidedly corrosive of the established civil order is the post-1994 Republican Party in the US, which has flaunted one unwritten rule after another in its quest for power; see Paul Pierson and Jacob Hacker, Off Center (New Haven, CT: Yale University Press, 2006).

61 One prominent example is the Polish People's Republic's decision to allow the Catholic Church to continue to operate. Its leaders surely calculated that they were incapable of closing it down, and that any effort to do so would prove too risky even for a totalistic régime such as theirs, one backed, moreover, by Soviet tanks. Ultimately, of course, the church proved an important breeding ground for the Solidarity Movement, which was the first crack in the edifice of Eastern European state socialism. Something very similar occurred within Protestant churches in East Germany. 
given polity, the more likely will be the survival of its democracy. ${ }^{62}$ This, it seems to us, ignores the possibility that the emerging civil society after a period of autocratic rule may be deeply divided by ethno-linguistic identities, highly fragmented into class and sectoral interests, polarized by religious, cultural or ideological passions, or all of the above - or even that established civil societies in REDs can deteriorate in these ways under new kinds of pressures (e.g., from economic decline, globalization and immigration) and political entrepreneurs seeking to take advantage of them. Finally, whatever their relationship to democracy may be, civil societies - especially when comprised of parties and interest associations, and even social movements to some extent - are generally populated and dominated by political élites rather than the governed themselves. ${ }^{63}$

\subsection{The Cleavages}

The more deeply political agents are divided - from each other and from those in power - and the smaller the number of broad groups or coalitions into which they aggregate themselves, the more portentous the resulting political conflict and the greater the potentiality for profound political transformation. Politologists have seriously theorized both poles. Marxian historical materialism teased out of the normal operations of capitalism an inexorable tendency to divide society into two great classes, emptying out the middle ground, whose struggle would produce a cataclysmic economic, social and political upheaval that would usher in a new socialist epoch. Pluralists discovered the secret to eternal, pacific democratic politics in the kaleidoscopic fragmentation of interests engaged in civil competition. Actual politics has not yet corresponded perfectly to either theoretical model.

One conceptual starting point distinguishes between cleavages and factions. ${ }^{64}$ The former are rooted in the enduring inequalities of resources or

62 See Robert Putnam, Robert Leonardi and Raffaella Nanetti, Making Democracy Work: Civic Traditions in Modern Italy (Princeton, NJ: Princeton University Press, 1993). A considerable amount of work has been done in this area suggesting more nuanced approaches. Putnam, Feldstein and Cohen have distinguished civil society that "bonds" members as opposed to organizations that build "bridges"; see Robert Putnam and Lewis Feldstein, with Donald Cohen, Better Together: Restoring the American Community (New York: Simon and Schuster, 2005). Sheri Berman highlights the role of the state in tempering civil society; see her The Social Democratic Moment: Ideas and Politics in the Making of Interwar Europe (Cambridge, MA: Harvard University Press, 1998). Ariel Armony has examined illiberal civil society groups; see his The Dubious Link: Civic Engagement and Democratization (Stanford, CA: Stanford University Press, 2004).

63 See Gordon White, Jude Howell and Shang Xiaoyuan, In Search of Civil Society (Oxford: Clarendon Press, 1996).

64 Here, the usage is societal rather than narrowly political and élitist in the sense of a small group of like-minded political leaders jockeying for power. Such factions regularly occur in REDs as well as autocratic régimes. Examples of the former include 
treatment that are collectively experienced by social or cultural groups within a given polity. They are relatively large in scale, aggregating substantial proportions of the society into a small number of groupings that are easily identifiable and long-lasting. These "structural" differences in interests, passions and (as we shall see in the next section ${ }^{65}$ ) convictions are likely to be multiple. Virtually all polities have embedded in them generic conflicts between men and women, between center and periphery, between younger and older generations and, building on some combination of all these, perhaps the most salient and resented political cleavage of all, between "insiders" and "outsiders." In addition to these come cleavages that are more historically specific to a particular polity. They can be based on religion, language, race, ethnicity, class, status, sector, profession, location, climate, education - the list of potential sources seems interminable. ${ }^{66}$ Provided that they are sufficiently salient and potentially actionable, the persons and groups affected tend to acquire distinctive identities and create formal organizations which tend to be much more difficult to suppress than the more natural (i.e., less socially and economically constructed) individual differences in personality, capacity or preference. Such cleavages are by far the most serious threat to orderly politics.

By contrast, factions are smaller in scale and more diverse in content, informal in organization and limited in time. James Madison defined them as "united and actuated by some common impulse of passion, or of interest" - and he thought they represented the greatest danger to the republic he was engaged in founding. ${ }^{67}$ Fortunately, for that republic and other régimes (including even some autocratic ones), their sources and resources were not as varied or nefarious as he feared. In order to be a threat, however individual and intense those passions and interests may be, they almost always require working with others. And these days (as we have just seen), this, in turn, more often involves work-

the Japanese Liberal Democratic Party, which is in important senses a federation of patron-client "factions" within the Party and Diet, "Brexiteers" and "wets in the British Tories, and the "Freedom Caucus" in the Republican Party. The latter have been characteristic of almost all Communist Parties in power, where, not surprisingly, the leadership has regularly gone way beyond Madison in not just denouncing, but also violently eliminating them on the grounds that they violated party discipline and, therefore, threatened state power.

65 See "The Motives," page $41 \mathrm{ff}$.

66 Schmitter once thought he had found a new one: height. At a conference on the Isle de Gorée celebrating the success of the secret meetings between the Nationalist Party and the African National Congress that took place there and laid the foundation for South Africa's negotiated transition to democracy, the cabinet of the Senegalese government appeared and they formed an almost perfect triangle, with the Prime Minister being the tallest of all surrounded on both sides by less and less important ministers - each smaller than the next. Schmitter subsequently discovered that this was actually an unobtrusive indicator of ethnicity in a political coalition dominated by the tallest tribes.

67 Alexander Hamilton and James Madison, The Federalist Papers (New York: Penguin Classics, 1987), No. 10. 
ing through organizations. These two desiderata have tended to moderate the destabilizing potentiality of Madisonian factions.

Madison is deservedly famous for the wise observation that, since attempting to eliminate these differences of opinion and identity in the population was a cure worse than the disease, it was better to multiply them - by deliberately increasing the scale of the polity and the diversity of interests and passions within it. With this stroke of the pen in 1787, he articulated the core hypothesis of what would much later be called pluralism and become one of the most significant and original concepts in "the American Science of Politics."

But the validity of Madison's argument for pluralism depended on two dubious empirical assumptions: (1) that this multiplicity of cleavages would combine to form a specific macro-structure of passions and interests (and convictions) in which the lines of conflict would tend to cut across each other and, therefore, to produce different winners and losers according to the diversity of issues that would emerge; and (2) that on each continuum of conflict, there would be a more or less "normal" distribution of preferences and, therefore, most citizens would find themselves somewhere in the middle of each issue. If so (and with a few exceptions - slavery and racial equality being the most obvious - the US subsequently seemed to conform to these assumptions), politics would tend to be centripetal in nature and moderate in content. Agents would be more likely to compete for support from those with centrist positions and, hence, more likely to reach and accept compromised solutions. ${ }^{68}$

If, however, cleavages form a cumulative macro-structure such that the same persons or groups - most often classes, races or religions, with the recent addition of genders - are always on the winning or losing side and have come to be recognized as such (often after long periods of being ignored or sidelined), and if they are also more likely to hold passions, interests and convictions closer to the opposite poles of each continuum, the politics will tend to be centrifugal in nature and potentially extremist in content. Agents will claim to represent the preferences of those at opposing ends of the political

68 One of the favorite "mechanisms" used by American politologists to explain voting behavior and advise candidates on their strategy involves the notion of the "Median Voter." It is presumed that, eventually, in order to win elections, parties have to move to the center in order to capture more of the presumably large number of citizens whose preferences are moderate on a range of contentious issues. Needless to say, this presumes a so-called "bell-shaped" or "normal" distribution across the relevant issues. But what if there are no or only a few voters in the middle? What if they are divided into polarized positions? Since this tends to be the case for issues involving personal morality and tolerance of diversity, e.g., abortion, racial equality, immigration and gay rights, and since these issues have become increasingly salient in many REDs (and especially in the US), this may help to explain why it has become so much more difficult to predict the outcome of elections or even to comprehend the discourse of political conflict. 
process and be much less likely to accept compromises as binding on all parties.

And even though the politicization of cleavages and the development of factions may seem to rely on agents' capacity to express and organize them freely and openly as "interests," an environment we tend to associate with REDs, they can also occur in autocratic régimes. The state socialist régimes were full of all manner of internal bureaucratic politics involving the clash of sectoral and regional interests. But for them and other sorts of autocratic régimes, the threshold for economic and social cleavages and factional conflict (in the Madisonian sense) to burst into the open has been and continues to be much higher. Subjects need to feel their dissatisfaction deeply and pressingly enough to be willing to take the considerable risk of expressing them openly. Moreover, they must have some confidence that if and when they do, they will find themselves among a critical mass of likeminded agents that can help protect them from retribution. That is, they have to have a sense that there are many other people who feel as they do and who are likely to be equally emboldened. ${ }^{69}$ That is why broad protests in autocratic systems tend to coalesce around the most fundamental and salient issues and moments. ${ }^{70}$

Whatever the conflicts, the social, economic and cultural cleavages that give rise to them will change as a result of structural changes that shape them, past political decisions, and quite autonomous processes and events. In terms of structure, ${ }^{71}$ of course, deep economic transformations in the mode of production or régime of accumulation, or social transformations in racial and gender relations or international migration, are bound to reshape the demand side of any political landscape. Turning to agency, cleavages and factions themselves become explicanda as they are reshaped by major régime changes and/or incremental policies. ${ }^{72}$ Finally, politics is always deeply em-

69 An exceptional counter-example occurred In China during the Cultural Revolution, when Mao Zedong actually mobilized considerable, authentic political conflict, including at the popular level, around the cleavage between, on the one side, the party authorities who had been using their newfound political power to feather their own nests as well as those who had benefited from their largesse, and everyone else on the other.

70 For example, stolen elections by autocratic leaderships have provided a fertile ground for "colored revolutions." Here, the electoral fraud cleaves the voters into just two large groups: the aggrieved opposition voters and the loyal supporters of the régime. And the issue at hand is among the most fundamental in any political system: will it be a RED or not? See Philipp Kuntz and Mark R. Thompson, "More than Just the Final Straw: Stolen Elections as Revolutionary Triggers," Comparative Politics 41, no. 3 (2009): 253-272.

71 See page 15 , footnote 4 .

72 Whatever damage they did on many fronts, including their own socialist ideals, the state socialist régimes radically reduced social and economic stratification among 
bedded in a wider context of contingent events and developments that it does not and cannot completely control, pace the aspirations of would-be "totalitarian" régimes or the even electoral calculations of strategists in REDs. In short, political rules and institutions may be intended by their creators to be immutable - especially if they are constitutional - but they are constantly being challenged. Hence, political conflict includes both wielding power within the pre-established parameters of a given polity but also changing its rules and practices.

\subsection{The Motives}

Roughly speaking, agents form their preferences and acquire their motives in one of six ways. Probably, the most common in contemporary societies is the pursuit of self-regarding interests. It is not unusual for analysts - academic or otherwise - to presume that it is the or, at least, the most common basis of conflict and motive for action. Even more restrictive is the notion that these interests are primarily if not exclusively material or monetary in nature and can be pursued as rationally as one may purchase goods and services through the market.

In its origins, political thought gave priority to passions, i.e., some inbred compulsion to act in response to either the agent's sense of self or his or her personal understanding of the social/ethical norms of some group of reference. Honor, glory, justice, respect and identity figure prominently in such "passionate" works, but the principal one has always been "the desire for power" itself. ${ }^{73}$ Human beings from the earliest recorded thoughts about politics have been regarded as having an intrinsic passion for and deriving a distinctive pleasure from dominating other human beings.

Third, there are convictions. Historically, these were usually connected with religiously inspired beliefs. More recently, in more secularized societies, the key element of motivation has become ideology - a system of concepts that provides the agents with a comprehensive understanding of their environment and position within it, and a set of commitments to a cultural, economic, political or social goal. Needless to say, interests and passions are usually embedded somewhere in such belief systems, but the motive for action is more other-

classes, genders, regions and the urban/rural divide. Witness also the significant reduction in inequality effected by Fordist and social democratic régimes in capitalist REDs, and its subsequent increase under the neo-liberal political economies that succeeded them.

73 Here, the proper historical/theoretical reference is to Thomas Hobbes and Niccolò Machiavelli, considered the founders of modern political science. They attribute human behavior to both material interests and personal passions. See Richard Ned Lebow, A Cultural Theory of International Relations (Cambridge: Cambridge University Press, 2009) for an updated argument about the cultural motivations of political action. Thanks to Tony Spanakos for this emendation. 
regarding and oriented to the polity as a whole. With the emergence of political parties as important competing or revolutionary agents (even when the revolution ends the competition), their appeal to members, voters or "the people" was (at least, initially) based on ideologies combining different elements of religious, ethnic or class conviction.

Fourth, we return to loyalty. We discussed it earlier ${ }^{74}$ in terms of passivity in the face of a situation in which agency is possible. But people may also act out of loyalty to other people - a leader, an informal group or a formal institution. Here, they need not hold any conviction to the cause or belief motivating those to whom they feel fidelity; it is simply the allegiance that is operating for them. For agents ensconced in stable relationships, loyalty can forge a bond as or even more potent than conviction; to act, they do not require beliefs or rationales, which can be challenged by new arguments, information or situations, but only identification with other individuals or collectivities to whom they relate. Their motivation may also lack the passion grounded in their personal understanding of the social/ethical norms of some group of reference; here, it is enough just to be part of the group without necessarily believing strongly in what it espouses. The motive is just to remain identified with others. ${ }^{75}$

Fifth, people - even citizens in a democracy - may act politically neither intentionally, nor responsively, nor emotionally, nor loyally, but simply out of habit. They are socialized to conform to rules and norms that were chosen or developed under different circumstances in the past, but have been reified and dignified so that they can be applied in the present. They observe the behavior of others who may be more consciously and critically motivated and just instinctively imitate what these "relevant others" do. Voting may be an appropriate example of this. Most potential voters have no interest in participating since their individual contribution to the outcome is minimal - unless the contest is thought to be very close. Nor are they likely to feel passionate about such an activity - unless they are particularly attracted to a single candidate's personality or position, or because they are particularly repelled by some candidate and vote passionately against him or her. Conviction is only likely to play a role if the stakes in the election are especially high or if some social group (e.g., a religious outfit, family, work unit) links voting to belonging.

74 Page $23 \mathrm{ff}$.

75 Examples here could include many members or followers of political parties or labor unions who affiliate because they identify with other partisans or fellow workers. The most momentous political act of all is putting one's life on the line; yet as soldiers or revolutionaries actually do go over the hill, what is in their minds at that crucial moment often has much more to do with feelings for their platoon or comrades than for the cause for which they are fighting. (Of course, they may also do out of fear of the consequences of not doing so - the sixth and last motivator, to which we turn just below.) More prosaically, agnostics who continue to attend or support religious congregations, who may well comprise a significant proportion of their members, generally do so because they identify with their fellow "believers." 
And yet, many voters turn up even in the absence of feelings of loyalty to their party or candidate. Faute de mieux, many voters probably vote out of habit (unless they are compelled to do so by law). They did it before; their neighbors are doing it; the norms of citizenship seem to require it. Unfortunately, this habit seems to waning in virtually all established and many new REDs. The proportion of abstainers has been increasing almost monotonically from one election to the next. Most people do not live for or because of politics. Many prefer to live without it and to do so frequently and habitually if they can. ${ }^{76}$ That said, political habits do have real content, and they vary considerably over time and space. As Gramsci emphasized, they involve what passes for "common sense," and form an essential component of any functioning hegemony. Thus, their creation, reproduction or transformation is an eminently political project.

Finally, there is the omnipresence of fear. Regardless of who the agents are and what is the régime in which they are embedded, politics is ultimately all about coercion and, in order to be effective, it must be accompanied by the threat or the application of sufficient sanctions to invoke fear. In wellestablished democracies, most citizens will accept this as legitimate, i.e., as a necessary and predicable condition for the peaceful resolution of conflicts and acceptable distribution of public goods. Someone has to police the rules and their efforts to do so are likely to be more legitimate if those who apply them can be held accountable for their actions.

It is commonly assumed by public opinion that in autocracies - with the possible exception of those based on traditional norms of dynastic inheritance or religious virtue - coercion is much more frequently applied, feared and resented. Many politologists specializing in autocratic systems are not so sure. Fear is usually a motive for inaction and, hence, difficult to observe and measure. So it is difficult to validate. Moreover, there is a functionalist danger here: just because a régime traffics in fear does not necessarily mean that fear is what enables it to govern. There are good reasons to believe that the people of autocratic régimes, especially state socialist ones that came to power in genuine class or nationalist struggles, are motivated by a mixture of the same motivations as those of REDs, though probably with different distributions among them. For that matter, the distributions from country to country among the categories of REDs and autocratic régimes surely also differ a great deal, perhaps just as widely. $^{77}$

76 One reason that abstention from politics (and distrust of politicians) has increased may have something to do with the fact that more and more of the representatives they elect live off of politics and have no other profession. For this reason, the distance in life experience between citizens and their elected representatives has widened and generated a formidable increase in distrust.

77 In China and many other autocratic systems, there is plenty of interest-based politics in the form of industrial strikes, protests and riots. The popular uprisings in Hungary 
Whatever the motive(s), the central feature of power is to get some person, group or institution to do something that the agent prefers and that the latter would not otherwise do and may even actively oppose. Presumably that "something other" is to the self-perceived advantage of the power-holder whether because of interest, passion or conviction. Virtually, everyone who has written about power - and there have been many - would agree with this generic definition. Where their disagreement begins (and has not ended) is what has to be done to accomplish this feat.

\subsection{The Processes}

Motives have to be put into motion. This involves interacting with others in accordance with their power capabilities. Really powerful agents, especially those backed by legitimacy, may simply refuse to enter into annoying transactions with weak claimants. Less well-endowed agents will not be capable of resisting the politicization of the issue at stake and will, therefore, be compelled to or choose to enter the political process or to knuckle under. When they do the former, this usually means (as we have discussed in Section 1.2) acting within some prescribed set of rules which are embedded in some type of régime (as we shall see in Section 2.9). ${ }^{78}$

By and large, the mantra of most modern scholars of politics is competition. Agents exercise their relative power by competing with each other in order to satisfy their respective interests, passions or convictions - and to avoid having to conform out of fear. In the case of politics within an established régime, this presumes the existence of a pre-existing institutional context in which conflicting motives are channeled by mutually respected rules into a process that limits the use of specified power resources and the range of possible

in 1956, Czechoslovakia in 1968, Poland in 1980, China and Eastern Europe in 1989, Hong Kong starting in 2014 and the various "colored revolutions" were driven by real passion. Conviction is still evident in so many Soviet and Chinese workers' ongoing belief in the values of their Stalinist and Maoist pasts. No doubt, many people living in autocratic régimes manage to go about most of their daily business in blissful indifference rather than fear of their governments.

78 Of course, the institutionalization of rules in an effort to pre-empt, manage or negotiate conflict with organized or spontaneous resistance is not particular to a given régime type. There has been a wave of literature that documents the institutionalization and politics of legislatures, political parties, courts and local governments in autocratic régimes. See, for instance: Jennifer Gandhi, Political Institutions Under Dictatorship (New York: Cambridge University Press, 2008); Yongshun Cai, "Power Structure and Regime Resilience: Contentious Politics in China," British Journal of Political Science 38, no. 3 (July 2008): 411-432; Tom Ginsburg and Tamir Moustafa, Rule by Law: The Politics of Courts in Authoritarian Regimes (New York: Cambridge University Press, 2008), all of which describe concrete returns to institutionalization, namely in the arenas of régime survival, stability and economic performance. (Thanks to Mishella Romo for this contribution.) 
outcomes. Otherwise, the agents would engage in unruly conflict not bound by such constraints and would exercise their power by threatening or exercising violence to impose their interests, passions or convictions.

This seems both a reasonable and realistic assumption, and there are certainly many cases of polities in which the use of power has been domesticated in this fashion to the mutual benefit of the agents involved. The major source of distortion comes when students of politics reduce its application to the process of electoral competition in REDs. The fact that political parties compete with each other for the representation of territorial constituencies, the selection of parliamentary deputies and the right to form governments - even when these elections are freely and fairly conducted, and their outcomes uncertain - does not exhaust the channels through which political agents compete with each other over "the authoritative allocation of values."79 Not surprisingly, these other channels are populated less with individuals than with groups and institutions: competition between interest associations to influence public policy; prosecution of politicians for violating legal norms by law firms or public interest groups; demonstrations by social movements to set the public agenda or to block the implementation of policies; revelations by rival media firms to discredit or support the reputation of rulers; jockeying among state ministries for budgetary resources; factional fights within both ruling and opposition parties; e cosi via. Many of these can occur in autocracies as well as REDs. All of them and so many more are important (and often highly institutionalized) features of normal politics that deserve at least as much scholarly attention as the more regular, periodic and routinized conduct of electoral competition in REDs.

Another process also deserves a more prominent place in the micro-foundations, namely, cooperation. Unfortunately, it is when politics fails and violent conflict prevails that both the consumers of political knowledge and its producers pay the most attention to it. The much less salient and routinized processes whereby agents solve problems collectively tend to pass unobserved. Why should politicians feel more satisfied when they have defeated their opponents, rather than cooperated with them? ${ }^{80}$ Why should the general public reward their rulers for winning at the expense of others, rather than for improving the welfare of all of the protagonists? Why don't they recognize that, if competition is not to degenerate into conflict, agents have first to cooperate by agreeing upon and observing the rules - formal or informal - that limit and channel their use of power? Ad-

79 David Easton's famous definition of politics. David Easton, A Framework for Political Analysis (Englewood Cliffs, NJ: Prentice-Hall, 1965), 50.

80 Marx accused even Darwin - whose work he admired - of being subject to bourgeois ideology for emphasizing species competition and survival of the fittest over symbiosis. At the risk of essentialism, one could also theorize a role for culture, hormones or both: are those cultures that value men over women - and, therefore, have political régimes exclusively dominated by men - more likely to reward those leaders who score a successful victory over those who negotiate a successful compromise? 
mittedly, many of these rules consist of habits inherited from previous generations and are taken for granted, but they are continuously subject to challenges as power relations and the identity of agents change and therefore require periodic reaffirmation. Moreover, these agents also cooperate in alliance with each other, both to modify the pre-existing rules of engagement and to affect present policy outcomes. While it is understandable that the public should pay more attention to disorderly conflict because it is so threatening and orderly electoral competition because it is so "theatrical," that does not excuse politologists for also doing so. Cooperation deserves greater status and more attention within the discipline than it usually receives.

And so does its perverse form: collusion, i.e., agents on the inside acting in concert to prevent outsiders from competing or cooperating. This process is much more likely to escape detection since the agreements involved are usually secret or implicit. It can, however, be inferred from patterns of behavior - for example, when previously competing political parties develop more similar platforms or even co-sponsor candidates. In the case of autocratic régimes, collusion would seem to be the normal modus operandi of the political process. In democracies, it is a rarer occurrence and, when it appears, a sure sign of entropy or decay.

Politology should be capable of explaining which of these processes will be used in a given instance, time and place. The task is greatly facilitated if the context is Type Two (abnormal). Virtually by definition, in the absence of "dikes and dams," the agents involved will be in conflict and, therefore, compelled to resort to coercion (or the threat of it) to resolve the issue at stake - and the outcome will be determined by the relative distribution of power resources and the willingness to apply them in that specific instance. ${ }^{81}$ The choice of processes is more complicated in Type One (normal) situations. The range of alternatives is greater and the strategic choices are more difficult to make. The "standard" assumption among politologists working on established régimes is that agents will compete with each other through channels that are fashioned by pre-existing "dikes and dams." Only when these channels are poorly defined or disputed will they resort to overt (and potentially unregulated, i.e., violent) conflict. The strategy of cooperation seems to be contingent on a factor that we have thus far only mentioned in passing: trust. ${ }^{82}$ If the agents

81 Although even the most hard-core realist in the international relations sub-discipline would probably admit that there are elements of cooperation in the formation of alliances and collusion in the balance of power. Nevertheless, these are expected to be episodic rather than institutionalized as in Type One politics.

82 Trust has recently become more prominent in the politological literature, which is ironic since virtually all of the research on public opinion demonstrates a remarkable decline in it - whether applied to political institutions or the people who run them. Perhaps this is yet another case of Hegel's Owl of Minerva taking flight at dusk - i.e., only when the explicandum is already in decline or disappearing. 
involved are confident enough that their opponents will respect the existing rules, norms and practices, even when it is manifestly not in their immediate interest, passion or conviction to do so, and, moreover, that they will continue to do so if the outcome is not what was expected, then a mutually binding agreement can be reached and should be self-enforcing, i.e., not require either additional coercion or competition. In other words, trust emerges in situations in which (relative) winners agree to limit their gains and (relative) losers can afford to lose because they are confident of being able to play the game in the future. Even though trust is in short supply in many political contexts, and the exercise of power tends to breed mistrust about intentions and motives (even in Type One situations), it can develop over repeated interactions when agents have learned to respect each other in the past and know that they will have to deal with each other repeatedly in the future. ${ }^{83}$ Its great advantage is not only to save the costs of expending scarce resources, but also to potentially generate more resources by enlarging the total sum of benefits. Its great disadvantage is that it can morph into collusion vis-à-vis outsiders.

\subsection{The Mechanisms}

The instruments or mechanisms for exercising power are not only multiple, but they can be wielded in different combinations as agents attempt to produce their desired outcomes.

Coercion involves an action or threat by the power-holder to deprive citizens/subjects of some valued resource, up to and including their freedom of action or even their existence. It can be wielded legitimately according to established and mutually acceptable rules, or illegitimately in violation or the absence of them. Moreover, it can be deployed by state institutions or private agents.

Cooptation refers to an action or offer that promises rewards to the recipient(s) in exchange for their support either for some given party or policy or against some other party or policies. This usually means offering some positive benefits in return for conformity, but it can also include promises to be left alone and not be subsequently affected by the power-holder.

Manipulation means that those exercising power seek to limit or distort the information available to the citizens/subjects or rival politicians either to

83 Political trust is not the same thing as cultural or social trust. It is a strategic choice, not an inculcated or habitual reaction. It is possible to have a great deal of the latter and very little of the former. For example, Schmitter lives in Italy and trusts his neighbors sufficiently to give them a key to his house (and they do likewise). However, everyone is extremely mistrustful about Italian political institutions and the politicians who run them. Moving back from these phenotypes to the genotype, it becomes clear from this example that trust has its roots in historically specific social, political and economic settings rather than some cultural generalization. 
narrow or widen the agenda for decision-making and/or to alter the latters' conception of the alternatives available to resolve a given issue. Here, power is wielded long before it is actually exercised by influencing, through indirect, social, cultural and/or educational means, the preferences that others have in such a way that they conform to or are compatible with those exercising power. Its utility depends on the availability (or not) of multiple sources of information and the capacity of agents to process information independently and critically, and to disseminate their opinions.

Hegemony involves the exercise of power through the consent of the ruled. A number of conceptual problems and distinctions arise here.

- Consent may be passive or active.

- In the former, those wielding power get their citizens/subjects to acquiesce, i.e., "to accept something, typically with some reluctance; to agree to do what someone else wants; to comply with, concede." 84 This may be achieved through compromise, when subjects/citizens realize that they lack the resources to achieve enough power to realize all their objectives, much less to rule. It may also be achieved if the preferences of the subjects/citizens are relatively mild.

- By contrast, active consent involves the positive affirmation of another's preferences, framing, narrative or world-view. Strictly speaking, it may not be a mechanism of power at all, since by definition, power is the capacity to make others do what the wielder of power wants them to do which they would not otherwise wish to do. But it may still qualify as the exercise power in the sense of the capacity to rule - i.e., to make the decision to act in a way that has or produces the active consent of the ruled. Put differently, the exercise of power through active consent does not obliterate the distinction between the rulers with power and the ruled who lack it.

- Consent may be achieved organically or through the exercise of other forms of power.

- In the former, those with power make decisions that accord with the actual interests, preferences and/or values of those without power. ${ }^{85}$

- In the latter, those with power achieve it through cooptation or manipulation.

84 Oxford English Dictionary. http://www.oed.com/view/Entry/1716\#eid24362476.

85 In REDs, those with power claim to be exercising it with the institutionally achieved consent of their citizens by conforming to democratic processes - mainly, but not exclusively, elections. In state socialist autocratic systems, the Communist Party claims to be the organic representative of the "masses," which it has acquired by winning a revolution. 
The efficacy and relative weight of these mechanisms - coercion, cooptation, manipulation and hegemony - in a particular time and place does not depend alone on the resources and efforts of those who are wielding power. It also has to do with the resources and efforts of other subjects/citizens or rival politicians whose behavior they wish to target. It is commonly thought that because in REDs the ruled are citizens with constitutional rights involving the capacity to hold power-holders accountable, freely available information and protection for political expression, power will tend to be exercised more in accordance with consent and less on the basis of cooptation, manipulation or coercion. Likewise, in the case of autocracies, where there is much less political accountability, informational freedom and legal protection, it is often presumed that the resources of the ruled will be fewer and less diverse, resulting in greater deployment of power through a more encompassing and formidable form of domination. In this case, individual and collective subjects would be much less able to resist the imposition of arbitrary rules and actions - whether of a public or a private source.

However, there are problems with these presumptions of a tripartite continuum of power mechanisms arrayed from coercion at one (autocratic) end though cooptation and manipulation in the middle and (democratic) consent at the other. Of course, all régimes rely on some combination of all four mechanisms; the question is always about the mix and what dominates it. Sophisticated autocratic régimes have made concerted and often effective efforts to gain consent. Overconfident and desperate REDs have resorted to cooptation, manipulation or coercion. ${ }^{86}$

This is not to say that the distinction, in theory and practice, between autocratic régimes and REDs, is eroding. The élites in REDs still have to face voters who can hold them to account in elections, perhaps the bluntest weapon and most minimal form of political participation available to citizens, but still one that need not concern autocratic leaders (even if it remains the envy of many of their subjects). Moreover, in REDs, citizens should have greater resources to pursue their competing interests, passions and convictions independently of

86 Italian Fascism and German Nazism worked hard to gain popular support, through organizations (e.g., in the former, the youth outfits Opera Nazionale Balilla and its successor Gioventù Italiana del Littorio, various fascist trade unions and the Opera Nazionale Dopolavoro for leisure and cultural activities; in the latter, the infamous Hitler Youth and Deutsche Arbeitsfront), extensive "educational" and propaganda activities, and public rallies and spectacles (most notably, the 1936 Olympics). Likewise the Chinese state, with its Youth League, Women's Association and Trade Union Federation, its "China Dream" campaign, and its own Olympics and Shanghai Expo. Turning to even well-consolidated REDs, Indira Gandhi suspended Parliament for two years in the face of a high level of strikes. Richard Nixon regularly tried to coerce his opponents and the press. Margaret Thatcher used force to break the back of the National Union of Miners. The American GOP has pushed gerrymandering and attacks on the franchise to new heights that have produced significant anti-democratic (as well as Democratic!) distortions. 
the efforts of rulers - and, therefore, it should be more costly and risky for incumbents to try to suppress them. At the extreme, citizens in REDs may even have the capacity to exit from particularly arbitrary constraints - and even from politics itself - by voluntarily limiting the pursuit of some of their more intense interests, passions and convictions.

Another major difference between the two types of régime is that rulers in REDs, when faced with the inevitable changes in resources and ideas, can adjust peacefully (and usually incrementally) by changing their composition and policies in response to the outcome of elections, the pressure from interest associations and/or the mobilization of social movements. Most, though not all, ${ }^{87}$ autocratic rulers - especially when they are bound to a comprehensive system of domination - are either deprived of these signals for change and/ or less capable of making or, given the absence of competition, less inclined to make marginal adjustments in their practices. In short, the great historical advantage of REDs in the struggle for power has been that they can "change without changing" and, in so doing, retain the legitimacy of their institutions.

Finally, the relative balance across the world's régimes between autocracies and REDs has always been affected by international trends, cross-border influences and economic and social crises. In the late twentieth century, autocracies and their leaders started to come under pressure from neighboring (or powerful but distant) REDs, international advocacy groups and foreign democracypromotion programs. ${ }^{88}$ But the economic crises of neo-liberal globalization and war-induced refugee exoduses in the early twenty-first century produced a riptide of autocratic tendencies in many REDs, including some of the most highly consolidated ones. ${ }^{89}$ Politology has registered this shift. In the latter half of the twentieth century, modernization theory, followed by the Washington consensus, and summed up by the liberal triumphalism of "the end of history," gained favor. ${ }^{90}$ Most politologists assumed that "real-existing democracy" was here to stay. It had become "the only game in town." But with the new century

87 China may be an exception in that it engages in regular public opinion polling.

88 Jimmy Carter's foreign policy emphasis on human rights did promote a norm that had significant influence for several decades, prompting, for example, reversals in American support for several autocratic régimes such as Ethiopia, Argentina and Uruguay. See Roberta Cohen, "Integrating Human Rights in US Foreign Politics: The History, the Challenges and the Criteria for an Effective Policy," Brookings Institution-University of Bern Project on International Displacement, 2008. Perhaps the most spectacular effect of the international human rights movement were the arrests of autocrats par excellence such as Augusto Pinochet and Slobodan Milosevic, the latter of whom faced trial in The Hague.

89 Examples abound: Trump in the US, Brexit in the UK, Bolsonaro in Brazil - all winners of elections; and the rise of contenders who, as of this writing, have not yet won in many other countries, including Rassemblement National in France and Alternative für Deutschland in Germany.

90 Francis Fukuyama, The End of History and the Last Man. op.cit. 
at hand, theories of "authoritarian resilience" and recognition of the deep and generic crises of liberal democracy began to displace these assumptions, and their most prominent and optimistic theorist even issued a retraction. ${ }^{91}$

\subsection{The Temporalities}

Politics takes time and takes place in time. Chronological time is important because the exercise of power rarely has an immediate effect and, even when it does, its indirect (and often uncalculated) effects are almost always delayed. Historical time - which historians term "historicity" - is even more important because when someone acts or reacts, it can have a significant effect on the outcome. Acting too early or too late, being "in sync" or "out of sync" with others, understanding or ignoring the surrounding Zeitgeist $t^{92}$ - these are all normal and highly consequential aspects of politics. ${ }^{93}$

91 Fukuyama blamed the subsequent onslaught of identity politics for liberalism's woes (The Demand for Dignity and the Politics of Resentment (New York: Farrar, Straus and Giroux, 2018). But to paraphrase Marx's quip about Proudhon, he hears the bells ringing but knows not from where: identity politics' rise and apotheosis are, arguably, themselves grounded in neo-liberal globalization and its crisis. Cf. David Rieff, "Multiculturalism's Silent Partner: It's the Newly Globalized Consumer Economy, Stupid," Harpers, August 1993: 62-72. On "authoritarian resilience," see, among many others, Andrew Nathan, "Authoritarian Resilience," Journal of Democracy 14, no. 1 (January, 2003): 6-17. It too was proclaimed to be on its deathbed: Cheng Li, "The End of the CCP's Resilient Authoritarianism? A Tripartite Assessment of Shifting Power in China," China Quarterly 211 (September 2012): 595-623. But like Mark Twain, reports of its demise proved "greatly exaggerated," or at least Xi Jinping, who acceded to the Party Chair in that same year, did not get the memo: Xi has stunned ordinary Chinese and Western politologists by radically ramping up autocratic rule. On the crisis of politics in the REDs, see two celebrated analyses: Larry M. Bartels, Unequal Democracy: The Political Economy of the New Gilded Age, 2nd ed. (Princeton, NJ: Princeton University Press, 2016); Steven Levitsky and Daniel Ziblatt, How Democracies Die (New York: Crown, 2016). For a critique of this literature and its assumptions, see Philippe Schmitter, "Crisis and Transition, but not Decline," Journal of Democracy 26, no. 1 (January 2015): 32-44.

92 There is no perfect English translation for this German term. "The Spirit of the Times" does not quite capture its intrinsically contingent nature, nor the extent to which it includes not just the dominant ideas, but also the recurrent practices and embedded expectations of relevant agents. Machiavelli captured this distinctive feature of politics in his concept of virtù, but that is even more difficult to translate.

93 The historicity of the Chinese structural reforms is rarely mentioned even though it is absolutely crucial to their stunning success. China's new leadership was able to embark successfully on its pathway of economic "opening up" in 1978 because at that very moment, world capitalism was beginning to globalize, and also because the US, needing to wind down the Vietnam War, was taking advantage of the early but still discernible decline of the USSR by way of a tactical feint in China's direction. Had the Cultural Revolution occurred a decade earlier and caused the same legitimacy crisis, it would have been much more difficult for the leadership that emerged from the wreckage to attempt to legitimate itself through marketization. Indeed, China did face such a crisis 
Karl Popper famously referred to this distinction by calling chronological time "clocks" and historical time "clouds." 94 We would only add that the politologist (depending obviously on his or her subject) should keep a third metaphor - "cyclones" - in mind in order to anticipate the possibility that disruptive and usually unexpected events - e.g., rebellions and revolutions - may burst suddenly on the scene, radically altering rules and practices, as well as their future consequences. ${ }^{95}$

Unfortunately, the scholarly literature about contemporary politics tends to ignore or to take for granted many aspects of this temporal dimension. We are told that "X" (say, a dramatic decline in the rate of economic growth) tends to produce "Y" (say, a change in voting behavior or even a change in type of régime), but very rarely does the hypothesis have an explicit temporal sub-script (say, for just the forthcoming election, or only if neighboring countries have already experienced this effect). Norbert Lechner, a distinguished Chilean politologist, referred to "the cursed factor of time" as one of the primary obstacles to our understanding. ${ }^{96}$ Descriptions of politics in articles and books are full of time-related expressions: time, timing and tempo being the most common, but also sequence, rhythm, phase, cycle, interval, period, moment, deadline, memory, dread of or reverence for the past, fear of the future, delayed response, anticipated reaction, lag-time, lead-time, time-horizon, time-constraint, time-budget and, of course (but less often), la longue durée and Zeitgeist - but it (whatever it is) is rarely made an explicit component of conceptualization and theorization or explored systematically. ${ }^{97}$

In this section, we shall only have time (!) and space to explore selected aspects of temporality in political life. In Machiavelli's Type One politics, rules

in the wake of the disastrous Great Leap Forward in the early 1960s, when the historicity was very different; it responded, or, better, failed to respond, only with ongoing élite conflict leading to the decade-long Cultural Revolution itself.

94 Karl Popper, "Des nuages et des horloges. Une approche du problème de la rationalité et de la liberté humaine," La connaissance objective (Paris: Aubier), 319-382.

95 Political "cyclones" do not have to involve collective violence or even immediate institutional change. David Collier and Ruth Collier have introduced the concept of "critical junctures" in an effort to capture these rare and fleeting moments when a number of conditions - including especially increased state autonomy - coincide to produce a "path independent" outcome that could not be explained by any of them alone. Ruth Berins Collier and David Collier, Shaping the Political Arena: Critical Junctures, the Labor Movement, and Regime Dynamics in Latin America (South Bend, IN: University of Notre Dame Press, 2002). On path dependency, see Paul Pierson, Politics in Time: History, Institutions, and Social Analysis (Princeton, NJ: Princeton University Press, 2004).

96 Norbert Lechner, "El (maldito) factor tiempo." Espacios 5 (1995): 66-71.

97 Ibn Khaldûn is an exception. In his comprehensive historical analysis, he postulated a very explicit time period - three generations - between changes in régime. His political generations lasted a long time: 50 years. Today, we would probably calculate them at about 15 years. Ibn Khaldûn, The Muqaddimah: An Introduction to History, trans. Franz Rosenthal, ed. N. J. Dawood (Princeton, NJ: Princeton University Press, 1994). 
and practices tend to follow prescribed rhythms and intervals, and the timing of outcomes tends to be more or less predictable - usually, taking longer than promised. As we shall see in a subsequent section, ${ }^{98}$ these temporalities vary according to different types of régime. They are much more an established feature of REDs than autocracies. In the former, leaders come and go; governments are formed and un-formed according to the rhythm set by the electoral cycle. Losers agree to lose partly because they are confident that they will have an assured opportunity to compete in the next cycle. ${ }^{99}$ In the latter, the political process is likely to be more erratic, varying according to the life span of a single leader or the success or failure of plotting among competing factions. The resistance to losing (if one is still alive) is greater since no one can be confident that there will be another cycle, least of all, one that obeys the same rules of competition. In Machiavelli's Type Two politics, the rhythms and intervals are utterly unpredictable and no one can be sure about the timing of the outcome. This is why virtù becomes so much more important. Everything depends on the ability of politicians to choose not just what is the right strategy, but also when to apply it. Thus, they have to learn how to manipulate time, not just conform to it. ${ }^{100}$

Political time, then, cannot be separated from the strategic interaction between agents. Even in the most established of Type One contexts, it is almost never purely chronological and absolute - although self-chosen or externally or legally imposed deadlines can have an independent effect. It is usually and inextricably linked to one's own time preferences, expectations, anticipations, delayed gratifications and aims for the future and those of one's allies and opponents. Memories of how time was used in the past also inform how one allocates and learns from time in the present.

These confrontations - not to say, conflicts - play a central role in defining the relational nature of political time. The likelihood of disparities in power (and, hence, in one agent's ability to prevail in a given confrontation) implies that the difference between winning and losing (even when tightly circumscribed by rules) still depends on contextual temporalities - often very fleeting "windows of opportunity."101 Differences in the availability or exploitability of time tend to benefit one side over another. Political time is never ethically

98 Page 58 ff, especially page 61.

99 In the jargon, this "contingent consent" on the part of losers is often cited as a core attribute of established democracies that helps to account for their extraordinary longevity.

100 Revolutionaries have often re-started even chronological time by declaring new calendars starting with year zero. In Taiwan, politicians and ordinary folk still sometimes speak of "year xx of the [1911] revolution." And, of course, Marx's seminal essay on autocracy and state autonomy still reminds us of the French revolutionary month of Brumaire.

101 Lenin had this in mind when he wrote: "[A]narchist dreams ... serve only to postpone the socialist revolution until human nature has changed. No, we want the socialist 
or practically neutral; someone always has an interest in manipulating it at the expense of someone else. For example, Michel Crozier and Erhard Friedberg pointed out that the capacity to set oneself the furthest possible time horizon can become an important, even the only asset of an agent.

Indeed in a situation of total powerlessness [the agent] will have nothing to lose; time itself will be a matter of indifference to him. Faced with another [agent] who is in a hurry, this indifference to time can become the asset which will allow him to regain power starting from a position of weakness. ${ }^{102}$

One implication of the peculiarity of political time is that there is not likely to be a single, monochromatic representation and experience of time. Rather, there will be plural and multiform temporalities based on different power capabilities, subjective experiences and cognitive maps. Any discrete happening in time and even the time inscribed on the faces of watches or the pages of calendars will be subject to widely divergent interpretations. Part of the challenge of consolidating any specific régime - and even less predictable autocracies - lies in the effort of its founders to synchronize different meanings attributed to time and to organize the business of politics according to a mutually acceptable schedule. ${ }^{103}$ As the rules of the régime become established, predictable allocations and coincidences of time set a mutually acceptable framework for interactions among agents. This, in turn, helps them to establish priorities and even to put off their confrontations, thereby opening up a wider range of eventual possibilities.

revolution with human nature as it is now..." Vladimir Lenin, The State and Revolution, in Robert Tucker, ed., The Lenin Anthology (New York: Norton, 1975), 344.

102 Michel Crozier and Erhard Friedberg, L'acteur et le système (Paris: Seuil, 1977), 73.

103 The indeterminate term of British governments (up to five years) compared with the fixed terms of American ones has produced all manner of profound political differences in two of the world's most consolidated REDs. Most prominently, politicians' calculus and room for maneuver has been much greater in the UK, where they haven't had to confront the certainty of facing the voters at particular and politically random moments. Instead, they have been able to play for short-term advantage and, if they succeeded, then called an election. They also haven't become lame ducks with the same frequency as their American colleagues. But as the ground has shifted under Britain's two major parties, Labour and the Conservatives, the latter were forced into a coalition with the third-party Liberal Democrats in 2010. To help cement what all three sides knew was likely to be an unstable arrangement, the new partners changed time by fixing parliamentary terms at five years. But when BREXIT had driven the seemingly triumphant Tory Prime Minister David Cameron from office just a year after the first quinquennial election, Teresa May, his successor, used the new clock's get-out provision to call a snap election anyway just another year later. That backfired, producing an even shakier coalition. 
Autocracies are indeed more prone to clock-fiddling than REDs, which are built on constitutionally agreed-upon schedules. This is most true in the least consolidated variants such as military dictatorships. ${ }^{104}$ Yet, some better institutionalized autocracies have also endeavored to consolidate their régimes by setting time limits. Because, by contrast with REDs, constitutional constraints mean less and political competitors are easier to shunt aside, these leaders have had an easier time stopping any new clocks they may have set in motion. Such a reversal is not cost-free, though, since it erodes their public credulity and, possibly, legitimacy that the new schedule was meant to shore up in the first place. $^{105}$

There is one aspect of political timing that is likely to affect all the others indeed, it deserves to be enshrined as a prerequisite for the successful domestication of conflict, whatever the type. For politics to be orderly, the agents affected must have agreed beforehand on the appropriate unit for their action. In the contemporary world, despite some notable transformations at the regional level in Europe, this unit is usually something resembling a sovereign and usually national state. This means that before they can settle into a predictable set of rules and practices, politicians have to have agreed - at least provisionally - upon a common overarching "national" identity, a distinctive territorial configuration and a state as the institution that is capable of exercising a monopoly over the exercise of legitimate violence within its boundaries. The embarrassing coda to this maxim is that there is no established way of deciding what this effective political unit should be. All modern states were produced by long-term, obscure and extremely complicated historical processes. These acts of war, revolution, marriage, empire and sheer accident somehow produced physical boundaries, cultural identities and state institutions that subsequently came to be accepted by their respective populations as appropriate. Within these essentially arbitrary confines, citizens/subjects have been coerced, coopted, manipulated or consented to be governed by politicians who have competed, cooperated and sometimes eliminated each other in order to create a régime of some type of or other. And the longer ago in clock time all that happened, the more likely that settlement is to have become thought of by all parties, inside and outside, as natural, which tends to make rule much easier and politics more stable. Much of politology, perhaps most of it, takes

104 Many a ruling general has promised an election soon after a coup, only to renege soon thereafter; quite a few have even "won" "elections" for a "fixed" term, but then canceled the repeat performance when the time was up.

105 After the 1989 nationwide protests in China threatened to toss the People's Republic onto the same scrap-heap of history as the USSR, the government announced a limit of two five-year terms for the Party Secretary and Premier to help it restore its legitimacy. After two-and-a-half cycles lasting 25 years, Party Secretary Xi Jinping undid his own term limit with the stroke of a pen. In private conversations, alarmed Chinese termed this their "Trump moment." 
this accidental historical outcome for granted as a point of departure - unless, of course, there are a sufficient number of dissidents capable of challenging it. By contrast, the more recently the boundaries have been drawn, the easier time dissidents will have challenging them. That is why territorial disputes so often involve age-old claims. ${ }^{106}$

\subsection{The Units}

As we have just argued, politics has to be practiced within a unit, usually one bounded by territory and possessing a distinctive population, although there do exist some functionally or ideationally determined political entities that operate across different territories and peoples, e.g., the Roman Catholic Church, the IMF, the International Red Cross or Amnesty International. Ever since Aristotle collected the constitutions of 158 Greek city-states (it is alleged, since only that of Athens has survived), the privileged unit in politology for both observation and analysis was supposed to have a relatively autonomous economy, a self-governing polity and a distinctive collective identity - all institutionalized and coinciding with one another in a given territory. Eventually, thanks to the evolution of European polities and their overseas empires, this unit became known as the nation-state, which combines internal sovereignty (control over its own territory and people) with external sovereignty (control over domination and predation by others).

Of course, the nation and the state often do not map (literally) onto each other. Many more states than politologists were, until recently, prepared to admit have been multi-national, formed by processes that did not involve the exclusive self-constitution of single nationalities. In many cases, several nationalities were thrown together through the highly contingent historical process of imperialism, as we discussed at the end of the previous section. In others, states were formed by the exertions of dominant national groups who subordinated others. And, of course, many nations have never had a state of their own. The all-too-common mismatch between nation and state has been a major source of political instability, and has often made it impossible to conduct even orderly politics - which we have defined as the "domestication" of conflict - leading instead to more or less continuous armed conflict.

It is usually presumed that only within functioning units (whether they are nation-states, multi-national states or sub-state units) are agents formed in the first place and become capable of making choices and implementing them

106 Israel-Palestine provides a textbook case. Setting the merits of the case aside, the very legitimacy of an Israeli state has been so prone to challenge by Palestinians living within it and by international critics precisely because it is so new. By contrast, supporters of the Jewish state have attempted to legitimate it with precisely an opposite temporal claim reaching back millennia. 
effectively; calculating their interests; developing passions and convictions; engaging in political competition and cooperation; deploying mechanisms of coercion, cooptation, manipulation and hegemony; and reckoning and constructing time. Virtually by definition, régimes (discussed next, p. 58 ff.) can only develop their stable and complementary institutions within such a framework. Nothing is more firmly rooted in the micro-foundations of politology than this assumption. Virtually, every existing proposition about politics in the discipline should be prefaced (not literally, of course) with the following phrase: "Take one (or more) existing national state(s) and, only then, will ...(X be related to $\mathrm{Y})$... in the following manner and for the following reason."

What if this unit of action and analysis can no longer monopolize attention and be taken for granted? What if that presumed coincidence among autonomy, capacity and identity has been disrupted beyond repair? In the contemporary world, no political unit can realistically connect cause and effect and produce intended results without regard for the actions of some agent or agents beyond its borders. Virtually all of them have persons and collectivities within their borders that have identities, loyalties and interests that overlap with those in other polities. Nor can one be assured that polities with the same formal political status or level of aggregation will have the same capacity for agency. Depending on their insertion into multi-layered systems of production, distribution and governance, their capacity to act or react independently to any specific opportunity or challenge can vary enormously. This is most obviously the case for those units that are subordinate parts of empires, but it is also the case for nation-states that have voluntarily entered into supra-national institutions such as the EU, or signed binding international treaties, such as those of the IMF or the World Trade Organization (WTO). Not only do they occasionally find themselves publicly blamed, shamed or even found guilty by such organizations, but also they regularly anticipate such constraints and alter their behavior accordingly. These pressures have become so severe as to have driven nation-states to disassociate themselves from such affiliations. ${ }^{107}$ If that were not enough, many national polities have been recently granted or been forced to concede extensive powers to their sub-national units. In some cases, these provinces, cantons, regions, republics, municipalities, Länder, estados autonomicos, regioni or départments have even entered into cooperative arrangements with equivalent units in neighboring national states. In extreme cases, such centripetal forces have actually overcome the polity of which they had previously been a part. ${ }^{108}$

107 Witness BREXIT and Trump's renunciation of NAFTA and the Trans-Pacific Partnership.

108 We mentioned earlier (footnote 52) Ronald Suny's argument about the collapse of the USSR. In the UK, proponents of Brexit argued for it on the grounds of the threat the EU posed to British sovereignty. Ironically, though, the greatest difficulty 
It will not be easy for students of politics to abandon the presumption of prior "stateness." Sovereignty has long been an abstract concept that many "knew" was only a convenient fiction, just as they also "knew" that almost all states had social groups within them that did not share a common national identity. One could pretend for analytical purposes that the units were independent of each other in empowering their agents, institutionalizing their cleavages, processes and mechanisms, establishing core temporalities, forming their régimes, and defending or extending their "national" interests in relation to other similar units - even when one "knew" that much of this was not true. The reason for this convenient fiction was obvious: there existed no other concrete, observable political unit that could do all this. Now that we are beginning to observe supra- and sub-national units that can accomplish some of these feats, should we not at least challenge the monopolistic grip that the "sovereign national state" has had upon the study of politics in general and the discipline of political science in particular?

Yet when all is said and done, it still seems self-evident to most analysts that this form of organizing political life will continue to dominate all others, spend most publicly generated funds, authoritatively allocate most resources, enjoy a unique source of legitimacy and furnish most people with a distinctive identity. However much we may recognize that the sovereign national state is under assault from a variety of directions beneath and beyond its borders, its considerable resilience has been repeatedly observed and reasserted. To expunge it (or even to qualify it significantly) would mean, literally, starting all over and creating a whole new language for talking about and studying politics. ${ }^{109}$

\subsection{The Régimes}

Most students of politics assume that the political unit they are analyzing has a relatively stable configuration of institutions that are complementary to each other, either as the result of a historical experience of trying alternatives and eliminating incompatible ones through competition or conflict, or of the institutions adapting to each other functionally. The actions produced by each institution's agents, motives and mechanisms are somehow - functionally, ideationally or intentionally - related to each other at a higher foundational level, such that their nature or importance cannot just be assessed alone and

in implementing it proved to be the threat that Brexit itself posed to British sovereignty - around the specific problems of the border between Ireland the Northern Ireland. And advocates of Scottish independence have used the opportunity of concessions there to stump for their own increased political autonomy leading, many Scots would like, to eventual sovereignty.

109 The assiduous reader will have noted that we have already tried to do this by frequently referring to "polity" or "unit" when the normal expression would have been "state" or "nation." We doubt if many others will follow such a dubious (and awkward) precedent. 
uniformly. They are embedded in a macro-institutionalized (in many cases, constitutionalized) whole - a régime - that coordinates and conditions what role can be played by agents, processes and mechanisms, and may even determine what the unit itself should be.

These régimes are given a label, and it is presumed that those in the same generic category will share many foundational elements. At one time, there were three such generic labels: democratic, totalitarian and autocratic (also known even more widely as authoritarian ${ }^{110}$ ). More recently, the middle one has almost completely dropped out as the result of the collapse of Soviet and Eastern European state socialism and the transformation of Chinese state socialism as well as critiques that (1) "totalitarian" unhelpfully and ideologically conflated Fascism and state socialism; and (2) in any event, the Soviet, Eastern European and Maoist-era Chinese régimes were more porous than the term implied. ${ }^{111}$ It has been replaced in those countries with "hybrids": a diminished version of democracy in the former, and a liberalized version of autocracy in the latter. ${ }^{112}$

Returning to the remaining two players of this round of "régime-type musical chairs," we have come to prefer "autocratic" to "authoritarian" - the latter still the coin of the conceptual realm as the alternative to democratic - for

110 Juan Linz developed the concept of "authoritarianism" to describe the régime in his native Spain under Francisco Franco. It did not fit neatly in the post-war dichotomy of democracy and totalitarianism. Nevertheless, it was not a mere intermediary form of domination along a continuum between the other two, but, he argued, a qualitatively distinct one. It was not, strictly speaking, simply a personalistic (or tyrannical) dictatorship. It seemed to possess some degree of both legitimacy and viability. See Juan Linz, "An Authoritarian Régime: Spain," in E. Allardt and Y. Littunen, eds., Cleavages, Ideologies and Party Systems: Contributions to Comparative Political Sociology (Helsinki: Transactions of the Westermarck Society, 1964), 291-341; and Linz's interview in Munck and Snyder, Passion, Craft and Method, 162-163. Many politologists, including Schmitter, made rich use of the concept - Blecher remembers discussing Linz's famous article in one of Schmitter's seminars, and, of course, it appeared in the title of O'Donnell and Schmitter's tetralogy Transitions from Authoritarian Rule: Tentative Conclusions about Uncertain Democracies (Baltimore, MD: Johns Hopkins University Press, 1986) and many other of Schmitter's works. Thanks to Mishella Romo for raising this with us.

111 Although it is still on display in North Korea. When Schmitter started contemplating the transition from autocracy to democracy in the state socialist régimes of Russia, Eastern Europe and Central Asia, he came up with the label "partialitarian" to emphasize that the previous "Stalinist" régimes had already begun to accord greater autonomy to institutions previously controlled closely by the Central Committees of their respective Communist Parties. No one else seems to have picked up the concept.

112 Mishella Romo reminds us that one of the first scholars to articulate and use the concept of a "hybrid régime" was Terry Karl (1995) in her analysis of Central American régimes. (Terry Lynn Karl, “The Hybrid Regimes of Central America,” Journal of Democracy VI, no 3 [July 1995]: 72-86.) The existence and, especially, the endurance of so many hybrid régimes should prompt politologists to question whether we can also study and associate them with the traditional assumption of "democracies with adjectives" (such as "real, existing" or if they have their own distinctive properties. 
two reasons. First, of course, all political régimes involve authority. Second and more important, we want to put at the front and center of the conceptualization of régimes the processes and principles - especially of accountability by which they were formed. Notice that we have also not included "who formed them" since, after all, all régimes are formed by political leaders, though some of them - even autocratic ones - have done so with significant popular participation and support. Thus, democratic régimes are those that have been formed, generally but not always ${ }^{113}$ with a significant role for citizens, by leaders who, during the moment of the régime's formation, chose or were forced by the political processes of that formation to make themselves institutionally (and constitutionally) accountable to their citizens. A régime whose leaders put themselves into power, without or even with public support (in, for example, a revolution, social movement or sometimes even a coup), but without making itself accountable to those it leads, is autocratic - literally, chosen by itself to rule. ${ }^{114}$

These régimes, then, produce governments that are presumed to be capable of governing, i.e. of applying coercion (real or potential) to affect the behavior of their citizens/subjects. Whether this coercion is "legitimate" and whether it is "effective" is the subject of much of the literature in comparative politics. 115 It recognizes that there are many different sub-types of democratic and autocratic governments and that these differences have serious consequences - both for their own citizens/subjects and for those suffering (and, sometime, benefitting) from their externalities. ${ }^{116}$

Most of this comparative literature on governments has been "institutional." It describes their formal organizational structures and, sometimes, even analyzes why they emerged and why they produce such different effects. Rarely, however, it has attempted to compare the governments of different generic types of régime. ${ }^{117}$ One of the purposes of this essay has been to overcome this separation and, to do so, we have had to literally invent a new system of classification. We propose to distinguish all governments according to two underlying

113 For example, the elite-led, "imposed" democratizations of Brazil and, especially, Taiwan, where popular forces played a particularly minimal role.

114 The key characteristic of autocracies is that they are "self-referential." The origins of this phenomenon can be quite varied, e.g., divine providence, genetic inheritance, revolutionary success, military prowess and/or national liberation (North Korea combines them all!), and this, in turn, is related to differences in their subsequent success at legitimation. Democracies are "other-referential," and it is their success (or failure) at remaining periodically accountable to their citizens that tends to determine their viability.

115 Many departments of political science in the US used to be called "Departments of Government" (and some still are), although it has long been evident that much, if not most, of politics takes place outside governments and before, during and after they get involved.

116 See Section 3.4 (page 73) for a more extensive discussion of externalities.

117 Which is why the academic study of state socialist régimes - Russian, Chinese or otherhas been almost completely separated from the more generic sub-discipline of comparative politics. 
principles: (1) whether power is exercised in conformity with pre-established rules of decision-making (pro lege) or not (ex lege); and (2) whether those rules specify a restricted period for governing (pro tempore) or not (ex tempore). Most "real-existing" democratic governments are pro lege and pro tempore and are called "liberal." Most "real-existing" autocratic ones are ex lege and ex tempore and should be called "tyrannical" or "dictatorial" or "despotic." There exists, however, a significant sub-set of democracies that are pro tempore in that they submit themselves regularly to electoral contestation that could end their tenure in power, but that rule ex lege in that they do not respect (and even may strongly contest and try to change) the existing rules of the game that brought them to power. In the contemporary jargon of politics and politology, they are called "illiberal" or "populist" or "demagogic." Among autocratic governments, there are always a few that, while almost always ex tempore in that they do not expose themselves to ruling for a pre-defined or accountable period of time (but see the Chinese exception just below); nonetheless, they do govern pro lege in that they predictably obey rules established previously by their countries' governments. ${ }^{118}$ There exists no contemporary consensus on the label for such régimes (some would argue that the very notion of a "law abiding autocracy" is an oxymoron), but we propose "institutional" or "bureaucratic" or, even, "constitutional." This distinction between democratic and autocratic régimes, on the one hand, and liberal/illiberal and tyrannical/institutional governments, on the other, should, we hope, provide politology with greater flexibility and clarity than it has previously had when dealing with the growing complexities of the rapidly changing régimes and governments of contemporary political life.

Returning to democracy and autocracy, the analyst of a specific case or cases must break down each of these into sub-types. Democracy typically has been subdivided into unitary vs. federal, presidential vs. parliamentary, twoparty $v s$. multiple-party (and even single-party), pluralist vs. corporatist, majoritarian vs. consociational, e cosi via - along with an almost infinite number of combinations and permutations of them. Autocracy has attracted even more

118 The autocratic régime of the Kaiser in Germany after the creation of the Second Reich in the early 1870s prided itself on being a Rechtsstaat - a law-abiding state or régime - and was widely recognized as such. The autocratic régime of the USSR operated with successive, ex tempore "governments" that maintained the previous pro lege institutional arrangements while developing not just different leaderships but also significantly changing priorities and strategies - think Stalin, Khrushchev, Brezhnev and Gorbachev. Starting in 1992, China converted itself into a pro tempore autocracy by declaring term limits for its "governments," each of which, like the USSR, had not just different leaderships but also developmental priorities and styles of rule. This was regarded, both in China and outside it, as a positive development. Xi Jinping, who headed the third such "government," caused a major political shock when he reverted to ex tempore rule in 2017. Throughout, however, the basic pro lege constitutional and institutional arrangements remained in place. 
dichotomies, e.g., civil vs. military, personalistic vs. bureaucratic, jefe vs. junta, Leninist vs. "non-Leninist," single-party vs. no-party, legalistic vs. arbitrary, domestic vs. foreign, repressive vs. homicidal e cosi via. Which of these subtypes is useful will depend on the specific units and time periods the analyst has chosen to investigate.

For example, Guillermo O'Donnell and Schmitter, in their work on transitions to democracy, found it useful to divide the hybrid category in two: dictablandas, in which elections are regularly held (but in which the incumbents are foregone winners), various civic rights - of association, assembly, petition and media freedom - are formally tolerated (but informally restricted), and arbitrary harassment and arrest of opponents has declined (although they can still be applied, if needed); and democraduras, in which elections are regularly held and fairly tallied (but under conditions that favor the governing party), various civic rights are protected legally (but erratically enforced), and the harassment and imprisonment of opponents has become rare (but remains a plausible threat). ${ }^{119}$

Likewise, Blecher's work ${ }^{120}$ has stressed what amount to régime-level differences between the USSR and China. Both were ruled by post-revolutionary Leninist parties that comprised intensely vetted and trained "vanguards," filled all political space and operated according to strict internal discipline, all characteristics that grew out of their experience of leading armed class struggle. Yet, Mao Zedong radically transformed the Chinese version by unleashing a heady dose of critical "mass supervision" of the Party by the workers, farmers and even the revolutionary-minded offspring of the former exploiting classes. This contributed to very different factory-floor politics, to the "Hundred Flowers" campaign of 1956, the purge that followed it, and, most dramatically, uniquely and consequentially, the Cultural Revolution, all of which eventually proved essential in stimulating the equally radical structural reforms that followed after 1978. These profound differences between the sub-types of Leninist autocracy in the two countries directly set up a régime collapse in the first case and

119 Guillermo O'Donnell and Philippe Schmitter, Transitions from Authoritarian Rule, new edition (Baltimore, MD: Johns Hopkins University Press, 2013). While democracy and autocracy typically occupy the opposing ends of the continuum of régime types, there exist plenty of other concepts which attach substantive content to specific cases: plutocracy (rule by the rich), oligarchy (rule by a closed elite), monocracy (rule by a single person), mobocracy (rule by a mobilized mass), aristocracy (rule by the most prestigious), meritocracy (rule by the best), theocracy (rule by clerics), monarchy (rule by inherited family origin), partitocracy (rule by a sclerotic system of parties), kleptocracy (rule by thieves), mediacracy (rule by or via the media), anarchy (rule by no one), timocracy (rule by property owners), technocracy (rule by experts) and, of course, the one proposed by Robert Dahl as a substitute for democracy: polyarchy (rule by multiple overlapping minorities).

120 Marc Blecher, China against the Tides: Restructuring through Revolution, Radicalism and Reform (New York: Continuum, 2010). 
another régime shift in the second one (between radical state socialism and, equally radical, state socialist "structural reform"). ${ }^{121}$

The implications of this intrusion of "régimes" into the micro-foundations of the discipline are considerable - and still debatable. For one thing, the recognition of such categorical diversity means giving up the "Holy Grail" of politologists, namely, the quest for universalistic, immutable "covering laws" that can be applied to all agents, motives or mechanisms. Individuals or organizations do not behave the same way in democracies and autocracies; the "reasonableness" and "appropriateness" of interests or passions depend on the institutions to which they are addressed; mechanisms such as competitive elections or cooperative multi-party alliances can take on different meanings depending on their complementary relationship with other mechanisms of competition/conflict or cooperation/collusion. ${ }^{122}$ This may be reflected in the quite noticeable decline in references to "national" or "regional" peculiarities in explaining political behavior. Adjectives such as "Asian," "Latin American," "African," "Bolivian" or "Albanian" placed in front of nouns such as democracy or political culture now tend to have a descriptive rather than analytic importance. What count are generic institutional configurations wherever they are located, rather than geo-cultural specificities.

Returning from regional and political sub-types to the big generic categories, democracy has always played a prominent role in the modern study of politics, if only because data about these régimes have been more accessible and academic inquiry - even critical inquiry - about them has been more protected and even encouraged. Indeed, in some countries, teaching and research about politics are confined almost exclusively to inquiry into the rules and

121 The commonplace term for the vast changes that have taken place in China since 1978 is "reform." It is appropriate insofar as it refers to aspects of the process by which these transformations have occurred. Change has been pursued gradually and mostly peacefully. But "reform" can hardly capture the depth and breadth of the substance of the changes. Since 1978, China has not merely been tinkering with, perfecting or toning down Maoist state socialism. Something far more thoroughgoing is afoot. The country has been seeking, often successfully, to excise, root and branch, the basic elements of its Maoist polity, economy, society and political culture. It has questioned almost everything that went before. Its leaders and people have sought to create new forms of political authority, economic activity, social organization and cultural expression that have no precedent in China or indeed the world. If revolution is defined as a "basic transformation of a society's state and class structures" (Theda Skocpol, States and Social Revolutions (Cambridge: Cambridge University Press, 1979): 4), then, what China has been undergoing is no mere "reform," but rather something that would more aptly be called a "peaceful revolution." Another, perhaps less oxymoronic term to capture China's gradual and peaceful process toward "basic transformation of the state and class structures" would be "structural reform."

122 For example, coalition politics in the UK, which has returned to center stage since the 2010 election, has proven much more problematic and dysfunctional even than in its cousins on the Continent. 
practices of democracy. There are normative or aspirational reasons as well, since democracy often has more popular and ideological appeal than autocracy, even, or perhaps especially in, autocracies (though the crisis of RED may be eroding that).

More accurately said, the analysis of democracy has been confined to the institutions and practices of REDs. For what its scholars observe and analyze is not, strictly speaking, dēmokratía, i.e., "rule of or by the people," but politokratía, i.e., rule by politicians who claim to represent the people because they have been elected by a part of the people. ${ }^{123}$ All REDs are based primarily on the "vicarious" participation of their citizens in decision-making (although sometimes they include elements of direct participation such as referendums, initiatives, plebiscites, demonstrations, riots and so forth). They are also the product of some sequence of historic compromises with or opposition to other, pre-existing political institutions, e.g., monarchy, autocracy, theocracy, aristocracy, charismatic rule, oligarchy and tyranny, and with other principles of authoritative distribution, e.g., divine right, inherited privilege, slavery, feudalism, liberalism, socialism, communism and, above all, capitalism. The first thing to keep in mind when studying "real-existing democracy" is that it is always incomplete and defective when judged by the standards of "ideal-not-yet-existing democracy." Indeed, it is this persistent (but periodically widening or narrowing) gap between actual practices and ideal principles that explains in part why REDs are under almost constant pressure to reform themselves. Put differently, REDs are (and should be) "moving targets." Like all social institutions, they are subject to entropy, i.e., a tendency to decline in efficacy, but - "mind the gap."

Autocracy, by contrast, has been far more common since time immemorial, starting with ancient imperia, some of which lasted for millennia outside Europe, where they were challenged by theocracies, feudal monarchies and, eventually (but unevenly), democracy (and then state socialist autocracy). Just as autocracy has stimulated democracy, REDs have often produced or fostered autocracy, both at home but also through imperialism and clientelist "régime change" abroad. Many parts of the world have only ever experienced autocracy, and many more have only begun to move away from it in recent decades. The frequent argument of political scientists and politicians in REDs that modernization and, especially, capitalism are the great democratic drivers has now come under assault not just from politologists, but also from resurgent autocracies. This has occurred not only in economically dynamic China, where, as

123 An even more bizarre development in contemporary REDs has been the emergence (and public acceptance) of self-selected celebrities who claim to represent some deprived and underrepresented social or cultural category (or even an entire continent!). 
noted earlier, ${ }^{124}$ scholars and observers have begun speaking of "authoritarian resilience." Wolfgang Streeck has argued that even Western capitalism has generally preferred autocracy over democracy, and still does. ${ }^{125}$

Autocracy may also be a more politically variegated category than democracy. Institutionally, it can vary from simple, tyrannical, often kleptocratic dictatorships to sophisticated régimes with complex, layered jurisdictions and functionally differentiated bureaucratic institutions that produce high levels of state capacity in political, economic, social and cultural terms. The former have tended to produce stagnation, and the latter extraordinary dynamism, first in the Stalinist USSR and then in post-World War II East Asia. ${ }^{126}$ Stunningly high levels of economic growth there have, in some countries, provided "objective" conditions favorable for democratization, but not via the demands of rising middle classes, as theorists of the post-war decades predicted so much as by "liberalizing" autocrats themselves. In Japan, the victorious US imposed a democradura, a one-party democratic régime. In Taiwan, it was autocrats who played the key roles in abolishing autocracy from above in the late 1980s. ${ }^{127}$ Likewise, the democratic transitions in Central and Eastern Europe, Latin America and Africa around roughly the same time had less to do with the

124 Supra, pages $50-51$.

125 "Capitalism and democracy had long been considered adversaries, until the postwar settlement seemed to have accomplished their reconciliation. Well into the twentieth century, owners of capital had been afraid of democratic majorities abolishing private property, while workers and their organizations expected capitalists to finance a return to authoritarian rule in defence of their privileges. Only in the Cold War world did capitalism and democracy seem to become aligned with one another, as economic progress made it possible for working class majorities to accept a free market, private property régime, in turn making it appear that democratic freedom was inseparable from, and indeed depended on, the freedom of markets and profit-making. Today, however, doubts about the compatibility of a capitalist economy with a democratic polity have powerfully returned. Among ordinary people, there is now a pervasive sense that politics can no longer make a difference in their lives, as reflected in common perceptions of deadlock, incompetence and corruption among what seems an increasingly self-contained and self-serving political class, united in their claim that 'there is no alternative' to them and their policies. One result is declining electoral turnout combined with high voter volatility, producing ever greater electoral fragmentation, due to the rise of 'populist' protest parties, and pervasive government instability." Wolfgang Streeck, "How Will Capitalism End?" New Left Review 87 (May-June 2014): 40-41.

126 And not just in China under post-Maoist structural reform. Even in the Maoist period, China produced very strong economic growth, which would have been even more striking and widely recognized had it not been for its contemporaneous penchant for political radicalism. Likewise, North Korea's economic growth matched and sometimes exceeded that of the South in its early decades. Finally, post-war Vietnam has become something of a developmental "tiger" in its own right.

127 Stephan Haggard and Robert R. Kaufman, The Political Economy of Democratic Transitions (Princeton, NJ: Princeton University Press, 1995). 
happy pathway of social and economic "modernization" than with specific, contingent crises of a wide range of military and civilian autocracies. ${ }^{128}$

So what? Why does all this matter? What does all this Sturm und Drang, this sound and fury, produce, and does politics' impact amount to much more than Hamlet's feared "nothing"?

128 Guillermo O’Donnell and Philippe C. Schmitter, Transitions from Authoritarian Rule (Baltimore, MD: Johns Hopkins University Press, 1986). 


\title{
3
}

\section{THE CONSEQUENCES}

\begin{abstract}
Politics has consequences - many, diverse, often unexpected, but almost always serious. It is "the Master Science," since virtually all other aspects of collective human existence depend on what it produces, which affects almost everyone. "Who gets What, When, How and Why?" is an encapsulated version of this observation. The major consequences of politics have to do with order, material goods, recognition and respect, effects on other political systems, and legitimacy.
\end{abstract}

Politics has consequences - many, diverse, often unexpected, but almost always serious. Presumably, this is why Aristotle baptized the study of it as "the Master Science," since virtually all other aspects of collective human existence depend on what it produces. "Who gets What, When, How and Why?" is an encapsulated version of this observation, since the answer is that "almost everyone" is affected in some way or another by this process of authoritatively allocating scarce values. ${ }^{1}$

1 The slogan (minus the "why") is to be credited to Harold Lasswell. More accurately, politology could be called the science of explaining not only the present, but also "who got what, when, how and why?" in the past and (more rarely) "who will get, what, when, how and why?" in the future. The phrase, "the authoritative allocation of scarce values," is David Easton's well-known definition of what politics is all about. See Harold Lasswell, Politics: Who Gets What, When, How (New York: McGraw Hill, 1936); and David Easton A Framework for Political Analysis, op. cit., 50. 


\subsection{Order}

This (or its absence) is certainly the most important product of politics. ${ }^{2}$ Its presence is not to be confused with stability or the mere persistence of the same persons in power or policies in effect. Order is produced by adapting to change, and we have argued infra that change is endemic to politics. This process of orderly adaption involves the domestication of power so that it does not degenerate into violence and remains within predictable limits of coercion, but responds to the continuous change in the resources that agents have at their disposal, as well as the intrinsic tendency they have for being "restless" and, therefore, for being curious, experimental and/or dissatisfied with their environment.

Order can be imposed involuntarily by the superior coercive force of a concentrated group of agents, or it can be generated voluntarily through the formation of consent among a broad range of them. This, more or less, corresponds to different régime types and subtypes. One of the abiding strengths of the category of democratic régimes is the greater availability of information about the resources and restlessness of agents and the capacity to respond by peacefully rotating those in authority and responding incrementally to changes in citizen demands. By contrast, as we discussed earlier, ${ }^{3}$ it is much more difficult for rulers in autocracies to capture reliable information about their subjects (or the latters' views of their rulers), to respond by "changing policies without changing politics," and to manage orderly succession in power. ${ }^{4}$ Still, there is a range of variation here among autocratic sub-types: the Chinese case shows us how one with deeper and more extensive social penetration, more resources to survey and surveil the population, greater tolerance for and capacity and sophistication in dealing with quotidian protest (so long as it does not turn into a protest wave) and deeper anxiety about its legitimacy may in fact stand as good a chance as some democracies of keeping in touch with the public pulse and maintaining order.

The by now classic device for ensuring the continuous production of order is to constitutionalize the rules for the domestication of power (and, presumably, to impose its formal provisions upon the informal practices that inevitably

2 As Hobbes argued in Leviathan, any actions that contribute to it are preferable to those that destroy it - up to and including devolving absolute authority upon a single person. Consider the options open to the inhabitants of a "failed state" (or even of a "failed régime") in which life has become "nasty, brutish and short," just as Hobbes predicted. For them, any order - no matter how produced - is likely to be more appealing than the existing disorder. Of course, as we discuss just below, revolutionaries tend to take a different view.

3 Page 50.

4 Mario Vargas Llosa described Mexico as "the perfect dictatorship" because, unlike other autocratic régimes, it managed to institutionalize rotation in power within the ruling party consensually for more than 40 years. (He had the temerity to say this in a live interview on Televisa, a dominant Mexican broadcaster that dubbed itself "a soldier of the PRI." "Laughing at Power," The Economist, October 22, 2014 (https://www.economist. com/prospero/2014/10/22/laughing-at-power; accessed November 29, 2018). 
arise from resolving political conflicts). With very few exceptions, these days all régimes - whether democratic or autocratic - have such a document whether "plebiscited" from below or promulgated from above. In five cases, ${ }^{5}$ constitutions are not written as discrete documents, but enshrined instead in various pieces of legislation, regulation and legal opinion. This does not mean that all constitutions are respected and obeyed. ${ }^{6}$ And all of them have their "abeyances" - aspects of power relations that cannot be formally codified. ${ }^{7}$

Finally, not all leaders, even those in power, value order. Some, from a wide range of political ideologies, goals and régimes, with outsized ambitions and high levels of either anxiety or, oddly, confidence in the prospects of holding onto their power, may purposely stir the pot in a deliberately disorderly fashion. ${ }^{8}$ And it goes without saying that violent revolutionaries are apolitical in the strict sense we have defined it, since they eschew order as the enemy of desired transformation. They are, however, eminently political in two other senses: they seek to transform the overall institutions, rules and norms by which power is held and exercised; and, deploying a dynamic, forward-looking temporality, they argue that what passes for order in the present in fact involves systemic violence, which will be ended once the new order is established.

5 Canada, Israel, New Zealand, Saudi Arabia and the United Kingdom.

6 From his earlier experience as a Latin Americanist, Schmitter remembers a boutade about someone asking a Venezuelan if he knew the constitution of his country; the respondent quipped: "No. I do not keep up with the periodical literature." Venezuela may be the world's constitutional champion. It has had 26 of them - the latest dating from 1999 which, as of this writing in 2020, was being vociferously contested by the political opposition. And, of course, every American high school student, at least in the kind of schools we attended in the previous century, was taught (incorrectly) that the Soviet and Chinese constitutions were not worth the paper on which they were printed.

7 Two notable examples of such abeyances are civil-military relations and bargaining between capital and labor. With the exception of the 1982 Chinese constitution's provisions on some less crucial aspects of civil-military relations, we do not know of any that accurately specifies either of them. Many core political interactions are also left to secondary legislation and usually made easier to modify. For example, very few constitutions contain provisions for electoral competition or recognition of political parties.

8 Mao Zedong is probably the poster child of "pot-stirring" with his incessant calls for "uninterrupted revolution," the most audacious of which was the Cultural Revolution, which nearly produced a civil war. See page 24 , footnote 37 . In this, he had company of Thomas Jefferson, of all people.

What country before ever existed a century \& half [sic.] without a rebellion? \& what country can preserve it's [sic] liberties if their rulers are not warned from time to time that their people preserve the spirit of resistance? Let them take arms. The remedy is to set them right as to facts, pardon \& pacify them. What signify a few lives lost in a century or two? The tree of liberty must be refreshed from time to time with the blood of patriots \& tyrants. It is its natural manure.

"Letter from Thomas Jefferson to William Stephens Smith," Fact/Myth, April 26, 2017 (http://factmyth.com/factoids/thomas-jefferson-called-for-rebellion-and-revolution/, accessed November 29, 2018). 


\subsection{Production and Distribution 9}

Politics alters the production of agents' desired goods (and unwanted bads), and it changes their distribution in ways that would not be experienced if they were affected only by social custom, religious conviction, class interest or market forces. Whether something is produced and how much of it is produced is affected by the decisions of public authorities. To some degree, they license the producers and regulate their products. Someone always wins or loses, more or less, when powerful agents intervene to convert private goods into public ones. The critical issue in terms of its relation to order is whether this process of regulated (re) production or conscious (re)distribution is acceptable to those affected. On this issue, the criteria seem to vary considerably according to the type of régime, but they could also be culturally or ideologically sensitive regardless of régime type. Abstention from subsidization and regulation is the mantra of economic liberalism, although even the most convinced of neo-liberals would probably admit that political intervention is required for private property to exist and markets to operate at all. Equality of benefits (or in the distribution of costs), or at least the opportunity for the same, is the mantra in democratic theory, although citizens seem to accommodate in practice to various (even more recently, very high) levels of social and economic inequalities - provided, perhaps, that the order produced by the régime is conducive to overall growth in the availability of scarce goods and a noticeable diminution in the existence of avoidable bads. ${ }^{10}$

In autocracies, the mere avoidance of violence (especially coming from external sources) may be enough for subjects to tolerate higher levels of repression, distortions in production and inequalities of distribution. ${ }^{11}$ Their leaders are also likely to argue (and be believed by their subjects) that only their presence ensures a reliable rate of growth in the total quantity of goods to be distributed

9 To be more precise, this section should be entitled: "Production and Reproduction, and Distribution and Redistribution." Politics can affect not only whether goods and services will be produced (and how much), but also whether the human species will reproduce itself (and, if so, how often). It can also choose to distribute these goods and services within the same social, cultural or economic group or redistribute them from one group to another.

10 One could say that, realistically, given the compromises that democratic equality has to make with capitalist inequality, most citizens in REDs settle for some version of equity in which the differences in benefits are justifiable according to acceptable criteria.

11 After Polish General Wojciech Jaruzelski crushed the popular movement Solidarność, killing dozens and arresting its charismatic leader Lech Wałęsa in 1981, some liberal Poles nonetheless eventually found it in themselves to feel grateful that his coup had staved off a Soviet invasion. Domestically, in China, one frequently hears from good friends, even when they are sober, that whatever problems have been generated by the structural economic reforms, they are grateful that they do not have to endure any more Maoist-era upheavals. 
(and bads to be avoided). ${ }^{12}$ A similar rationale seems to be effective in justifying the role of technocrats and experts.

\subsection{Recognition and Respect ${ }^{13}$}

Politics unavoidably involves recognizing the existence of differences and assigning a status to them. The most salient one - at least since the nation-state has asserted its hegemony - has been (and still is) membership in the political unit itself, i.e., (often) nationality and, with or without it, always citizenship or subjecthood. ${ }^{14}$ The privileges and obligations that accompany this status have varied a great deal over time and across régime types, but everywhere a distinction is made between those who are recognized as "inside" the polity and those who are "outside" it. Moreover, whether this involves citizenship or subjecthood, until recently, it has usually been presumed that belonging to a given unit is primary - and that all other recognitions are secondary and dependent upon it. ${ }^{15}$

12 In 1997, Blecher interviewed a veteran Chinese factory worker who had been laid off after decades of service when her factory was put into bankruptcy by the ministry overseeing it. Yet, she averred that many of her friends were still working simply because they were fortunate enough to be employed in more profitable plants. When he pressed her on whether she found this sort of "lottery" outcome unfair, her responses were, first, that the government couldn't possibly take care of so many unemployed workers, and, second, that she was happy to be living in a city that was booming in many ways even though she was too old to find employment that would allow her to take advantage of it. Moving from anecdote to aggregate data, there is convincing evidence that inequality is not a salient issue in China. See Martin King Whyte, The Myth of the Social Volcano: Perceptions of Inequality and Distributive Justice in China (Stanford, CA: Stanford University Press, 2010). This is so even among expropriated farmers and hyper-exploited workers denied their benefits and even pay, who tend to focus on their own just desserts rather than the resulting inequality.

13 Again, to be more conceptually precise and complete (and perhaps, dare we say it, even dialectical), the rubrique should be "Recognition and Disregard" and "Respect and Disrespect."

14 That is, states are often, but certainly not always, founded on the basis of shared nationality. Even when they are not, they often try to create a new nationality out of everyone in the polity.

15 In the contemporary context, an intermediate category has emerged between natives and foreigners: "denizens" or those who live legally within a given political unit but to whom the rights and obligations attached to its normal members do not obtain. Only recently, politologists have recognized this category and, in some cases, accorded it some distinctive status with policy implications. See, for example, Meghan Benton, "The Problem of Denizenship: A Non-Domination Framework," Critical Review of International Social and Political Philosophy 17, no. 1 (January 2014): 46-69. This question can also arise within a (nation-)state. In Chinese cities, there is a huge phalanx of rural migrants who, as officially designated "rural householders," are not qualified to receive the same benefits as their neighbors who are designated as urban householders. This cleavage has become a major phenomenon - there are many more rural migrants than urban 
Having made this distinction, politics goes on to recognize a large number and variety of other identities - and to assign to them distinctive statuses and treatments. Supporters and opponents are the most prominent, and can be augmented to distinguish between loyalists and subversives. ${ }^{16}$ Membership in political parties, interest associations and social movements contributes to the creation of a wide variety of secondary identities - whether voluntarily in democratic civil societies or obligatorily in regimented autocracies. ${ }^{17}$ All régimes recognize the distinction between rulers and ruled, although how one acquires the more exalted status and what he or she can do with it varies a great deal from one type to another.

Just as politics inevitably involves the distribution of goods and bads, so it also involves struggles for the recognition of those who participate in it. The rules that assign memberships and identities are not fixed and are subject to contestation - just as are the rules for allocating costs and benefits. This corresponds to the earlier observation that order often depends upon indigenous change in response to exogenous challenges. Part of that adjustment process means not just recognizing the existence of diverse categories of agents but also modifying the rules that assign differences in status (rights and obligations) to them. To the extent that these assignments are regarded as fair to and respectful of those affected, they contribute positively to the overall objective of domesticating power. In the midst of rapid cultural, economic, political and social changes, changing such rules is a high-stakes game for politicians, since it creates all manner of new winners and losers. ${ }^{18}$

proletarians - with, therefore, huge consequences for the country's economic growth and political stability.

16 The insider/outsider cleavage starts young, at least at the sub-sub-sub national level. Blecher's four-year-old granddaughter, who until two months earlier had been a fan of a popular cartoon character called "Daniel Tiger," announced proudly one fine day that she had now joined "The Anti-Daniel Tiger Club."

17 In China, the state is pioneering the use of big data to create an entirely new socioeconomic hierarchy of "social credit." Everyone's expenditures via digital payment systems are compiled into scores that are used to rank people in terms of their suitability for purchasing or renting housing in certain neighborhoods, for certain kinds of employment and credit, and for admission for their children to certain schools, to name just a few. We can certainly expect Western states to eventually follow suit - although private "rating agencies" have been doing much the same there for some time.

18 China has probably gone further than any country in politically engineered transmutations of social respect and status, from the radical and tumultuous class politics of the Maoist period to the reordering of rural and urban and the better and less well educated under the structural reforms. In the 1960s, many of the best and brightest high school students preferred placements in factory jobs to an extremely scarce university admission, because being an intellectual risked political "trouble" (mafan [麻烦]). By the 1980s, many poorly educated workers and government officials were cast aside, leaving them disillusioned and prone to protest. 
Other difficult challenges lie this way, for both leaders and citizens/subjects. One involves the problem of inter-subjectivity, as no one can ever see others as they see themselves. Another is that respect is amorphous and potentially bottomless: there is no way to have confidence that one has given or received enough or the right kind. Yet, another is that even if respect can be conceived, received and perceived, the persons or groups receiving it may doubt the motives of those giving it. Of course, the more diverse the population, the more complex the politics of respect has become. Ambitious demagogues continue to be very well practiced at exploiting them, often undermining any possibility for politics itself and, thereby, producing disastrous conflicts and human suffering. ${ }^{19}$

\subsection{Externalities}

No political unit, least of all contemporary nation-states embedded in increasingly complex networks of interdependence with units beyond their borders and beyond their control, can ensure order within its borders without dealing with the consequences of its impact upon these other polities. The fancy word for these effects is "externalities." They can be positive in the case of the unilateral exploitation of less potent outsiders ${ }^{20}$ they can be negative when the outsiders demand compensation - and are powerful enough to ensure that it will be forthcoming. Historically, in the study of politics, this was a subject that was assigned to specialists in international relations and, therefore, presumed to be condemned to Type Two politics. There could be no orderly solution to such conflicts since, by definition, this was a realm of political activity that was "anarchic," i.e., without orderly rules or practices and beyond the capability of creating them, given the (presumed) sovereignty of the agents involved. Only something called a "balance of power" among such independent units could (temporarily) produce order in what came to be called "frozen conflicts."

One distinctive and original characteristic of contemporary politics has been the attempt to "domesticate" the impact of externalities by creating formal, institutional "international régimes" - usually dominated by technical experts that register their effects and generate rules that allocate the costs involved among those affected, positively or negatively, on some pre-established, mutually acceptable ("fair") basis. By far, the most elaborate of these régimes has emerged at the regional level in Western (and subsequently Eastern) Europe.

19 Examples here could include everything from the internecine ethnic cleansings in the former Yugoslavia or Rwanda and Burundi, to the racial and regional cleavages that have rent American politics since the end of the last century, to the "culture wars" stoked by radical identity politics over the same period. It is no accident that political theory has developed a rich literature on recognition and respect during this time.

20 Sometimes referred to as "imperialism." 
It is now called the European Union and, while it is presently in a serious crisis, it has made and still is making an important contribution to the overriding objective of order - in large part, by internalizing what would have been disruptive and dangerous externalities between its member states. Literally hundreds of other regional organizations have emerged all over the globe, but only the EU has managed to acquire a degree of "supra-national" authority that allows it to deal with these externalities in an orderly and consensual fashion. There is also a myriad of so-called "functional" international organizations and agreements many attached as specialized agencies to the United Nations - that are trying to extend Type One politics into arenas previously characterized by Type Two politics and, hence, previously regarded as intrinsically ungovernable. Needless to say, these efforts are unevenly distributed - geographically and functionally but they have contributed to reducing the resort to violence or coercion to resolve cross-border conflicts.

\subsection{Legitimacy}

If the (implicit) theory underwriting this segment of the essay is correct, order occupies the top line among the consequences of politics and legitimacy forms its bottom line. In between, production/distribution, recognition/respect and internalities/externalities connect the two. There will only be legitimacy if there is order and how much of it and what kind of it will depend on the intervening consequences.

Power and legitimacy are among the most frequently used and essentially contested concepts in politology. ${ }^{21}$ They are also very difficult to measure quantitatively or even to observe qualitatively because they share a peculiar characteristic: when they are most present, they are least evident. An agent with absolute power does not have to act in order to produce compliant behavior; an agent who is absolutely legitimate can invoke conformity without doing anything and without meeting resistance from others. How do you explain something that is not happening - a dog that is not barking? The only available instrument that we can think of depends on the plausibility of exploring a counterfactual, namely, what would the compliant-conformist agent have done if the powerful-legitimate agent had not been there? Even the most gifted of politologists will find it difficult to make such an assessment credible.

First, let us define this elusive concept. Legitimacy is a shared expectation among agents in a relation of power such that the actions of those who rule are accepted voluntarily by those who are ruled because the latter are convinced

21 This may explain why they are so often invoked. The ambiguities in meaning coupled, as we shall see, with intrinsic difficulties in measurement can be very useful. The researcher can explain almost any outcome ex post by relying upon either of them since no one can be sure that this might not have been the case. 
that the actions of the former conform to pre-established and mutually acceptable norms. This implies:

1 That the bases upon which these norms are pre-established and become acceptable can vary from one arrangement, site or time to another - not only from one country or culture to another, but also within a single country/ culture according to function or place.

2 That these bases can come in a wide variety of flavors - historical, political, material, economic, social, cultural, legal, linguistic - that can combine in a rich panoply of concatenations.

3 That the units within which relations of sub- and super-ordination are being voluntarily practiced can also vary in both time and space. While there is a tendency in the politological literature on legitimacy to accept passively the sovereign national state as the "natural" and "exclusive" site for it, there is no reason why other (sub- or supra-national) "polities" cannot have their own normative basis of legitimate authority. ${ }^{22}$

4 That the norms must be accepted and "shared" by the agents, both those who rule and those who are ruled. This implies, first of all, that they must know who they are and what their respective roles should be. It also implies that the exercise of authority is "systemic," i.e., it is embedded in a collectivity that is sufficiently interdependent and mutually trustful so that disputes over the validity or application of rules can be (and usually are) resolved by the intervention of trusted third parties within them.

5 That the agents involved may be individuals or collectivities of various sorts. Most of the literature conveniently makes the liberal assumption that the unique judges of legitimacy are individual human beings. This allows it to rely heavily on notions of family socialization, "moral sentiment" and a personal ethic of responsibility as the source of norms and the virtually unconscious mechanism for their enforcement. And this, in turn, tends to lead one to the conclusion that it is only in polities that have acquired a high degree of cultural homogeneity - e.g., nation-states - that legitimate political authority is possible. When one introduces (as we have done infra) the heterodox idea that most of the exchanges in modern politics are between organizations, and that these organizations tend to rely upon and reproduce norms of prudence, legal propriety and "best practice" that transcend individual preferences and even national borders, it then becomes possible to speak of legitimacy as "systemic" and not just "personal," and as "strategic" and not just "cultural." Organizations, including historically quite staid ones, do not always display this naturally "conservative" tendency. When they radicalize, they discard the norms and practices underlying the

22 Catalan and Scottish readers will have no trouble understanding the point. 
legitimacy in which they previously operated, and often are quite explicit about their project of "de-legitimation."

6 That the basis for voluntary conformity is presumably normative, not instrumental. In a legitimate polity, agents agree to obey decisions that they have not supported made by rulers for whom they have not voted or otherwise endorsed. They also agree to do so even if it is not in their (selfassessed) interest to do so - and they should continue to do so even when the effectiveness of the polity is in manifest decline.

Having defined this ambiguous concept, let us now turn to the more difficult question of what produces it. ${ }^{23}$ Earlier, we have argued that order, in the first place, and then production/reproduction, recognition/respect and internalities/ externalities all contribute something to its existence. The more acceptable a given institution, régime or person is to its population with reference to these consequences, the more legitimate it or they are likely to be. But these are correlations, not causes. Legitimacy is the product of strategic choice, not of unconscious habit or inculcated obedience. ${ }^{24}$

23 A caveat, first. As observed some time ago by Max Weber, there are many potential normative grounds for deciding that a given person, organization, policy or unit is legitimate. Here, we are presuming that the relevant grounds are something analogous to what he called "legal-formal" - not traditional or charismatic. A political régime, therefore, would be legitimate if it obeyed prescribed rules that were regarded as legitimate. It would be democratically legitimate if these rules were previously drafted and approved after discussion and endorsement by the general public or among elected representatives of it. Agreement on these rules would be more likely to be forthcoming and more likely to retain their legitimacy if the subsequent consequences produced by that régime were broadly favorable. This combination has been baptized as "input legitimacy" and "output legitimacy" by Fritz Scharpf in the debate over the legitimacy of the European Union. Fritz W. Scharpf, "Problem-Solving Effectiveness and Democratic Accountability in the EU," Max Planck Institute for the Study of Societies Working Paper 03/1 (February 2003). In China, the post-Mao leadership faced an unmistakable if necessarily vague legitimacy crisis in the wake of the Cultural Revolution. Deng Xiaoping staked the farm on a strategy of "output legitimation," promising economic growth and quotidian calm in return for a re-founded popular legitimacy. As the economy responded so vigorously, this source of legitimacy kicked in, sustaining the régime even in the wake of the dangerous and potentially de-legitimating and, indeed, life-threatening 1989 political crisis.

24 Most of the existing literature on this topic would disagree with this assertion. It tends to treat legitimacy as the product of something called "political culture." Presumably, this consists of a set of norms and expectations that individuals learn ("are socialized into") at an early age and, therefore, are predisposed to rely upon instinctively and without calculation when they have to act politically. Such a view leaves little space for change or for understanding it. The examples we have set forth in the previous two footnotes illustrate our argument. In all of them, "political culture" was transformed by specific political choices of ambitious, effective leaders who eventually found ready and willing subjects. 
Three generic mechanisms seem to be involved. First, the agents (or, more specifically the most powerful ones) have to have demonstrated their willingness to "under-utilize" the resources at their disposal that could be deployed simply to coerce subordinates to comply, an action which convinces the latter that the commitment of the powerful to obey the rules is not just opportunistic. REDs have a structural advantage over autocracies here: since they are generally hemmed in by liberal rights guaranteed to their citizens, their rulers are less capable of exercising broad-scale coercion, or even the threat of it, as a ubiquitous mechanism of domination. Still, they often engage in it in a targeted way against citizens they view as obstacles to their rule. ${ }^{25}$ And, consistent with our point here, when they do, they tend to lose their legitimacy among those people. $^{26}$ While autocracies face fewer, if any, such structural obstacles from liberal guarantees, many do nonetheless "underutilize" their capacity for coercion, either because they too seek legitimacy, because the collateral political or economic costs would be too high, ${ }^{27}$ or because the direct costs of organizing it on an on-going basis are also too high. They can reduce the cost by selective and prominent displays that create credible threats - known in China as "killing the chicken to scare the monkey."

Second, these leading agents can employ a range of tactics in their strategic campaign to cultivate their followers' sense of the leaders' legitimacy. Where nation or religion is closely mapped within the same unit, they may be able to make nationalistic or religious appeals; and where it is not, they can appeal to their institutional and political commitment to multi-nationalism ${ }^{28}$ or secularism. ${ }^{29}$ Convictions, religious or tribal, and ideologies, communism or liberalism, can also be brought into play. ${ }^{30}$ As we have seen, so can order itself (after a long period of disorder) and prosperity (after a long period of deprivation). Legitimators can ground any of these claims in offensive or de-

25 Schmitter remembers seeing the following maxim on a wall in Rio de Janeiro: "Para os amigos, tudo; para os indiferentes, nada; para os enemigos, a lei." (For one's friends, everything; for the indifferent, nothing; for one's enemies, the law.) Admittedly, at that moment, Brazil was a military autocracy, but it is not difficult to imagine that the maxim might also apply to those interludes when the country is a "real-existing" democracy.

26 Among many others, prominent examples are African-Americans targeted by a wave of police violence, and workers involved in lengthy and politicized strikes who suffer armed crackdowns, such as British miners in 1984-1985. Their governments have suffered significant and long-lasting de-legitimation among these groups and their supporters.

27 Witness China's restraint in the face of the sustained, broad-gauged protests in Hong Kong in 2019.

28 Compare here, for example, Belgium and France, the former of which is populated by many "nationals" or at least "ethnics" of the latter. Nation has also proven a major arrow in the quiver of legitimation strategies in China.

29 India (before the rise of the BJP) and Pakistan are (or, better, were) archetypes after independence from the British rule.

30 The latter two mark the poles of the US and the USSR during the Cold War, of course. 
fensive terms, either of which can be made peacefully or executed violently against insiders (a very high-risk strategy) or outsiders. Thus, many complex historical, spatial and political contingencies come into play in a given political situation. ${ }^{31}$ The examples we have suggested in this paragraph's footnotes make it plain that all of these can be usefully deployed by widely different types of régimes. ${ }^{32}$ It is high time for politologists to recognize and discard the notion that REDs are intrinsically more successful at legitimating themselves than autocracies.

Third, since the rules of politics are always ambiguous and prone to interpretation in self-serving ways, the legitimacy of any agent in an exchange involving unequal power resources depends on the extent to which they can call upon the support of third parties (themselves often part of the structure of legitimation), who are not directly involved in the exchange, but may be ultimately affected by the reaffirmed rules at stake. ${ }^{33}$ Contra our point about tactics just above, REDs are more capable than autocracies of deploying the third-party approach, because their underlying principles generally include the rule of law and judicial impartiality.

31 In terms of nationalism, East Asia during the rise of its "tigers" displays an intriguing patchwork. Nation has proven a major arrow in the quiver of legitimation strategies in China and in both North and South Korea, despite their extraordinary differences. Japan, which built a hyper-nationalist imperial and, more important, imperialist political strategy during its economic rise in the first half of the twentieth century, has had to back off all that after its defeat in WW II precisely because of the nationalist depredations it committed; it re-founded its legitimacy on a new ideological basis by becoming a Pacific good citizen as well as a Pacific economic powerhouse. In Taiwan, a small minority of Chinese in the Kuomintang, who ruled a large majority of Taiwanese, avoided nationalist claims and, of course, the Taiwanese majority in the rival DPP played them up.

32 Returning to the immediately previous footnote on nationalism in East Asia, there is no simple correlation across these cases with régime type. Even during their transitions from autocracies to REDs, the place of nationalism in the legitimation strategies of South Korea and Taiwan did not waver. By contrast, while China has remained an autocracy throughout, nationalism has been much more prominently on display in the structural reform period than during its Maoist predecessor.

33 Needless to say, these third parties may be specialized in this process of outside, presumably neutral, evaluation between contenders, i.e., it is often done by domestic (and very rarely international) juridical institutions - provided that they are regarded as sufficiently independent of powerful rulers. Technocratic, so-called "guardian institutions" - e.g., the International Labor Organization, Amnesty International, the American Bar Association e cosi via - are also frequently invoked in this context. 


\title{
4
}

\section{THE DISCIPLINE}

\begin{abstract}
How have people understood and analyzed politics, and how can they do it better, both in terms of clearer comprehension and making a more effective contribution to grasping and achieving worthy goals? We argue that it needs to devote much more attention to political theory and abandon its bias toward liberal individualism. The chapter concludes with a survey of main methods of politology and the ways it has attempted to link explicanda (what is getting explained) and explicans (what is doing the explaining).
\end{abstract}

We now turn our attention to the ways in which humans have understood and analyzed politics - an activity which, dialectically, has shaped and been shaped by the practices of politics themselves. Sadly, modern-day political science has diminished its own analytical potentialities by sidelining political theory. To become much more of what it is capable of becoming, and if it is to have any hope of stimulating better politics in the interest of preventing political conflict from spilling over into violence (of which more in Chapter 5), it must get back in touch with its rich panoply of underlying principles, and examine its practices in light of them.

\subsection{The Theoretic Trajectory}

Given its ubiquity, it is hardly surprising that politics has been a constant subject of philosophical thought and empirical inquiry - probably ever since human beings began to live in permanently settled communities. Surely, there were efforts in pre-history to understand its peculiarities, but they have been lost to us - either because they were strictly oral or because the material they were written on 
has perished. Systematic thinking about politics usually is traced to the ancient Greeks, who wrote down and conserved their thoughts and who, appropriately, often disagreed with each other. But they did share certain core elements.

1 Politics is an important component of collective human existence - because, as Aristotle observed, human beings are zoon politikon (political animals). Therefore, he claimed, the study of politics was the "master science" since all other human endeavors depend on the order it produces or fails to produce.

2 Politics is a relational, conflictual and uncertain activity in that one's action produces another's reaction and the outcome of such an exchange is not often predictable because its main determinant, power, cannot be accurately assessed until it is applied.

3 Politics, however unpredictable it may be in specific instances, does tend to settle into observable patterns of behavior (rules and practices), and it is by comparing these patterns across a number of units that a distinctive "science" of politics can be established. ${ }^{1}$

The trajectory of Western thinking about politics has been relatively linear. It began among the Greeks with a strong emphasis on passion as the primary motivating (and threatening) force. The Romans continued along this line but began to add an element of conviction based on the values associated with Roman citizenship, laws and traditions. Medieval and early modern political theory was firmly and predominantly associated with the notion that conviction rooted in Christianity was (or, better, should be) the most important element determining political behavior and was uniquely capable of overriding the erratic and dangerous passions of individuals. Machiavelli represents the turning point when interest makes its appearance - admittedly along with heavy doses of a passion for power among leaders and a downgrading of the role of conviction in mass publics. Since then, the calculated pursuit of selfregarding advantage without consideration for others has become the standard assumed motivation, although mass passionate convictions in the form of various nationalisms and ideologies have periodically injected a stronger, more emotional and less calculated element into the political life of Western polities. As for conviction rooted in religious dogma, it may have declined in the West (except among Christian fundamentalists in the US), but it is still very much on display in the Muslim societies of the Middle East, North Africa and parts of Southeast Asia, and in resurgent Hinduism in the Indian subcontinent, among many others. Habit or conformity seems to wax and wane in accordance with the stakes attached to winning or losing in the political game. The previously indifferent can suddenly discover that they have a passion, an interest or a conviction that is at stake and enter the game, with unpredictable results.

1 Here, at the outset, we do unabashedly make a claim for the central place of comparative politics in politology. 
During the past century or so, the study of politics has become increasingly specialized and professionalized through the creation of an academic discipline usually called Political Science or, less commonly, Government or even Politics. $^{2}$

While the exercise of power can be found in a great variety of sites, e.g., families, firms, churches, tribes, clubs, e cosi via, politologists have focused almost exclusively on its exercise within and around the institutions of the state, i.e., the government and other public agencies that are assumed to be capable of making and implementing decisions binding on all persons within a given territory. Virtually by definition (as we have seen earlier in the discussion of units), it was further presumed that this political unit possessed sovereignty, i.e., its decisions were not just binding within its borders, but also taken independently from the power of other political units. Even more controversial has been the assumption that these persons within the unit shared an overriding common identity, i.e., they formed a nation.

In the contemporary globalized world with its enormous variety of supranational organizations and policy régimes, all of these assumptions have become questionable. All states, even the most powerful ones, find that their autonomous capacity to take decisions is not only limited by the actions of other states, but subject to review and modification by institutions exercising power (even legitimate authority) over and above them. And virtually all of them also have social groups within them who consider themselves members of a different nation. The academic discipline that calls itself political science has only begun to adapt to these sea-changes in the multi-layered nature of its units.

From its Greek origins in philosophy, the study of politics has always been concerned with social norms and personal values. This can hardly be surprising since politics itself has always involved judging and acting according to one's assessment of what is good and what is bad, e.g., the famous fourteenth century facing frescos by the Lorenzetti brothers in the Palazzo Civico of Siena of il buon $e$ il mal governo (good and bad government). Even when the choices are manifestly dominated by self-interest, it is at least prudent to justify them in terms of their favorable, other-regarding, implications. Of particular importance has been the role played by ideals and ideal-types. ${ }^{3}$ In REDs, the former are the characteristics of what politics should strive to achieve: Liberty, Equality and Fraternity (to use a familiar trilogy from the French Revolution); the latter are the configurations of institutions that best exemplify some overriding norm: Democracy, Federalism and Limited Government (to use an American trilogy),

2 As we have argued earlier, it should be called politology. But outside of several European countries from whom we have taken our cue, and China, where zhengzhixue (政治学) is closer to "politology" than "political science" (see page 9, footnote 23), almost no one yet (in the Anglo-American world!) does so.

3 On the third wall of the Sala del Nove are depicted the Allegories of Good Government: Wisdom, Peace, Fortitude, Prudence, Magnanimity, Temperance and Justice. 
but also to indicate their institutionalized inverse: autocracy, centralization and statist intervention. Many autocracies do not bother with the niceties of selfjustification, relying merely on coercion, cooptation, manipulation and/or indifference to stay in power. But most of them, especially those driven by strong ideological or foundational convictions, do invest in self-justification - often stridently, powerfully and effectively. The point of such idealistic exercises is not descriptive, but didactic, evocative and political. By definition, such concepts cannot be perfectly realized in a political world that inevitably involves compromises and constraints, but they can provide an incentive for action that would approximate reaching them or avoiding their opposites.

The modern discipline of politology has prided itself on its realism and even gone so far as to claim that its practitioners should only deal with observable facts and are, therefore, free from the potentially distorting influence of their own norms. ${ }^{4}$ The discipline observes agents and their effects in the populations it studies, but is presumably unaffected by them. Analysts are not supposed to care about the welfare of their subjects, except as it can be conceptualized and verified scientifically and dispassionately (for example, through a utilitarian approach such as "public choice"). Most faculties and departments of political science do tolerate the presence of a small group of scholars called "normative political theorists" or "historians of political thought" who do care about the fate of political agents and the good or bad outcome of political choices, while nonetheless viewing them as a sort of atavism inherited from the past. Their contribution rarely influences the teaching and research of the dominant group of strictly empirically minded political scientists. In our view, the latters' claim to practicing value-free science is not only specious, but also deprives them of access to enormously rich, historical sources of concepts and assumptions.

\subsection{The Liberal Bias}

The scientific study of politics did not begin in the Anglo-American world, but its subsequent development was strongly influenced by scholars coming from the US, Great Britain, Ireland and the countries of the so-called White Commonwealth: Canada, Australia and New Zealand. They brought with themselves a number of normative and empirical assumptions that are rooted in their respective political experiences. The most salient of these are related to liberalism. Contrary to the opinion of many, liberalism is not the same thing as democracy. Not only did it precede democracy historically, but several of its basic assumptions (and practices) have been antithetic to democracy - at least in its original unrevised form. "Liberals" (and the nomenclature is itself ambiguous)

4 During the Cold War, this was sometimes a way of concealing or even proudly promoting politologists' own norms and, more specifically, overt political commitments: that liberal democracy was founded on the civilized contestation of opposing ideas whose validity could be scientifically verified - "speaking truth to power" - compared with the enslavement of the quest for truth by "totalitarian" power in fascist or state socialist régimes. 
preferred to confine the practice of citizenship to those with "a stake in the game," i.e., educated, wealthy males paying sufficient taxes and usually of the dominant religion and race. By the end of the nineteenth century, however, most of them had come to terms with "mass democracy" in which these restrictions on citizenship had been lifted and the role of the state expanded.

The influence of liberal ideology, however, continues to affect core assumptions of much of contemporary politology. We consider them to be the following:

1 Liberalism's exclusive emphasis on the individual citizen and on individualism - substantive and procedural as well as methodological - in its analysis and evaluation of existing political practices;

2 Liberalism's commitment to voluntarism in the form and content of political participation, as well as in the recruitment of politicians who are presumed to be temporarily as well as voluntarily active in politics ${ }^{5}$;

3 Liberalism's fixation with territorial representation ${ }^{6}$ for providing the basic constituencies into which citizens can be meaningfully grouped, and with partisan competition in these constituencies for providing the most legitimate link between citizen and state;

4 Liberalism's confinement to the bounds of the nation-state and its institutions when applying its precepts, as well as its long-standing (if tacit) complicity with nationalism;

5 Liberalism's indifference to persistent and systemic inequalities in both the distribution of material benefits and the representation of citizen interests;

6 Liberalism's preoccupation with the stability of its institutions (despite the inherent dynamism of the party competition it celebrates) and its efforts to reduce all change to incremental and marginal improvements in the status quo; and

7 Liberalism's concentration of its normative attention on protecting the citizen from eventual sources of illegitimate authority (tyranny) and, therefore, advocacy of limiting political authority to a minimum, i.e., especially to the policing of contracts and protection of property, known by the metaphor of the "night watchman" state because it exists mainly to protect private property.

5 "Freedom" is a concept endemic to the vocabulary of liberalism and is closely related to the emphasis on voluntarism as the basis for actions by individual agents. The normative claim is that only when they are liberal will democracies produce and protect the "freedom" of their citizens. What is not acknowledged is that freedom in politics can only be realized in the context of the domestication of violence and that this is possible only when it is collectively regulated. Otherwise, it is only available to those individuals who have sufficient power - usually based on property or inherited status - to impose their freedom on others.

6 Probably grounded (literally!) in liberalism's origins in private ownership of land.

7 For this reason, hardcore liberals also harbor ambivalent feelings about one of the core principles of democracy, namely, majority rule. They frequently assume that majorities composed by "ordinary" citizens, i.e., those who do not own productive property and/ 
Most practicing political scientists, especially those from Anglo-America, would probably agree with these postulates. They have become so pervasive that they are regarded as commonsensical and rarely contested (or, for that matter, explicitly defended). ${ }^{8}$

Aside from the criticisms of their one-sidedness that we just sketched in footnotes 5 and 7, the core problem is empirical. In the contemporary world, virtually every one of these characteristics is threatened by one or another of the major trends in the social, economic and cultural environment of politics:

1 The globalization of trade, finance and production systems;

2 The changes in the role and sources of technological innovation;

3 The concentration of ownership of the means of production and distribution, and the wealth they generate;

4 The formation of supra-national trading blocs and regional organizations;

5 The strengthening of sub-national political forces that challenge existing nation-states;

6 The expansion and interpenetration of communications systems;

7 The increased vulnerability to business cycles (itself stimulated, ironically, by neo-liberalism, which undermined many Keynesian mechanisms of economic regulation (per $\$ 12$ below);

8 The necessity for industrial restructuring;

9 The liberalization of trans-national financial transactions;

10 The individuation of life situations, especially with regard to work;

11 The decline of institutional agents that can provide a necessary check on liberalism's (and in particular capitalism's) built-in tendency to excesses ${ }^{9}$;

12 The growing international insecurity due to dramatic changes in the role of Great Powers and declining capacity for government by national institutions alone; and, finally, last but not least

or who are less well educated, are disposed to be "tyrannical" when they win elections or mobilize to influence authorities in order to appropriate private accumulations of wealth. Presumably, they believe that minorities composed of more affluent and better educated elites do not threaten the persistence of RED when they come to power. As a student of comparative politics, especially one who used to specialize in the politics of Latin America, Schmitter finds little or no empirical basis for such a general assumption. Some of the most tyrannical régimes in that part of the world were promoted and supported by property-owners and well-educated middle-class citizens.

8 Although as one distinguished student of American political thought has argued, not only has liberalism gone through multiple permutations and reinterpretations, but the present dominant version - a product of an unusual confluence of democracy and capitalism in the post-World War II period - is resolutely "procedural" and, hence, deficient as an operative public philosophy. Michael Sandel, Democracy's Discontent (Cambridge, MA: Belknap Press, 1996).

9 Here, see, in particular, Wolfgang Streeck, "How Will Capitalism End?"; and Yanis Varoufakis, "How I Became an Erratic Marxist," The Guardian (February 18, 2015). 
13 The absence (despite all of the above) of a credible threat of revolution that might induce power-holders to reform their institutions.

Granted that some of these explicans are not new and that liberalism and its particular form of democracy have managed to survive analogous challenges in the past, nevertheless, the magnitude and multiplicity of these trends are unprecedented - as is the absence of any "systemically plausible" alternative régime for coping with them. The discipline of politology is slowly (and, in many cases, reluctantly) adjusting to these changes in the environment in which politics is embedded.

\subsection{The Methods ${ }^{10}$}

Politology uses many methods, and politologists argue incessantly about which is generically the best - "the most scientific" - and even about which is the better for studying a particular topic. Few of their methods are indigenous to the discipline; most have been adopted from one of the other social sciences. ${ }^{11}$

Grosso modo, politologists can be grouped into four "schools" and, needless to say, each of them has its distinctive set of methods and data-gathering. ${ }^{12}$ Most of them are "realists." They study what it is (or has been), and their methods involve various forms of empirical observation and pattern recognition. Some of them count and others describe, but both are only interested in what actually has happened or is happening. Others could be called "idealists" who study what should be happening, and apply normative standards to evaluate what it is (or has been). Third, there is a very small group of "surrealists" who are interested in what might have been in the past and what might exist in the future. Finally come the "sur-idealists," who try to answer questions such as "Why did agents not engage more vigorously when this would have resulted in greater gender equality?" or "Under what conditions will they engage in the future in order to improve social justice?"

Since realists dominate the discipline, we will focus on their choice of methods. As we have pointed out supra, ${ }^{13}$ idealistically minded politologists are

10 Most courses on methodology in the discipline are essentially exercises in applied statistics. In this essay, "methods" refers to the choices researchers must make prior to actually gathering the data that is presumed to be relevant to their concepts - whether or not they are eventually to be manipulated statistically or compiled into a narrative. It focuses on how you find out if something exists, rather than what you do with the data once you have them.

11 By far, the most distinctive and visible method in politology has been the measurement of public opinion by means of questions posed to a random sample of the population. Almost no election would be complete these days without the application of such a method and without pundits appearing in the mass media to interpret its results. This has become more and more embarrassing for the status of the discipline since this method of research has markedly declined in its capacity to predict election results correctly.

12 The fancy way of expressing this choice is "epistemological."

13 Page 82. 
usually segregated into a compartment called the "history of political thought" or "normative political theory." They are tolerated by the former as a sort of residue from the pre-scientific origins of the discipline, but largely ignored. The surrealists and sur-idealists are, generally, not taken seriously as political scientists, especially by the realists. ${ }^{14}$

Realists have a rich tool kit at their disposal - usually arrayed along a continuum running from the qualitative to the quantitative, i.e., from telling a convincing story to discovering a significant correlation. ${ }^{15}$ The former are proud of their capacity for including many "explanatory factors" in their "rich descriptions," and the latter have an ingrained preference for parsimony in their choice of "variables" and for statistical proofs as the basis for their conclusions. ${ }^{16}$ Both open their respective tool boxes by defining an explicandum - that which they propose to explain - followed by an explicans - that which is supposed to do the explaining. In the professional jargon, these are referred to as the "dependent variable" ("Y") and the "independent variable or variables" ("X or $\mathrm{Xs}$ "). ${ }^{17}$ They are supposed to be distinct from each other in both their origins

14 Some "surrealists" have created a label for themselves: "futurologists." They are usually to be found in non-academic sites such as think tanks or firms engaging in risk analysis. Not infrequently, they produce best-selling books for the general public proclaiming the advent of some disastrous, "shocking," future. They also specialize in appearing as pundits on television programs. Unfortunately for them, politology is much better at retrodiction than prediction, thanks to the complexity, reflexivity, dynamism and resulting indeterminacy that we have highlighted throughout. For example, those specialists who were researching a micro-foundation as basic as the units involved in politics failed to anticipate the most significant developments of recent decades: the collapse of the Soviet Union and its Eastern bloc, the reunification of Germany, the Arab Spring and BREXIT, as well as, most recently, the crisis of REDs, the emergence of populist candidates and parties across Western Europe and the US, and the resilience and, indeed, transformative power of market Leninism in China and Vietnam. Once these seismic shifts had occurred, of course, they were posthumously capable of explaining why they had to have done so.

15 As the adage goes, "you can put a number on anything; you can describe (almost) everything." But which is better for analyzing a specific topic?

16 A growing number of politologists can be found somewhere in the middle of this methodological continuum. For example, it has become very fashionable to collapse some combination of quantitative and/or qualitative data into something called an index and then use it to rank the units involved. This method has proven especially appealing to think-tankers and policy advocates who use it to "shame and blame" countries, parties or persons when they are at the bottom of the ranking or when they descend it in relation to their peers. Another intermediate method involves scoring a set of variables by their existence or nonexistence (1-0) over time and tracing their respective trajectories toward some eventual cluster of outcomes. This has been called Qualitative Comparative Analysis (QCA) in the jargon of the discipline.

17 The language of "dependent" and "independent variables," adopted uncritically from quantitative or physical science methodology, seems too mechanical and even potentially simplistic - not to mention antithetical - to capture what the qualitative methodologists do, and unable to express the sheer complexity, co-variation and qualitative (and not just quantitative) variability of so much the study of politics. They might do better to stick with the older but richer terminology of "explicans" and "explicandum." 
and presence, ${ }^{18}$ but related to each other in some significant manner. ${ }^{19}$ It may be that the latter is necessary for the former to exist and, in extreme cases, both are necessary and sufficient for it to exist. In most cases involving politics, it is enough that $\mathrm{X}$ is capable of producing some change (positive or negative) in $\mathrm{Y}$, and in doing so sufficiently frequently and significantly such that it could not be just due to pure chance. Their relation may be expressed as an explicit and potentially falsifiable hypothesis that specifies why and sometimes even how they are connected, ${ }^{20}$ but often it is enough just to begin with a hunch that they may be related in some fashion or for some reason. ${ }^{21}$

Needless to say, both explicandum and explicans have been conceptualized in "lower case" terms, i.e., identified as instances of some class/category of events or processes, even by politologists working on single cases. Even when they do not explicitly compare, politologists work, implicitly or, increasingly, explicitly, with concepts and theories of more general applicability. The "upper case" work on explaining singular happenings is usually left to historians or area specialists. Furious battles have broken out between them, which is unfortunate because each has a great deal to offer the other. The latter can help sensitize the former to "explicans" they might not have considered, and the former can help the latter overcome the danger of parochialism that is built into their approach.

Cutting across the classical, intra-disciplinary dispute between quantifiers and qualifiers is another continuum of choice: should the researcher use

18 If they are not separable, this is called the endogeneity problem in the jargon of the discipline, and it negates the potential value of testing any hypothesis about how or why they are related since $\mathrm{X}$ and $\mathrm{Y}$ are the same thing - just labeled differently. "Demonstrating" that countries with greater freedom of association are more likely to be democratic does not make a significant contribution to knowledge. Nor does "proving" that those democracies in which the media are owned and operated by private firms or persons are more likely to be "liberal."

19 The typical assumption is that this relation is temporal: the independent X or Xs are supposed to come before the dependent $\mathrm{Y}$, which means that chronology is an important component of story-telling, and lagged variables are often used in the process of calculating statistical correlations. Both of these have a problem in dealing with the occasionally perverse political phenomenon in which agents anticipate behavior based on foreign precedents or prescient theories and act on the explicandum before the explicans has occurred. As a rule, politological theories are not very good at specifying exactly how long the relationship of $\mathrm{X}$ to $\mathrm{Y}$ has to exist in order for it to produce its hypothesized effect.

20 Whether or not it is explicitly recognized (and it usually is not), all political research operates in the shadow of the null hypothesis, namely, that the relation between $\mathrm{X}$ and $\mathrm{Y}$ does not exist. It is only by disproving this that the politologist can go on to prove whether the relation is necessary, sufficient, significant, prudent, desirable, convenient or just plain interesting.

21 This situation is often deprecated as "barefoot empiricism," but it can be indispensable when studying political phenomena that are either rare or unprecedented. Moreover, the very act of separating the variables into two categories may be distortive in contexts where such a high degree of interdependence prevails that there is no distinct "cause and effect" - just a lot of mutual effects (and, not infrequently, confusion and chaos). 
obtrusive or unobtrusive methods? In the former case, the data gathered involve active intervention, for example, by asking questions to a random sample of citizens/subjects or to a select set of informants. In the latter case, the politologist passively collects data that have been made publicly available or can be "scored" without the knowledge of the agents involved. Whether the data collected come in the form of numbers or of descriptions depends on the topic (and on the researcher's training, not to mention the fashion of the discipline at the time) or on the ease of access to the information needed. Both can contribute to the systematic accumulation of knowledge; both can also produce data that are irrelevant with regard to a given concept. ${ }^{22}$

Most politologists conceive of the X-Y relationship in linear terms: changes in the former are expected to produce changes in the latter by direct interaction of some predictable magnitude or for some comprehensible reason. For example, so-called "development (aka modernization) theory" was rooted in the observable empirical relation between the per-capita wealth of a given unit and its type of régime. The richer a country was, the more likely its régime was to be democratic. If strictly linear, this implied that each increment in USD per capita would "buy" some more democracy. When this did not always happen, analysts began transforming the nature of its linearity - by inserting thresholds or by postulating various curvilinear effects.

A more promising variant of this has been to pay much greater attention to the potential role of "contextual variables." This involves different forms of "lateral thinking" in which the usual linear approach is supplemented with one or both of two considerations: (1) specifying the variables that were previously necessary in order that $\mathrm{X}$ and $\mathrm{Y}$ could become related to each other; and (2) identifying the conditions that emerge - usually unexpectedly - from the interaction of $\mathrm{X}$ and $\mathrm{Y}$ and may modify its outcome. The former suggests that $\mathrm{X}$ and $\mathrm{Y}$ may be related to each other to different degrees and even in opposite ways during different historical periods, in different cultures, or according to different sequences of occurrence. The latter is even more subversive for "realists" since innovation and unpredictability are intrinsic features of their subject matter that can and do intervene ex post to change the preferences and behaviors of the agents involved. ${ }^{23}$ In other words, politics is a "contingent business," and the study of it should recognize as much methodologically. ${ }^{24}$

22 In the jargon of politology, this is known as the problem of validity. Do the data gathered accurately reflect the meaning of the concept that they are supposed to be measuring quantitatively or observing qualitatively? Needless to say, if they are not valid, the entire research effort is likely to be worthless - however elaborate the statistics or rich the narrative.

23 In fancy, philosophically tinged language, this can be conceived as the dialectic of subject and object.

24 It is possible to test for such mistaken inferences. This tends to take two forms: either some ignored condition is necessary beforehand for the relation between $\mathrm{X}$ and $\mathrm{Y}$ to exist, or the relation between $\mathrm{X}$ and $\mathrm{Y}$ is an illusion since both are caused by some 
As we have seen earlier, most academic students of politics begin (usually implicitly) by presuming that the politics they propose to study are of Type One, i.e., already embedded in institutions and practices that are capable of channeling the efforts of agents when they exercise power in predicable and rule-regarding ways. Students of international relations used to think of themselves as condemned to studying Type Two politics, but have more recently begun to recognize the orderliness and rule-abidingness that prevail between nation-states in some regions of the world. ${ }^{25}$ Even among students of "domestic" politics, robust literatures on revolution, non-revolutionary transition and "path-independence" (such as work on "critical elections") have highlighted and elaborated the richness of Type Two politics.

Politologists are usually not content just to display the data; they want to analyze them (and maybe even to make causal inferences and generalize on the basis of what they find out). One of the longest lasting disputes in the social sciences has been about the purpose of this exercise. ${ }^{26}$ Is it enough just to demonstrate and correlate the mechanism(s) whereby $\mathrm{X}$ and $\mathrm{Y}$ are related to each other? Or should one go beyond this in order to capture what the agents thought about the relationship and what they intended to do about it? The first presumes that political power is basically "structural or functional" in nature. It is built into entrenched institutions or independent operations and, therefore, produces its effects without the agents necessarily considering the possibility of alternative responses or even being capable of fully understanding what they are doing. ${ }^{27}$ The second is "voluntaristic" in that the outcome depends critically on the attitudes and objectives of the agents involved - and they are likely to be aware of other potential courses of action. Needless to say, most situations in the real world of politics have elements of both, but the choice to emphasize one or the other at the stage of conceptualization will have a major impact on the methods applied (and, of course, on the eventual data that have to be gathered).

Researchers must choose not just their topic but also the cases within which to examine it, a matter that is bound to shape, often fundamentally, their findings and analysis, since in politology units studied are anything but equivalent or even homologous. Section 5.4 in the next chapter takes this up.

unspecified third variable (Z). Tests for errors due to contingency or spuriousness are easier to perform when the method is quantitative - it merely involves gathering additional data and introducing them as control variables into the equation. In the case of qualitative analysis, these two possible errors tend to get surreptitiously submerged in the "richness" of the narrative.

25 Today, it is more likely to be students of régime change, civil war and failed states who start with the explicit assumption that they have to deal with Type Two, "unruly and undomesticated," political situations.

26 This was known as the Methodenstreit between Erklären (explanation) and Verstehen (understanding) among German social scientists at the end of the nineteenth century. It has not been resolved and probably never will be.

27 Strident "explainers" regard such matters as little more than speculation, and even ideologically driven by the preferences of the "understanders" at that. 


\title{
5
}

\section{THE DESIGN OF RESEARCH ${ }^{1}$}

\begin{abstract}
Good political research requires an explicit design. This chapter illustrates a cycle of choices that begin with the transformation of an idea into a topic and end with the drawing of inferences from the patterns of association one finds and evaluation of the results. In between lie critical decisions about concepts, hypotheses, case selection, indicators, measurement and tests for association.
\end{abstract}

To make an original contribution to our knowledge about politics - whether based on explanation or understanding or both - requires research, and research requires a design. This begins with an idea that has to be transformed into a topic that is believed to be of sufficient importance and feasible execution so that it is worth exploring further and, potentially, capable of making such a contribution. It may become a book, a doctoral dissertation, a master's paper, a journal article or just a simple seminar exercise. But regardless of length and complexity, it will have to be translated - via a series of strategic choices - into a project. It is this process of translation that constitutes a research design.

Granted, not all political research is self-consciously designed. In many areas of inquiry, the design is literally given along with the topic, e.g., survey research

1 This chapter is a revised and abbreviated version of Philippe Schmitter, "The Design of Social and Political Research," in Donatella della Porta and Michael Keating (eds.), Approaches and Methods in the Social Sciences (Cambridge: Cambridge University Press, 2008), 263-295. We encourage those of our readers contemplating doing political research not just to consult the original, but also the other chapters in this volume. It is a collective attempt by Schmitter's colleagues at the European University Institute to provide a more pluralistic and less positivistic alternative to the prevailing standard manual in American political science, namely, Gary King, Robert Keohane and Sidney Verba, Designing Social Inquiry: Scientific Inference in Qualitative Research. It appears here with the permission of Cambridge University Press. 
and the prediction of electoral outcomes. ${ }^{2}$ However, as we have discussed earlier, politology is not (and may never be) a "normal science" in which there is an overwhelming consensus on concepts, assumptions and methods. The subject matter is too mobile; new methods are constantly being invented: and, consequently, the appeal of different theories and approaches waxes and wanes over time. This means that many politologists (especially those just entering the discipline) will not be choosing topics whose research design is given. They will have to find or invent an appropriate one - and they should be prepared to understand and defend the choices involved.

Moreover, as we have argued, their intent should be comparative. They should anticipate including more than one case or set of observations and drawing inferences across them - even if they do not do so themselves. Making the right strategic choices will greatly enhance the value of the data they gather and the inferences they can draw from them; neglecting these choices or taking them for granted could result in idiosyncratic scraps of information and inferences rooted in exceptional circumstances that make no reliable or cumulative contribution to scientific knowledge.

Figure 5.1 depicts a schematic and idealized representation of the complete "political research cycle." Each of its boxes involves an important set of interrelated strategic choices and its implication is that these should be made in the displayed sequence, i.e., beginning with an idea that defines a topic at 12 noon and proceeding clockwise until the researcher arrives at an evaluation of his or her findings that may or may not re-define the original topic at midnight. Inside the boxes lie a number of alternative courses of action. Choose among them wisely and the research will be better. Ignore them or fail to grasp their significance and you run the risk of committing serious fallacies at each stage.

The most important message to keep in mind while proceeding through the entire cycle is that there is no single best strategy or set of strategies for researching all political topics. Everything depends on the point of departure, i.e., on the nature of the substance initially chosen for research. At the beginning of the cycle in Figure 5.1, the range of options tends to be most extensive and, hence, most confusing. Interesting topics clamor for equal attention; different theories and concepts can seem equally compelling. As one proceeds clockwise, the successive choices are increasingly related to each other and the options become more limited. At some point, the researcher may well adopt or fall into an "established disciplinary routine." This can save a lot of time and worry - some would say that it is the inevitable and desirable product of the

2 And even in this sub-field, the consensus on design has diminished. The success in predicting/estimating outcomes seems to have been predicated on a prior condition, namely, the strength of party identification within the electorate. As fewer and fewer voters have stable and prior commitments to specific parties and, therefore, tend to switch their preferences from one election to another (and also to do so at the last minute), it has become embarrassingly difficult to predict who will win from random surveys of the population. 


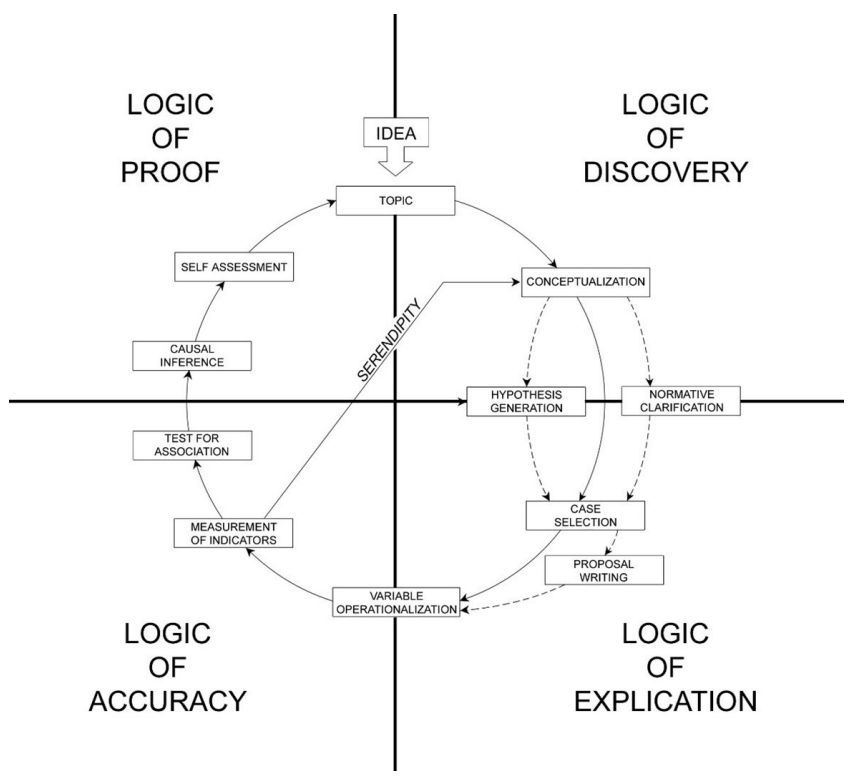

FIGURE 5.1 The Cycle of Social and Political Research and Its Four Logics.

"professionalization" of the discipline - but this will only be of benefit if the topic and, especially, its conceptualization are sufficiently isomorphic, i.e., conform to the basic characteristics of the topic that has already been successfully researched by others. Applying even the best established and/or most fashionable design to the wrong topic can be a formula for disaster, especially, when it comes to drawing inferences. ${ }^{3}$

Very few researchers "really" enter Figure 5.1 at noon and leave at midnight. Most have consciously or unconsciously taken some shortcut in order to get started in the process. For example, many begin their research careers already knowing which case or cases they intend to work on. Not infrequently, it happens to be the country they come from or are trained in. So-called "area specialists" usually have some prior personal commitment related to their knowledge of history, culture or language, and this tends to affect the topics they select. Some begin with a political or ideological commitment, and light upon a topic

3 For example, the widely accepted, and indeed almost exclusive, coin of the realm in the study of state socialist régimes in well into the 1960s was élite politics - "Kremlinology" and "Pekingology." Political sociology was barely practiced. As a result, politologists of the China, Eastern Europe and the USSR were utterly surprised by the Hungarian Uprising in 1956, the Chinese Cultural Revolution of 1966, the Czech rising in 1968 and Polish Solidarność - a pretty sorry record and one with profound consequences for the international relations of the Cold War. 
within which they can exercise it. ${ }^{4}$ Others may have picked up some novel statistical technique or measurement device that they wish to show off - and they search about for an apposite topic to which to apply it. Perhaps the most common (and, in our view, pernicious) point of departure concerns theories or approaches that are currently fashionable. Imbued with the conviction that only those espousing such a "paradigm" will find eventual employment, too many young researchers are prepared to take up any topic - no matter how trivial or obscure - if only to demonstrate their fidelity to its assumptions and postulates. This problem is made worse by senior scholars who prefer to churn out graduate students who elaborate the topic and paradigm invented by their patron.

Finally, do not presume that, once in the cycle, the researcher will have to go all the way around. As we shall see in the conclusion, there are many points of exit that will still permit one to make an original and significant contribution to knowledge.

Now, we can proceed to look sequentially into the "little black boxes" in Figure 5.1.

\subsection{Choice of Topic}

No one can predict where, when or why ideas will appear. With some knowledge of the researcher's personal and professional background, it may be a bit easier to predict the conditions under which an idea becomes a topic, i.e., when someone will attach sufficient importance to a given thought and place significant boundaries around it to make it worthy of investing energy to explain how it came about and/or what its consequences might be. Needless to say, this highly personal effort at selection can be an important source of distortion throughout the rest of the design and, especially, when it comes to drawing inferences from whatever data distributions or associations are generated. The very fact that one cares enough to select some topic probably means that he or she also values what it contributes or the effect that it has - whether positive or negative. However subliminal the thought may be, personal values tend to become embedded in the topic and can exert a persistent influence on the choices one makes in proceeding further in the research cycle. It is also very often the case that one is attracted to a specific topic because the society or polity surrounding it also cares about it. And never is this more evident than when the

4 In the US, research on the state socialist régimes attracted both anti-communists and leftists. Their diametrically opposed political commitments produced widely different research designs which did not talk so much as shout past each other instead of producing useful cross-fertilization. With the end of the Cold War and the rise of a new generation of less tendentious researchers, including many who hailed from the countries in question but trained outside them, politology on state socialism made significant advances. One lesson here is that the less parochial the politologists, the richer the politology. 
subject matter is in crisis or in fashion. As politologists, we are bound to be attracted to phenomena that call attention to themselves - whether they do so by creating further problems or by providing novel solutions. This is another way of saying that our topics may tend to be either failed experiences at the end of their useful existence or recent successes that have yet to reveal their complete impact. Rarely does one come across designs explicitly focused on explaining social or political phenomena that are regarded as mediocre or inconsequential.

Grosso modo, topics of research come in two guises: (1) projections where the researcher is confident that the existing approach and methods are adequate and deserve to be applied to units or time periods that have not already been covered or with greater precision to cases that only seem to be exceptional; and (2) puzzles where the researcher begins with the assumption that something is deficient in the way that the topic has been previously handled and that the units or time periods to be examined will demonstrate the existence of anomalies. Both projections and puzzles should be approached in the same "critically rational" manner, but the perspective of the researcher differs. If the topic selected is regarded as a projection, he or she has the intent (at least, initially) of confirming established wisdom and will take more seriously the obligation to make a cumulative contribution to knowledge within a specific discipline or paradigm. The perspective when tackling a puzzle leads one to seize on anomalies that seem to expose deficiencies in how the topic has been conceptualized, measured or reported, and that is more likely to lead the researcher to alternative concepts and methods - frequently by drawing on other disciplines. Needless to say, both are capable of making valid contributions; both are needed by politology.

\subsection{Conceptualization}

Almost all substantive matters emerge "pre-conceptualized" in the strict sense that they can only be recognized by the potential researcher and shared with others if they are expressed in some intelligible language. The idea may come initially as a shape or a color or an emotion, but words are the indispensable way in which it acquires factual specificity and shared significance. The complication for research resides in the high probability that the words initially involved will be those of the social or political agents involved - which, as we have seen, could bear many different meanings, be attached to a wide range of contrasting assumptions and involve much plain old confusion. ${ }^{5}$

Conceptualizing a topic invariably involves translating the words that surround it in "real-existing" societies or polities into variables. These are not just fancy academic labels applied to a specific event or process. They should identify analogies, i.e., generic conditions that are shared by a distinctive set of events or processes and can take on different values over time - whether these 
are quantitatively or qualitatively observed. They acquire their peculiar status as causes or effects according to the way they are connected to other variables by theories. Once you have assembled these variables, whether from the same or varying theories, they constitute your provisional argument concerning the topic you have chosen to explain.

This brings us to "the Elephant-in-the-Room" that is so rarely mentioned but so frequently the source of confusion at each stage of designing research. Even the most elementary and frequently used concepts - e.g., class, status, gender, age, region and religiosity - for explaining voting behavior derive their meanings from being inserted into a more comprehensive (and presumably coherent) matrix of concepts. Their definitions may sound the same and, as we shall see later, their operationalization may even be identical, but their role depends on prior assumptions and contingent relations that differ according to the theory, paradigm, approach or framework that is being applied. ${ }^{6}$ And no single piece of research can possibly specify what these are. If one tried to do this, there would be no time or space left for the analysis. In other words, all social and political research is part and parcel of "the state of theory" prevailing at the moment it is conducted. No research can be conceptualized ex novo without reference to what has been produced already on that and related topics. And this applies just as much to those who are trying to solve puzzles as those who are "merely" trying to make projections.

Choosing one's concepts is only the first step. Making them into variables means assigning a status to them, and this is where their embeddedness in theory most saliently enters into the research design. The most important is to distinguish between those that are regarded as operative with regard to the chosen topic and those that are inoperative. The former are expected to play some discernible role in the explanation of outcomes - either as explicans (i.e., that which does the explaining) or explicandum (i.e., that which is to be explained). The more elaborate the prior theory and, hence, the conceptualization derived from it, the more it may be possible to assign different statuses to the operative variables, for example, by distinguishing between primary and secondary ones, direct and intervening ones, continuous and episodic ones, and so forth. Needless to say, these initially assigned roles can be inverted - the explicandum can become the explicans and vice versa - especially where and when the objective is to explain a relatively long-term sequence of social and/or political processes.

Inoperatives are variables that are present and can be expected to take on different values as the subject matter is being researched, but whose effect is

6 For just one example, politologists have spilled boatloads of ink analyzing the relationship between class and voting behavior. But class is a highly contested concept. In the Weberian tradition, highly paid professional athletes are at the very top of the class structure. But for Marxians, they are proletarianized (and therefore unionized) employees of their teams, who are highly alienated (serving as a mere "left arm" in the bullpen, for example) and commodified (as they can be traded on a moment's notice). 
not expected to produce a discernible or significant difference. Needless to say, when it comes to making eventual inferences, allegedly inoperative variables may turn out to be important potential sources of spuriousness. Even constants, i.e., variables that were present but not thought to vary during the research period and, hence, a priori considered not capable of contributing to variation in the outcome, may gain eventually in importance - especially when it becomes evident that the impact of operative variables was contingent on slight modifications or even simple re-interpretations of such background factors. You may hope that irrelevant variables - those whose variation cannot conceivably be logically or empirically associated with the topic under investigation - will remain that way, though even that can never be guaranteed. And in fact, you can hope, by contrast, that they actually do not - i.e., that you can discover that a variable that no one previously imagined could be relevant was, in fact, driving the outcome. ${ }^{7}$

\subsection{Formation of Hypotheses}

Not all research designs involve the formation (or the eventual testing) of explicit hypotheses. There exists a very broad range of social and political topics for which it is possible to imagine, i.e., to conceptualize, the variables that may contribute to an explication, but not to assign any sort of provisional "if... then..." status to their relationships. For these topics, the apposite research logic is one of discovery and not of proof. The purpose is to improve one's conceptualization of a topic, probe its plausibility against a range of data and eventually generate hypotheses among its conclusions, but it would be premature to expect them as a pre-condition for conducting the research itself.

Obviously, the determining factor is again that "elephant-in the room," i.e., the prevailing state of theory on a given topic. Substantive matters that are of recent occurrence, that are only characteristic of a small number of cases, that incite strong emotions or political controversies, or that fall between different social science disciplines are obvious candidates for "discovery" status. And the potential researcher is reminded that accepting this status should not be taken as a sign of inferiority. Somewhere behind all research that today routinely follows the logic of proof, there must have been a glorious moment in the past when someone launched a voyage of discovery.

Unfortunately, behind the façade of increased professionalism and standardization of techniques, this message has been suppressed, and only the most intrepid of young scholars will be likely to accept the challenge of trying to make sense out of alternative conceptualizations of the same topic or piecing together potentially coherent and general arguments by "process-tracing" on the basis of

7 One now classic example is the argument that the sharp drop in crime rates in the 1990s was a result of the legalization of abortion two decades earlier, which resulted in a much reduced population of miscreants. 
specific cases or admitting that, in instances of highly interdependent and complex social or political systems, it may never be possible to distinguish between independent and dependent variables, much less to express them in terms of a finite set of bi-variant relationships.

\subsection{Selection of Cases}

For all but a few projects, the potential number of societies or polities affected by the chosen topic will exceed the researchers' capability for gathering data, testing for associations and drawing inferences. It is, therefore, normal that only some subset of these units will enter into your analysis. One of the most prominent of the strategic choices that has to be made involves the number and the identity of those to be included in this "sample" 8 and the criteria you impose to select them. This can vary from one unit (the single case or person) to as many as are apposite (the universe of those affected), but there is a fairly inescapable trade-off between the quantity of variables that have been included in the initial conception of the topic and the number of units for which one will be able to gather data. Including more cases probably also usually means poorer quality data, more missing observations and greater problems of conceptual equivalence. Inversely, the more narrowly these variables have been defined and operationalized, i.e., the lower they are on the ladder of abstraction, the less likely they are to be relevant in a wide range of cases.

Case selection may have its practical side when it comes to gathering data and, especially, making one's own detailed observations, but its real pay-off is analytical. Manipulating the identity of cases provides politologists with their closest equivalent to experimentation. It "simulates" the introduction of control variables. By "holding constant" across the sample potentially relevant conditions such as cultural identity, geographic location, level of development and temporal proximity, the researcher can at least pretend that variation in them is unlikely to have produced the outcome at which one is looking. Granted that the controls can be a bit approximate and that there still will remain many potential sources of "contaminating" differentiation among units in the sample, still, this is the best design instrument that he or she has available. It should, therefore, be wielded with deliberation - and caution.

To the extent that researchers agree with our core assumption that the comparative method is to be preferred - regardless of subject matter - they face yet

8 Our scare quotes here reflect a crucial point. A sample is a subset of cases that stands in for a wider universe whose basic features it captures. Treating a group of cases as a sample, then, necessarily but often implicitly involves the assumption that there are general laws or tendencies that affect all cases in the wider universe. But why should politologists presume that politics operates similarly in all similar polities? The question is too rarely asked in a discipline too much under the baleful influence of its envy of natural science, where the same forces do generally produce the same outcomes always and everywhere. Politics, we have argued extensively earlier, cannot be conceived this way. 
another critical choice, namely, the selection of relevant cases once the topic has been chosen. ${ }^{9}$ This can range from one - provided that it is conceptualized in generic ("lower case") terms that can potentially be applied to others - to the entire universe, all occurrences of the topic for which data can be gathered. Both of these extremes have potential defects. The lower-case concepts used to describe or measure variables in single cases may be so detailed and prolific as to be incomparable anywhere else. The entire universe - often all members of the United Nations when comparing nation-states - not only poses severe problems of empirical equivalence and data availability, but also makes the strong presumption that merely because the units have the same formal status, they also have analogous capacities for all manner of political activity.

The strategy most likely to be productive is usually to settle for "more than one and less than all" - some subset of units that share certain characteristics and differ in terms of their respective explicandum and explicans. For example, this is the standard justification for so-called "area studies," where the units presumably share a number of cultural, linguistic, religious or historical characteristics, but nonetheless may differ in their levels of development, degrees of external dependence, size of population or territory, colonial heritage, etc. This is (almost) equivalent to the experimental laboratory situation in which other potentially relevant conditions are controlled and can be presumed not to affect the outcome. In the most extreme instance, the design is a "paired comparison" between two virtually identical units - still presumably independent of each other in their political institutions and policy choices. ${ }^{10}$ And going still further, these units need not even be fully independent, but can comprise different subunits of a single country - a research strategy that brings comparative politics inside the realm of what had been "single country" studies.

This "most similar" comparative design works best when the topic has been thoroughly conceptualized and empirically studied such that the researcher can be confident that he or she has identified all potentially intervening variables and can control for them by selecting cases in which they do not vary (or vary so little as to be almost irrelevant). It offers the opportunity to break ground by identifying the power of a variable which has previously been overlooked, providing there is a significant difference between two very similar cases. The inverse, "most different" choice of cases, is especially useful when investigating a relationship that the researcher suspects is universal - likely to occur

9 Choosing the case or cases first and then conceptualizing the topic been labeled as "selecting on the dependent variable" and strongly disabused by most methodologists. In fact, it is perfectly normal to do this since the choice of cases is almost never a strictly methodological one and usually reflects the prior skills and interests of the researcher.

10 Which may be unrealistic since countries so similar are not only likely to be near each other physically, but also very well informed about each other's behavior - which makes the assumption of independence of choices dubious. The recent proliferation of regional organizations, such as the European Union, has further complicated this problem by literally institutionalizing the diffusion of institutions and policies across national borders. 
everywhere and whenever - and the intervening conditions of space, time and culture are not likely to obliterate it.

Needless to say, the strategic selection of cases will have a significant impact, not only upon the plausibility of any causal inferences derived from one's research, but also upon the extent to which they are likely to be generalizable when applied to others. Strictly speaking, the researcher does not select individual cases, but "configurations of variables" that co-habit the same unit and may even co-vary in a unique or distinctive fashion within that unit. But one cannot analyze "France" as such and compare it with, say, "Spain" or "Italy." There are simply too many different (and potentially relevant) conditions within each of these countries with regard to almost any topic. This holds even when comparing subunits within the same country where the number of variables can be more reliably controlled due to common constraints at the national level.

This is not to say that there are no significant differences between designs that are driven by the effort to isolate a small number of variables and test exclusively for their association with other variables across a larger number of units, and designs that begin with a larger number of interrelated variables (often combined via ideal-type constructs) within one country and then seek to find significant and persistent connections across a few, carefully selected, units of an allegedly comparable nature. But in either strategy, what is being compared are variables - one or many, alone or in clusters - not units. One exception concerns some research in international relations where the underlying theory (often erroneously) makes the assumption that the only relevant agents are sovereign states acting in their unitary national interests in a single "global" universe.

This brings us to the second aspect of case selection that has long been taken for granted and yet has recently become of growing concern. For a unit of observation to be a valid case for analysis, it must possess identical or, at least, comparable degrees of freedom with regard to the topic under investigation. A design that drew inferences - descriptive or causal - from a sample of units composed of Brazilian municipalities, Mongolian provinces, Spanish estados autonómicos and the permanent members of the United Nations Security Council about the efficacy of particular taxation systems would not attract much attention. Much as its author might (correctly) protest that this "sample" embodies a "most different systems design," critics would (rightly) object that agents in these units did not have remotely equivalent powers to make or enforce their decisions about taxation.

The usual formula for getting around this problem was to select only units that were at the same level of aggregation and enjoyed the same formal status within the world social and political system. This presumably explains why so many comparative research projects have been based on nation-state units or, to a lesser degree, on relatively autonomous sub-national units within federal or confederal systems. The reductio ad absurdum of this strategy has been reached with large $\mathrm{N}$ comparisons containing all the members of the United Nations for which data can be obtained - despite the blatant fact that these so-called 
sovereign states have radically divergent capabilities for governing their respective populations or even satisfying their most elementary needs.

Figure 5.2 sums up the complexities of case selection. Assuming that all researchers are committed to producing scientific knowledge, the preferred case selection strategy should usually be the "experimental" one, i.e., choosing the units of observation randomly and introducing some element of change in a subset of them while holding variation constant for the others. Unfortunately, most politologists have to operate in "real-existing" settings where this is not possible. And even when they are able to engage in experimentation, the topics

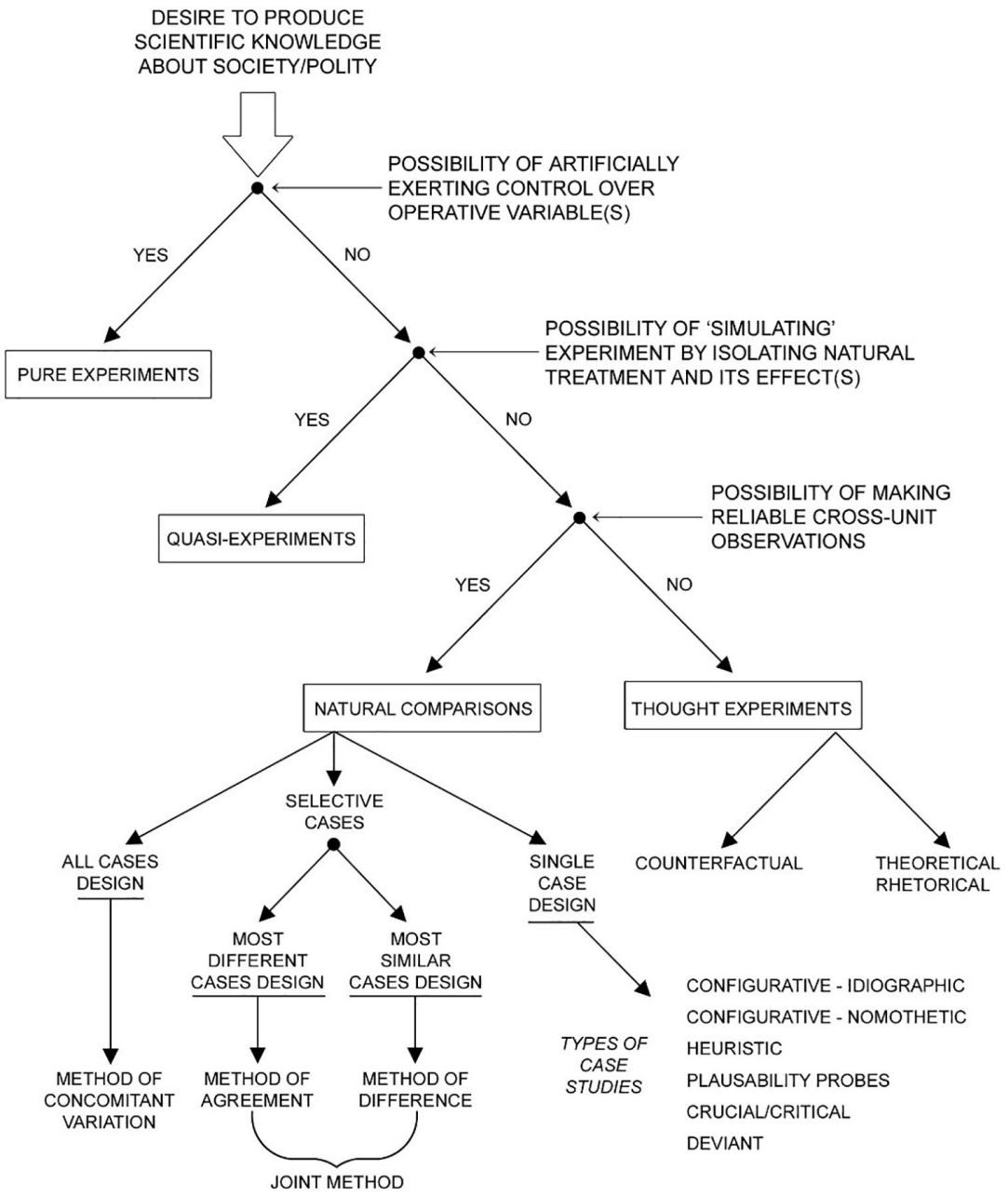

FIGURE 5.2 A Schematic for the Selection of Cases. 
tend to be so trivial and the settings so artificial that projecting inferences based on such findings to more "realistic" contexts is very hazardous. ${ }^{11}$

Quasi-experiments may be second best, but they offer some interesting advantages, both with regard to the efficiency of research and to the credibility of inferences. The case-base can be as low as one, although it is better to replicate the quasi-experiment in several other settings and, if possible, within the same timeframe. They are, however, limited to real-world situations where the independent variable is highly discrete and temporally circumscribed and where data-gathering over a sufficient prior period of time has been consistent and reliable. Assessing the effect of a new public policy or the impact of some unexpected social or natural event tends to fit this narrow bill of particulars, but only if nothing else of similar significance is happening to the unit or units at the same time. This is also a strategy of case selection that is especially vulnerable to diffusion or contagion effects, if the units involved know of each other's behavior.

Most political scientists will have to settle for the study of variations in their subject matter that appear "naturally," whether within a single case or across different numbers of them. There are, we would add, a number of other alternative strategies that are not usually included in texts on research methods or design - presumably because their scientific status is dubious. They typically arise in contexts in which it is risky or impossible to observe and record the behavior of "real-existing" units. All involve what Max Weber once called "thought experiments." The best known goes under the rubrique of counterfactualism and involves the researcher in an effort to imagine what would have happened to the topic if some condition, person, event or process had not been present. Usually, this focuses on a single country - e.g., how would Germany have evolved politically if Hitler had not been "available" in the early 1930s. But it can also be applied to a sample or even the universe of cases - e.g., what would be today the level of international insecurity in Europe if the EU did not exist? or, how many people in the world would know how to speak English if the Americans had lost their Revolutionary War? If this sounds "exotic" and a bit "flaky," researchers should remember that every time they invoke that famous and indispensable Latin phrase ceteris paribus before advancing a hypothesis, they are guilty of "committing" counter-factualism.

Moving even further from politological orthodoxy, one finds a vast number of seminar exercises, MA papers and $\mathrm{PhD}$ dissertations that are essentially rhetorical, theoretical or normative. These certainly deal with substantive topicsoften more important ones for "real-existing" societies and polities than those chosen by empiricists-cum-positivists - but their purpose is to follow the development of concepts or discourses over time, or to examine the logical 
consistency of particular arguments, or to promote the ethical acceptance of specific forms of human behavior. Should we conclude that these projects do not involve research - even though it is not uncommon that works of this sort have only a "heuristic" and "nomothetic" way of influencing eventual empirical inquiry? We think not. Just think of the impact of recent works by John Rawls, Jürgen Habermas and Jon Elster, or older, classical ones by figures as different as Jeremy Bentham and Karl Marx, upon how even the most "hardcore" empiricists select and conceptualize a wide range of topics.

\subsection{Proposal Writing}

This stage in the research cycle may be "optional," although highly desirable in our opinion. Different graduate programs place greatly different emphasis on the importance of defending a formal proposal before one's research committee, faculty colleagues, student peers and/or all of the above. ${ }^{12}$ Some MA and $\mathrm{PhD}$ advisors are keen on requiring it before allowing the candidate to "go into the field." Our personal experience suggests that the greater the plurality of approaches or paradigms surrounding a given topic and present in a particular institution, the greater will be the emphasis on writing and defending a proposal. In scholastic contexts dominated by a single theoretical or disciplinary orientation, the effort may be eschewed completely. The reigning orthodoxy favors problems rather than puzzles and may even dictate in considerable detail how topics should be conceptualized and operationalized. At the extreme, there is no "field" to go to, no specific cases to select and no measurement details to discuss. What matters at this stage is the normative or logical consistency of the "argument," i.e., of one's conceptualization of the topic, and how well it conforms to prevailing orthodoxy. The number and identity of cases are relatively unimportant, if not irrelevant, to the extent that both prior axioms and subsequent expectations are believed to be universal. The data can be simulated or assembled from the usual sources for illustrative purposes. The eventual inferences are usually predictable and in line with original expectations. The fellow

12 Our experience may be emblematic of this sort of diversity. At the University of Chicago, PhD proposals were extensively (and often contentiously) discussed in a meeting of the whole faculty and then before a public composed of professors and fellow graduate students - as well as within the supervising committee itself. At Stanford and UCLA, the proposal was a purely private matter between the candidate and the committee. At the European University Institute, in addition to an internal discussion within the committee (admittedly made difficult by the requirement to have at least one outside examiner), each student's "June Paper" (a sort of proto-proposal) was used as part of the general evaluation process for passing to the second stage of the PhD program. At British universities, it is common for the dissertation proposal to comprise the major part of the would-be graduate student's application for admission in the first place. 
members of your "research club" will enthusiastically congratulate you on your cumulative contribution to knowledge. Practitioners of other disciplines and members of other clubs within politology may well yawn and declare that you have "re-discovered the wheel" or produced something utterly trivial. In other words, there are costs as well as benefits in belonging to an established and fashionable research tradition.

Another condition affecting the utility of proposal writing is its potentially critical role in obtaining research funding. Where such support is assured or not subject to competitive pressures, you may content yourself with a brief statement of intention. Otherwise, your ability to summarize coherently and justify convincingly in a formal proposal the design choices that you have made up to this point could make all of the difference in determining whether you will be able to carry out your project at all. Although it is not frequently discussed openly, this "commercial" aspect of proposal writing can also be a source of distortion when the preferences of the sponsor come to be anticipated in the proposal itself and you find yourself pandering to them by modifying the topic, changing its conceptualization, restricting the range of hypotheses and even selecting different cases in an effort to please the prospective sponsor. Needless to say, more experienced researchers soon learn how to "fine tune" their proposals to get support from donors and then go on to follow the course of inquiry they think will lead to the most compelling inferences. Fortunately, national or supra-national sponsors rarely control for conformity between proposals and the research actually carried out.

The "real" purpose of writing a proposal should be to give you a chance to sit back and reflect critically on the strategic choices you have had to make and to exchange these reflections with supervisors and peers before plunging into the inevitably messy and absorbing process of gathering data and trying to make sense out of them. There will almost certainly be subsequent moments of self-criticism and changes in the plan of action - see the remarks below ${ }^{13}$ on the importance of serendipity - but writing and defending a proposal at this stage offer a unique opportunity to "re-write" and "re-submit" before becoming irrevocably locked into a course of action.

\subsection{Operationalization of Variables}

In principle, the conceptualization of variables should be carried out beforehand and without regard for how they will be converted into indicators and eventually measured. There is a very good reason for this. What is of 
paramount theoretical importance is to specify clearly the condition or factor that is supposed be present in order to produce some anticipated effect - alone or in conjunction with other variables. Having previously and independently conceptualized the projection or puzzle in such a fashion should provide a strong incentive subsequently to specify the observations that need to be made in order to verify the presence, magnitude, direction or persistence of that variable. During the early stages of research, this means that you should adopt the attitude that all "operative" variables can potentially be operationalized - and later be prepared to compromise when you start looking for indicators in the real world.

In practice, unfortunately, anticipations of such difficulties do tend to intrude and can even inhibit scholars from using concepts that are known to be "impossible" to operationalize. Just think of indispensable political properties such as power, authority and legitimacy. Or, of social ones such as esteem, respect and trust. For none of them is there a standard and easily accessible set of measures. Even elaborate (and expensive) attempts to operationalize them based on "reputational" criteria from public opinion surveys have been problematic. And criticisms of these efforts become more insistent the more such indicators are stretched across countries and over time.

Another way of putting this dilemma is that there are bound to be tradeoffs that have to be made at this stage in the research cycle. The higher one's concepts are on the ladder of abstraction - and, presumably, the wider their prospective range of application - the more difficult it is going to be to make convincing empirical observations about their presence in a specific case or set of cases. Increase the number of units in your study - either of persons or organizations - and you are almost bound to run into additional problems with missing data and misleading indicators. Do not be afraid to make these tradeoffs, but do so self-consciously. And admit it when it is necessary to tell your reader-cum-critic when you are settling for a less satisfactory indicator or a less specific level of observation. Be prepared when necessary even to eliminate cases, but also be sensitive to how this may distort your eventual capacity to draw inferences. Those research sites where operational requirements are most difficult to satisfy are usually places where social and political behavior is the least "normal" (i.e., where Type One politics does not prevail) and/or where the regime is the least tolerant of multiple sources of information. Of course, excluding them from the comparative design will probably narrow the range of variation and reduce the eventual strength of associations, but that is a price you may just have to be prepared to pay.

The theme that haunts all aspects of this stage of the research cycle is validity. Do the observations you propose to make accurately reflect and, hence, capture the meaning of the concepts you have chosen to bear the burden of explanation? No matter how accurate the observations, how comparable they are across units or how replicable they turn out to be when another scholar 
makes them, if they are not valid, your research will have broken down at one of its most vulnerable points. You may well have discovered something important, and the associations revealed by your indicators might be incontrovertibly "significant," but you will not have proved (or disproved) what you initially claimed. Therefore, your eventual findings are irrelevant in the strictest sense. They will not tell you or the reader anything about the topic that you intended to work on - just something (perhaps, very interesting) about something else (unless you are prepared to rely on serendipity and re-conceptualize your entire project from its very origins).

\subsection{Measurement}

At this point in the cycle, your choices will be more or less dictated by the ones you have already made - whether you did so consciously in relation to the specificity of the your project or puzzle (as we hope was the case) or unconsciously by your having settled into an established research tradition. There is a good reason why one should let oneself "go with the flow" at this point. Using existing techniques of observation and indicators for variables not only saves a lot of time and anxiety, but it can also provide an element of internal "quality control" - provided, of course, that the measures used are valid. Successful replication of previous research is a very desirable result - and one that can be personally very reassuring. Inventing and applying a new indicator or, worse, a battery of indicators - especially to measure some frequently used variable requires an especially strong effort at justification and the expenditure of a great deal of time and other resources. And if one's finding is more original than replicative, the reader is likely to wonder: does it really improve our knowledge of the topic, or is it only due to the idiosyncratic change in measurement of the variables?

The discussion on measurement tends to be dominated by the distinction between quantitative and qualitative indicators - with a marked bias in favor of the former. There is no reason to be surprised by this since most methodology texts are written by quantifiers and they have convincing arguments in their favor. Numerical data are said to be more reliable, i.e., more likely to provide agreement among independent observers, more accurate, i.e., more likely to produce agreement across units, and more useful, i.e., more compatible with different ways of testing for association. Certainly, the social science disciplines have tended to assign greater "scientific status" to quantitative over qualitative research - and to reward its practitioners accordingly. In the pecking order among such disciplines, there is an almost perfect correlation between status (and salary) in academe and the use of numbers and equations.

This is unfortunate for at least three good reasons: (1) it has encouraged researchers to attach numbers to variables when the validity of their connection with the designated concept was dubious; (2) it has resulted in the exploitation 
of standard numerical indicators whose multiple components are often theoretically disputable and whose weighted combinations are poorly understood by those who use them; ${ }^{14}$ and (3) it has discouraged the innovative use of more direct and imaginative techniques of observation - precisely to capture qualities inherent in complex and contingent relations. True, one can assign a number to anyone and anything, but nothing guarantees that the assignment will produce relevant information. If these qualities are differences in kind (nominal) rather than in magnitude (cardinal or ordinal), then - whatever the rule governing their assignment - the number could well be a worthless piece of disinformation. What matters is how one has conceptualized the topic, not the allegedly superior virtues of one over another form of measurement.

Of all of the stages in the cycle, this is probably the one that is best suited for serendipity, i.e., for learning from the research process itself in ways that can feed back to your previous choices and lead you to the introduction of improvements in them before "path dependence" has completely taken over. At last, the researcher is in direct touch with the "real-existing" subjects/agents of his or her topic - having already spent much time wandering around making abstract "disciplinary" decisions. Depending on the method of observation applied, they may be talking to the researcher directly about their intentions and perceptions, and they may even have some opinions about what is being asked of them. Even if the research relies exclusively on secondary or publicly available sources, there can be "voices" in such documents that can speak in unanticipated ways. Of course, there will be a lot of sheer "noise" generated by the data, and that can be very confusing when juxtaposed to the relatively (and necessarily) parsimonious approach that was inevitably applied to the topic at earlier stages of the research. Nevertheless, it can be rewarding to one's eyes, ears and mind open for subtleties and surprises, and be amenable to introducing "course corrections" - even some that go all the way back to the boundaries initially placed around the topic or the core assumptions present in key aspects of the original argument.

\subsection{Test for Association}

By now, the researcher may have momentarily lost almost all strategic control over the project and, at best, should consult one among many texts on methodology to discover which among all of the verbal or mathematical, symbolic or numerical, parametric or non-parametric, deterministic or probabilistic,

14 The most obvious example of this is the extensive use of gross national (or domestic) product as a numerator. It is a "witches' brew" of components and assumptions that largely or completely ignores the economic contribution of unpaid labor whether by housewives, children, other relatives, "informal market" operators, "clients" and slaves. 
quantitative or qualitative devices that are available for testing for association best fits the data that has been gathered. ${ }^{15}$

Variables can be associated with each other in different ways. Typically, the politologist will be interested in direction (whether the fit is positive, negative or null); strength (how much one variable affects another); and significance (the likelihood that the fit could simply have been due to chance). Since the research will almost inevitably be "historical," the time, timing and sequence of how they fit to each other should also be important ${ }^{16}$ - indeed, these chronological dimensions often provide the basic orientation to how one's findings are presented and defended.

And the reason for this is that the most powerful means of testing for the fit among variables and, therefore, for presenting one's findings has long been, simply, to tell a believable story in chronological order. And there is no reason to believe that this is still not the case. Perhaps, within some highly professionalized niches in politology, story-telling is no longer regarded as acceptable. The occupants of these niches - not infrequently, Americans or those trained in America - have forgotten that their disciplines are profoundly and irrevocably historical. What counts is not just what happens, but when it does and in relation to what else has already happened or is simultaneously happening. Moreover, the agents themselves are not just passive recipients of "scores," but active and reflexive keepers of those "scores." They remember what they and their ancestors did in the past, and their preferences in the present are conditioned by this knowledge. In our opinion, no means of testing for such associations has yet been invented that can supplant or even surpass the chronological narrative in capturing these subtleties of time and timing, and in bringing simultaneously into focus the multitude of variables involved in the sheer complexity of most social and political phenomena. The narration of findings can, no doubt, be considerably bolstered in credibility by inserting quantitative tests about specific associations into the basic narrative. Cross-tabulations, rank-orderings, regression equations, factor- or small-space analyses, even mathematical models, can often be helpful, but primarily when analyzing topics that are heavily circumscribed in time and space and that can be separated into relatively simple and repetitive components.

Even politologists firmly entrenched in their respective niches and relying exclusively on quantitative data may find it occasionally useful to come up with a plausible story that places the associations they calculate and the

15 We especially encourage students to begin with the "Inter-Ocular Impact Test," which consists in simply eye-balling the data - scatterplots are especially useful for this - to form your own visual impression of what is going on among the variables and across the cases. Hidden in a general distribution, one can often find "clusters" or outliers that hint at some contextual condition that may even be contrary to the general trend.

16 See Section 2.7. 
inferences they draw in some chronological order. Narration can also serve to fill in the gaps between cause and effect by providing a verbal description of the mechanisms involved - especially when mathematical formulae and formal models typically treat such exchanges as taking place within impenetrable "black boxes." Hardcore quantifiers may scorn this as unscientific "journalistic babbling," but it can help place their quantitative findings in a "real world" context, which may, in turn, offer them their only outlet to a wider audience.

This explains why these more specialized "niche players" are often researchers whose findings circulate only among small groups of conoscenti and are utterly incomprehensible to outsiders. Presumably, there are those who regard such incomprehension as a proof of their success as scientists, but whenever politologists aspire to enlighten and influence wider publics, they will either have to learn how to narrate their findings or to hire someone else to translate the esoteric results of their tests for association into more intelligible stories.

\subsection{Causal Inference}

This is by far the most hazardous - and the most rewarding - of the stages in the research cycle. And it is the one in which the researcher will have the least disciplinary or academic guidance and, hence, the widest range of discretionary choices to make.

Many politologists will have exited the process before arriving here. They will have made their accurate observations, published their empirical descriptions and gone home. Others will have stopped even earlier, before having gathered any data, and left satisfied that they have advanced further the plausibility of an argument or helped to specify the universe to which it can be applied. Some will have gone further and proffered tests - numerical and narrative illustrating how frequently and strongly variables have been associated with each other. But they will have prudently refrained from trying to answer the two obvious questions that the complete research cycle is supposed to address: (1) the retrospective one of why and how did these variables combine to produce the outcome that was the topic of the research in the first place; and (2) the prospective one of what will be the consequences of this in the future and when will these consequences happen?

Consider, as an example, the current controversies over climate research. Do you think that, if climatologists and other scientists had merely filed reports demonstrating that temperatures have been rising across the planet and that various chemical substances have been accumulating in its atmosphere, there would have been much of a reaction? As far as we know, these facts have been accepted by all as uncontroversial. It was only when these researchers correlated these indicators and drew the inference that increases in them masked a causal relation that could not be due to chance or fate that things began to get stirred up. And when they attributed primary causation to factors related to human 
intervention in the form of "greenhouse gases" and, even more, when they began to advance threatening projections about what will happen in the future, all hell broke out!

Even setting aside the proposition that all social scientists have a responsibility for generating such controversy, they should at least feel a more modest responsibility for exploiting their data to the fullest extent possible, and that almost inevitably commits them to drawing retrospective and (sometimes) prospective inferences. Just think back to the number of occasions when you have read a report on extensive and expensive research and still found yourself asking the "why" and "how" questions at the end. Granted that this could be regarded as favorable by younger researchers since it means that there is a very considerable amount of un-exploited data out there just waiting for "secondary analysis" at low cost. Nevertheless, it is lamentable when the scholars who initially chose the topic, conceptualized it, selected the cases and gathered the data do not go as far as they could in drawing "grounded" inferences about the causality their work might have revealed. Politology manuals are full of sage advice concerning the limits of doing this. Not infrequently, teachers of graduate courses and dissertation advisors will revel in providing the student with egregious examples of researchers who exceeded the confines of their data or ignored the contribution of other variables, and, hence, made what proved to be erroneous statements about causality or consequence. ${ }^{17}$

The controversy that tends to dog most discussions about inference is generalizability. A cautious researcher who draws inferences from his or her findings that are restricted to the cases investigated and the time period covered is less likely to face much criticism - or to generate much attention from others. Specialists on the topic will, no doubt, have something to say about the validity of indicators, the accuracy of measurements and the appropriateness of tests for association - but it is not until you dare to generalize across temporal, spatial or cultural contexts, i.e., until you trample on someone else's turf, that you will be seriously challenged. No one likes to be told that his or her topic can be differently explained by someone intervening from another theoretical or disciplinary perspective. ${ }^{18}$

17 Blecher has noticed that the scholarship produced by politologists teaching at liberal arts colleges such as his own is more likely to ask the bigger "so what?" questions at the end, and in fact embed those questions from the beginning, because, compared with graduate students, inquisitive and more "naïve" undergraduates love to do so.

18 Beware, however, of the "Pago-Pago Ploy." For almost every convincing, wellresearched finding, there will be some unit - usually in some exotic or esoteric place which contradicts it and some scholarly specialist who will delight in pointing this out. In his work on Western European politics, Schmitter has found Switzerland especially useful for this purpose. He is grateful to his mentor at the University of California, Berkeley, David Apter, for having alerted him to this possibility. 
And there are good reasons for this. Although they may seem arbitrary or anachronistic (and some no doubt are), the lines of specialization built into different social science disciplines have served to enforce professional standards and preside over the accumulation of knowledge. Generalizations that are based on alternative conceptualizations and/or novel methods should be especially carefully scrutinized. Nevertheless, this is where the real scholarly excitement lies - where "seminal" contributions are to be made - provided the researcher is well prepared to face his or her critics.

Needless to say, the strategy of case selection will play an especially significant role in this regard. Single case studies are rarely convincing - even socalled "critical" ones. ${ }^{19}$ Large $\mathrm{N}$ studies should be less objectionable, were it not for the fact that many of their cases are dubious in terms of their (alleged) common capacity to act and the probability that behind any associations found in the whole universe, there are bound to be subsets of cases (regions?) where the fit differs considerably - and may even reverse itself. Middle-sized samples based on controlling for the "usual suspects" (geographic location, development, size, religion, cultural area) by their very nature inhibit further generalization, unless they are replicated for different samples. Indeed, replication can be a powerful weapon - and not just to the extent that other sets of cases or periods of time produce the same direction, magnitude and significance of association. If one can show that a reliable pattern holds at different levels of aggregation within the same sample, he or she will have added considerable compellingness to the inference that it is more likely to hold elsewhere.

The other critical factor will come from accusations of researcher bias, often alleged to be the product of the researcher's nationality, academic discipline or political, ideological or ethical commitments. It is only human to prefer to discover what one thought was there in the first place and, then, to extend that finding to other places about which one knows less. Most often, this can be attributed to a natural tendency to "over-observe" what the researcher expected to see and to "under-observe" variation that one's initial conceptualization was less prepared to encounter. In addition to this "Type One Confirmation Bias" - affirming the presence of what does not exist - you also have to guard

19 A "critical" case study is one that is chosen because it is most likely to confirm the hypothesis, such that if it is disconfirmed, the hypothesis is very unlikely to be true. Schmitter's dissertation research on interest politics in Brazil was an example of this. The country had a strong temporal coincidence between economic development and a diversity of social, ethic and regional cleavages that should have produced "pluralism" in its structure of organized class, sectoral and professional interests. When he discovered an alternative system that he called "corporatist" - persisting even during the period of post-war democratic politics (1945-1964) - this constituted a "critical" rejection of the then dominant "modernization theory." 
against "Type Two Errors" - affirming that some relation does not exist when it actually does. It is possible (if less likely) that in this instance - perhaps out of an abundance of caution or for some perverse personal reason - the researcher will prefer to reject his or her original hypothesis and, thereby, under-estimate the degree of association that actually exists. Whether the peculiarities of national cultures or academic disciplines have anything to do with either of these typical errors seems dubious to us, but there is no doubt that both exist.

The most secure way of guaranteeing enduring respect for the inferences the researcher has drawn from his or her research - and of securing one's place in the Pantheon of Notable Politologists - is to place them under the protection of a "Covering Law." This offers an explanation for a much broader range of social or political phenomena, e.g., the Darwinian "Law of the Survival of the Fittest." It should be widely, if not universally, accepted by the preceding Notables as "seminal" and, ideally, it should not be derived from the theory with which one started out. But even if the researcher does not make it to this imaginary Pantheon, his or her contribution to knowledge can still be significant and form part of a very rewarding career in academe.

\subsection{Evaluation of Results}

Once the researcher has arrived at whatever stage in the research cycle he or she has chosen as the point of exit, the next and final objective should be quite simple: to make oneself into the best possible critic of your own work. Begin by anticipating all of the potential objections at each of the previous stages. Where possible, return and enter appropriate corrections. Since this is often impossible, given the numerous and irreversible "path dependencies" built into the research cycle, signal to the future reader-cum-critics that you are aware of the potential defects and try to convince them that, regardless, these potential defects have not led to misleading conclusions or inflated claims. Above all, remind yourself right from the start that no research is perfect and all researchers make mistakes. Anyone who aspires to "commit" political research should have inscribed above his or her desk (or on their screen saver) the Latin phrase errare humanum est - "to make mistakes is to be human" - and recognize that to be a human being studying human behavior is to be doubly vulnerable to this maxim. Our overarching purpose in writing this chapter has been to help the researcher to become his or her own best critic.

\section{Conclusion}

Political research is characterized by the diversity of its concepts, theories, designs - and logics. Only a few intrepid researchers will work "around the clock" as shown in Figure 5.1 and conclude with empirically grounded 
inferences about causal relations among explicitly chosen and measured variables. Many will choose a topic for which this would be premature or inappropriate, given the existing state of the discipline or the purpose for selecting a particular topic. They may exit the cycle relatively early, sometime between one and three PM - with, we hope, an improved understanding of the generic relations involved and, possibly, with a more elaborate set of hypotheses for future research. Still others will be interested in drawing out the ethical and normative implications of these relationships, perhaps, by exploring analogies with previous experiences or prior philosophic assumptions. In Figure 5.1, we have labeled this point of exit as "the Logic of Discovery," the idea being that those who take it will have made their original contribution by discovering empirical or normative relationships previously ignored or distorted by existing wisdom.

From three to six PM, fewer social and political researchers will be leaving the cycle. ${ }^{20}$ Their distinctive contribution will have been to identify the apposite universe surrounding the chosen topic, to select cases that represent specified distributions of key variables and to have invented new ways of defining these variables and embedding them in more comprehensive theories. Most importantly, they will have carried further and in greater detail the existing conceptualization of the relationships surrounding their topic, hence the notion that they have followed a "Logic of Explication."

Many more politologists will exit after six PM and before nine PM. They will have produced research that is fundamentally descriptive in nature. Here, the preoccupation is with the validity of their measurements and the accuracy of their observations. They will have gone into the field - even if it is in their own backyard - and generated new data about social and political phenomena. They are also most likely to have contributed to the development of better instruments of observation and more reliable indicators.

The segment from nine PM to midnight may be where the ultimate pay-off lies - and certainly where the highest disciplinary status is usually awarded but only a select few make it to this stage in the cycle, and even their conclusions are always contingent upon eventual replication and critique by other scholars.

The reader should not be discouraged by this. To do original research on a topic he or she cares about is an adventure. It can lead in different directions

20 Unfortunately, many of them will be the so-called ABDs (All But Dissertations) who come up with a design for a previously conceptualized piece of research, could have written a proposal and may even have given some thought about operationalizing its variables. Some never managed to actually find the time, resources or energy to gather the relevant data, much less to write them up. Much more sadly, others have left the profession because their fascinating ideas and proposals were deemed too unorthodox by their professors; this, of course, impoverishes politology even as it harms some of its most original, critical thinkers. 
and end in different places. A lot will depend on the point of departure, but he or she will also be influenced at every turn by professors and peers - not to mention the fads and fashions present in the discipline. The most important thing is to be conscious and confident of the choices one has made, and then to know when and where to exit from the cycle. We hope that this chapter will make the voyage easier and, ultimately, more rewarding. 


\title{
6
}

\section{THE PURPOSE}

\begin{abstract}
Why bother with politology or political science? It has not always improved the practice of politics. It has repeatedly failed to keep up with changes in its subject matter. And it is probably the most difficult of the social sciences to do well. ${ }^{1}$
\end{abstract}

Part of the answer lies in our original description of the nature of human agency. We study politics simply out of our intrinsic curiosity and restlessness because it is a salient component of our environment. For a few, it may help them to adjust to that environment and - eventually - to improve it. For others, it is a fascinating activity in its own right. But from a strictly rational and material perspective, the effort is not worth it. Even if you make it your profession, you could probably become much richer if you spent the equivalent amount of time and effort studying something else. ${ }^{2}$

Historically, the purpose of studying politics comparatively was to explain divergences. Why did such different institutions and practices exist in units so similar and so near to each other? What was their concomitant impact upon different social groups and persons? The units involved - city-states, principalities, bishoprics, monarchies, confederations and, eventually, nation-states - had

1 Machiavelli observed that the best one could expect from the study of politics was to be right $50 \%$ of the time. Would economists, anthropologists, sociologists or psychologists be content with such a modest "box score"?

2 Political science is often one of the most popular majors for undergraduates in American colleges and universities. However, the reason for this is quite often because students think, erroneously, that it provides the privileged gateway to a career that promises much greater rewards, namely, law. 
manifestly diverse origins and resources, and this was presumed to be related to their capacity to govern, to protect and reward their citizens/subjects, or even to survive. While there are still plenty of differences between nominally sovereign units to explain, the focus of politology in the future may be (at least, partially) inverted. It will increasingly be called upon to explain similarities. Why is it that, having such different origins and institutions, so many of today's polities are becoming more and more alike? Admittedly, they are doing so at a much increased pace compared with the very long history of divergence (and there are more than a few polities that remain outliers, although less so over time). This trend toward similarity seems to lie in massive increases in functional interdependence and ideational diffusion, the emergence of supra-national regional organizations and, almost everywhere, the intervention of global inter-governmental organizations and multinational enterprises. Historically, the major impetus was war. After each violent conflict, the victor would try to impose its political institutions and norms on the vanquished. Whatever the causes, explaining and understanding convergence will become a more salient objective than in the past.

From its origins, the study of politics has claimed to improve the practice of politics. When it initially became a recognized specialization within the organizational structure of a few European universities - apparently, first in Sweden and Finland - its purpose was to improve the quality of administration and the legitimacy of monarchs. In the US, where it flourished in the early twentieth century, it was firmly linked to liberal democracy via the so-called "Progressive Movement" which opposed the corruption of machine politics and the rapaciousness of unregulated capitalism. This positive orientation toward promoting change did not last long. After World War I - in the 1920s and 1930s - its practitioners became preoccupied with preventing fascism and communism from destroying "real-existing" liberal democracy, not improving it. After World War II, when faced with the expansion of state socialism in the East and the uncertainties generated by the liberation of so many countries from imperialism in the South, politology became literally obsessed with stability, based both in the hegemony of liberal democracies and the survival of capitalist economies. It was not enough just to promote the generically human objective of "domesticating" the use of violence. The discipline became committed to protecting the status of particular persons, parties and governments all incumbents in one sense or another. Much of its success (and its funding) during the 40 years or so after World War II was dependent on this effort - and this was reflected in its dominant theories, assumptions and concepts.

Today, politology is changing. For several decades now, it has been fighting off a challenge within its American ranks to convert the entire enterprise into a subfield of economics. These advocates of "rational choice" would have stripped politics of its components of collective passion and conviction, reduced its motivational structure to the marginal pursuit of material interests exclusively by individuals, converted politics into a form of routinized consumption 
between competing "brands" of politicians or policies, and treated its institutions as if they embodied voluntarily established, stable equilibria (rather than the outcome of differences in social power, the capacity for public sanction or the manipulation of information). In our view, this struggle is over - helped, we admit, by the concomitant collapse of the plausibility of many of these assumptions within the would-be "mother" discipline of economics. ${ }^{3}$

Politology is also coming to terms with changes in the very nature of its subject matter. It is highly likely that the practice of politics has changed during the time it took for us to write this essay (and, maybe, for you to read it). The threat of communism has evaporated, the prospect of an anti-capitalist revolution as well. Many polities are attempting to democratize themselves. Some that tried seem to be reversing course. New units with limited sovereignty (but still significant competences) are emerging beyond and beneath the traditional nation-states at the same time that so-called "failed states" have been threatening radically to disrupt the status quo.

Meanwhile, those paragons of previous virtue, the "well established, realexisting democracies" upon which so much of the discipline has based its theories, assumptions and concepts, have been entering into levels of crisis not experienced since the 1930s. The paradox of these times is that, precisely, when so many aspiring neo-democracies have emerged to the South and East, the archeo-democracies of the North and West have become less stable. Their citizens started questioning the very same "normal" institutions and practices that new democratizers were trying so hard to imitate. And they tended to find them deficient, not to say, outright defective. The list of morbidity symptoms is well known (if not always well understood): citizens in REDs have become more likely to abstain from voting, less likely to join or even identify with political parties, trade unions or interest groups, much more likely to distrust their elected officials or politicians in general, and much less likely to be satisfied with the way in which they are being governed and the benefits they receive from public agencies. One clear response has already emerged: voters in national elections have demonstrated an unprecedented propensity for volatility in their behavior and, hence, for throwing incumbents out of office. Historically, REDs were built upon competing hegemonic parties that ruled for long and consistent (if occasionally alternating) periods of time. Now, there are few ruling parties and mainly just temporarily governing ones. Moreover, citizens have shifted an increasing proportion of their votes to fringe, so-called "populist," parties of either the Right or Left. They are the side-product of systems of sclerotic and oligarchic political parties that have become incapable of representing existing citizen preferences or of articulating alternative and

3 And by the subsequent rise of "behavioral economics" that recognizes quite explicitly the implausibility of the ultra-rationalistic assumptions that had taken over the previous neo-liberal version of the discipline. 
credible future projects for the polity as a whole. ${ }^{4}$ Most populists are not so much anti-democratic as they are differently democratic, usually less politically liberal, sometimes "supra"-constitutional, and very often economically imprudent. Even when they do not succeed in occupying governing positions, they can push more established, centrist parties into adopting items from their platforms, thereby making increasingly difficult the formation of coalition governments. The formal procedural attributes of REDs - regular, fair elections; party competition; parliamentary autonomy; freedom of association and petition; freedom of the press with alternative sources of information; public justification and transparency of rulers; independence of the judiciary - seem to be assured in most cases. It can less and less be taken for granted that these institutions will be capable of holding elected rulers and their appointed officials accountable for their actions in the public realm. Previously, elections became dominated by "centrist" parties (even as the center of gravity has moved rightward) that agreed with each other on most issues; and in reaction to this, new "populist" parties have emerged on both the Left and Right fringes of public opinion; parliaments have lost authority with regard to executive and so-called "guardian" institutions; the press is more and more owned by large corporations, even multinational ones; transparency with regard to policies and their consequences may have increased, but public justification has often given way to "spin-doctoring." As a result of this menacing combination of factors, more and more citizens do not believe that their rulers are listening to them, but are acting in response to forces, especially transnational economic ones, they cannot understand or control. "Real-existing" democracy will probably survive this combination of challenges. It has done this several times in the past. But it will have to change in order to do so. And, in response to these changes, so will politology have to change if it is to remain (more or less) the same. ${ }^{5}$

Ditto autocracy. While in recent decades quite a few civilian and military dictatorships have transitioned to RED (and some haven't), most former state socialist countries of Russia, Eastern Europe and Central Asia have moved toward democradura (or is it dictablanda?). ${ }^{6} \mathrm{~A}$ handful of still-extant ones retain monopolistic rule by Leninist parties, but, except for North Korea, they have relaxed some of their "totalitarian" features: China has convened local elections (the study of which has attracted lively attention from democracy-minded politologists specializing not just on China) and established (but now revoked) term limits for its top leaders; media has been diversified and even privatized, even as

4 The Italians (who have suffered most from it among REDs) have come up with a word for this: partiocrazia.

5 We are, of course, paraphrasing here the famous maxim - "everything must change so that everything can stay the same" - of Giuseppe Tomasi di Lampedusa in his novel The Leopard, trans. Archibald Colquhoun (New York: Knopf Everyman, 1991).

6 See page 62 for the distinction. 
ministries of propaganda have both struggled to maintain the boundaries of expression and used digital platforms to monitor their subjects; critical literature and art have been allowed to develop within ill-defined, shifting boundaries; a limited space has been opened up for what many Western-oriented politologists have rushed to call "civil society" in the form of citizen-initiated nongovernment organizations (NGOs) so long as these outfits register with and report to the relevant ministry, ${ }^{7}$ as well as the bizarre Chinese mutant known as the "government-organized non-government organization" (GONGO); protests have been tolerated and the overall balance in the régime's strategies of rule has tilted slightly to downplay coercion (and threats of same) in favor of ever more technologically sophisticated modalities of surveillance and persuasion. The field here is dynamic and variegated. Politologists hailing from and/ or working on these countries are trying breathlessly to keep their analyses abreast of such developments with theories of "fragmented authoritarianism," "authoritarian resilience" and new, as yet ill-conceived, forms of intra-party pluralism and democracy. Many of those coming from the state socialist survivors are proud that their régimes, however autocratic they remain, have used their capacity to address urgent problems of human material welfare that are increasingly eluding the REDs.

In somma, politology seems headed for an uncertain and exciting future when it will have to devote more effort to dealing with change and similarity rather than explaining (and extolling) stability and difference. Fortunately, it will be ably assisted in this effort as more and more of its practitioners will be coming from the East and South where such conditions and expectations are hardly novel.

7 This very requirement as well as the Communist Party's strict commitment to monopolizing political space call into question the applicability of the concept of "civil society" to China - an example of how politologists' own political commitments and standpoint can influence their analysis. 


\title{
7
}

\section{THE PROMISE}

\begin{abstract}
In this chapter, we will attempt to summarize the basic assumptions and arguments of the book with the aid of a graphic that brings together two rather unlikely collaborators: Niccolò Machiavelli and David Easton.
\end{abstract}

Essays such as this one cannot have a conclusion. As the French etymology (essai, from essayer - to try) of the term connotes, they are tentative attempts to understand something, not efforts to prove something conclusively. Their intent is to provoke thought, not to preempt it. Moreover, writing about politics is like politics itself; it never ends and changes frequently. We look forward to your endless disagreements with and improvements on what we have argued.

In Figure 7.1, we have attempted to display graphically the basic assumptions and structure of our essay-cum-book. ${ }^{1}$ Its external parameters have been given to us by Schmitter's former neighbor in Tuscany, Niccolò Machiavelli. The outer shell is formed by necessita - the necessity of responding to the inevitable conflicts of interest, passion, conviction, habit and fear that plague all societies and compel them to engage in politics in order to preclude or to prevent these conflicts from destroying the collectivity, along with its productivity and identity. This effort at domesticating the exercise of power is continuously threatened from above by fortuna - the occurrence of events and conjunctures that could not have been foreseen - and from below by the exercise of virtu - the capacity of agents to understand these situations of conflict and to respond appropriately.

1 We are indebted to an anonymous referee of an early version of this manuscript who suggested that this would be useful to the eventual reader. 


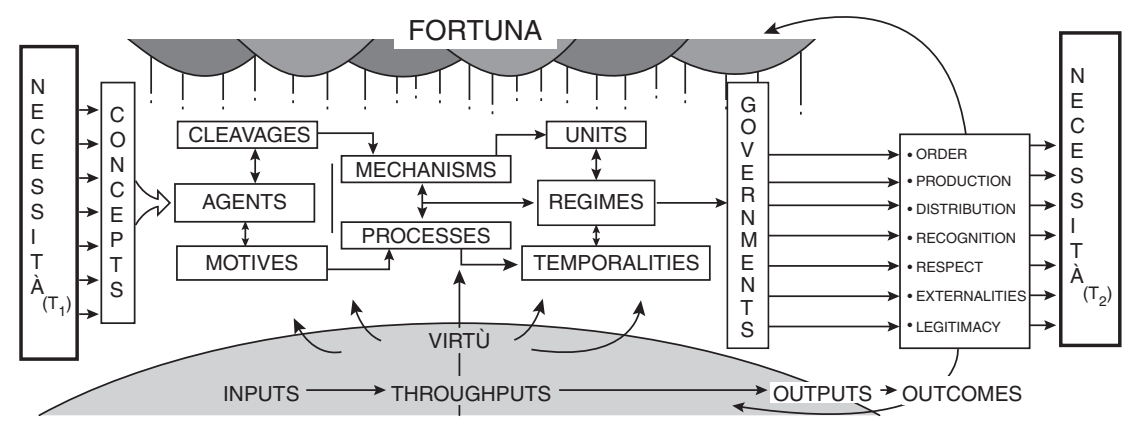

FIGURE 7.1 Politics as a Science: A Schematic Fortuna.

Its internal dimensions are structured according to a continuous and circular process of converting conflicts of various types (inputs) through some set of ad hoc arrangements or relatively permanent institutions (throughputs) into a pattern of responses that interact with the environment (outputs) and that produce consequences (outcomes) which may or may not have been foreseen and may or may not succeed in reproducing the previous arrangements or institutions. ${ }^{2}$

Politics itself begins with concepts. These serve a double need: (1) they are supposed to identify and label what is happening in ways that are intelligible to subjects/citizens; and (2) they are required by the agents involved to communicate with each other and to discriminate between supporters and opponents. This is another way of saying that political concepts are intrinsically controversial - both for those involved and for those studying them. However, any science of politics requires its own vocabulary. Its concepts may be written or spoken, precise or "fuzzy," theoretically grounded or circumstantially invented interpretations of the "necessary" environment from which conflicts emerge and of the responses, motives and cleavages of the agents affected. These politological concepts are attempts to capture the generic nature of what is happening so that any eventual explanation or understanding is not just empirically descriptive of that particular instance and place, but is potentially applicable to other, presumably analogous, instances. ${ }^{3}$ As we noted earlier, this is often a subject of confusion since many of these concepts may be identical with those used by the agents themselves.

2 We owe this "systemic" perspective to our former colleague and mentor at the University of Chicago, David Easton.

3 This may help to discriminate between those scholars who dedicate their efforts to understanding the peculiar properties of an individual country or region and those who aspire to explain what is common to, or different from, the behavior of many countries or regions. Both are capable of making significant contributions to knowledge. 
Agents discover and interpret the world of necessity that surrounds them by "consuming" (and sometimes inventing) words, and may be motivated sufficiently by them to act - although, as we noted, even those who do not react can still have an impact on the eventual output and outcome. Their calculation depends on some mixture of their previous perceptions and strength of cleavages (especially, along the antonymic lines of "friend vs. enemy"), their immediate intensity of motives (which may not always be coherent) and their estimation - (again, not necessarily explicit or coherent) - of the potential risks and benefits involved. ${ }^{4}$

At this point, a critical disjuncture arises which is not captured by the schemata. As we noted at the beginning, there are two presumably radically and generically different types of politics. In the orderly world of Type One, the agent already has some knowledge of the way in which conflicts are processed and can choose between pre-existing mechanisms and processes with some expectation about how he or she will be treated and what may contribute to eventual success. In Type Two politics, these either do not exist or are so unreliable that the choice cannot be made, and some sort of improvisation (usually involving violence or the threat of it) would be the probable reaction. Again, as we noted earlier, at a certain point in the text, we switched to an explication that presumed the prior existence of mutually recognizable (if not always legitimate) institutional settings and rules of the game (Type One).

This leads the analyst to considering three highly interrelated dimensions of political action: (1) in what type of régime are these mechanisms and processes embedded; (2) what kind of unit is placing territorial or functional boundaries on its politics; and (3) what sort of temporalities are affecting the rhythm and urgency of its decision-making.

From these three conditions emerges what is usually the central concern of most politologists, namely, a sub-set of agents who have acquired the capacity to exercise power over all others within the unit and for some period of time, i.e., a government. Its authority may be accepted as legitimate by its citizens or rejected by its subjects, but in all Type One cases, it is capable of prevailing continuously - at least until a rebellion or revolution displaces it and ushers in a period of Type Two politics. If the régime is democratic, the government rules pro tempore et pro legge - at least most of the time. If it is autocratic, it usually governs ex tempore et ex legge, but there exists much more variation among these governments than among REDs, whose institutions and practices develop from a well-known and fairly standardized playbook.

4 It may be convenient to assume "rationally" that agents have a fixed hierarchy of preferences and prioritize their responses accordingly. In the real world of politics, not only might the hierarchy be contingent on who is making the appeal, but also on the possibility that many preferences are incompatible - or, to use the vocabulary of "pluralism," that they may be "cross-cutting" and, therefore, conducive to inaction or moderation. 
Governments take decisions that have consequences. ${ }^{5}$ Some of these are intended, others not so. But, they are almost always consequential and, hence, provoke reactions, which accounts for the basic circularity of the political process. Needless to say, the purpose of most of those agents in government is to reproduce the existing régime and, even, their privileged positions within it - again, presuming that we are talking about Type One politics when they are more likely to succeed. We have suggested seven generic types of consequence: (1) Order; (2) Production (and Reproduction); (3) Distribution (and Redistribution); (4) Recognition; (5) Respect; (6) Externalities; and (7) Legitimacy. The list is by no means definitive. Despite the ideological entreaties of liberals and, even more, of neo-liberals, governments are constantly inventing new objectives - and the environment of necessità is inexorably generating new challenges. Fortuna plays an important role in this, as does the virtù of agents - in power and out of power.

Politics has become, and seems likely to continue to become, more variegated, complex, fissiparous, multi-layered, polycentric, penetrated by exogenous forces ${ }^{6}$ and, hence, unpredictable. The practice of politology does follow (and should incorporate) changes in "real-existing politics," but it has always done so with a considerable delay and often against entrenched professional (and political) interests. It has become a globalized discipline, even as most of its practitioners

5 There is something missing here - deliberately. An entire literature has developed in the academic discipline of political science around the concept of policies. It has even been baptized as a distinctive science that presumably has a logic independent from that of the politics that precedes and succeeds it. We have chosen to ignore it on the grounds that not everything governments do involves deliberate policies (and non-policies) and that the separation this implies between politics and "neutral" or "mere" administration seems artificial and, indeed, spurious to us. For a contrary affirmation that "policies make politics," coupled with an influential typology of policies, see the article by Theodore Lowi, also our colleague and mentor at the University of Chicago: "American Business: Public Policy, Case Studies, and Political Theory," World Politics XVI, no. 4 (1964): 677-715. In a very different theoretical and analytical register, few propositions about socialism have attracted more derision than Engels' infamous assertion that the triumph of the working class would end politics and the state, replacing them with the simple "administration of things." Robert Tucker, ed., The Marx-Engels Reader (Amazon Digital Services, 2018), Location 15273.

6 We have argued earlier that among the most important generic changes that have occurred in recent decades is the spread of "complex interdependence." Many anomalies and unexpected political outcomes can be traced to its influence. There is absolutely nothing new about the fact that formally independent polities have extensive relations with each other. What is novel is not only the sheer magnitude and diversity of these exchanges, but also the extent to which they penetrate into virtually all social, economic and cultural groups, and into almost all geographic areas within these polities. Previously, they were mainly concentrated among restricted elites living in a few favored cities or regions. Now, it takes an extraordinary political effort to prevent the population anywhere within national borders from becoming "contaminated" by the flow of foreign ideas and enticements. "Globalization" has become the catch-all term for these developments, even if it tends to exaggerate the evenness of their spread and scope across the planet. 
have remained national, if not provincial, in their origins and their approach to it. It will increasingly demand different and more challenging kinds of thinking from scholars who can work both as foxes and as hedgehogs, who study different polities in ways that increasingly cross the standard sub-disciplinary lines, ${ }^{7}$ and who hail from and spend much more time in many more places. Politology needs to get more difficult, more flexible and more cosmopolitan.

And it needs to focus more on substance - on what it is that agents are struggling over and what are the consequences of their action and inaction. Graduate students have found themselves in more and more seminars on methods, and fewer and fewer ones on substance. That has impelled some of the best, brightest, most heterodox and therefore most urgently needed ones to desert the field in disgust or disinterest (leaving it as well as them poorer for their absence). ${ }^{8}$

Politology must, of course, remain methodologically self-conscious, especially since its methods must change to adapt to the newly "de-centered" political environment it interrogates. The time-tested scientific formula of disaggregating complex phenomena, measuring their components precisely, analyzing them separately and then recombining them synthetically in order to arrive at convincing findings about the behavior of the whole will become less and less productive. Yet, in light of the burgeoning fluidity and feedback loops of politics, this approach could become more useful if it were deployed in the service of dialectical rather than causal/directional analytical modeling. ${ }^{9}$

Also dubious are growing efforts by political scientists to replicate the second time-tested formula of the physical sciences, namely, experimentation. This can lead to findings that are "internally valid," but also of limited significance even to the case at hand ${ }^{10}$ and still less to the production of "external

7 Blecher has a former student who has been doing fascinating graduate work at a top American political science department in an interstice of comparative politics and political theory. He has foundered because the theorists on his faculty looked down on him for being a comparativist, and the comparativists thought him too much of a theorist.

8 Blecher knows another brilliant young man who studied for his $\mathrm{PhD}$ at a top American department. He took a seminar on "Business and Politics." Bewildered, halfway through he finally asked when the class would be taking up the many fascinating, important questions of the relationship of business and politics. The answer came: "Oh no, that's not what we're doing. This is a seminar on the methodology of principal-agent analysis and the theory of the firm." Dispirited by repeated bouts of such hyper-methodologism and rationalism, and sadly for politology (and for him), he left the field.

9 After all, dialectics also decomposes a thing into its (opposing) parts, studying them separately, and then recombining them into a whole whose inner logic is presumably more fully revealed for having done so.

10 In the sense that replications are likely to produce the same empirical results, but only provided that the subjects of the research have been randomly selected from the same population, exposed to the same "treatment" and then compared to some control group that has not been treated similarly or given some other treatment. If one does not randomize, the subjects of the experiment are likely to have some characteristics in common other than the one specific source of variation that is being introduced, and validity problems will immediately rear their ugly heads. 
validity" - i.e., capacity to shed light beyond $i^{11}$ - both of which are essential to grasping politics' increasing complexity. Both the mechanical combination of discrete components and the arithmetic sum of individual responses to experimental treatments can certainly achieve some limited, but still scientifically significant, results. Leaving the analytical model or the lab for the real world of politics with all of its layers and angles may well produce different (but more politically significant) ones. As the world of politics is becoming more and more complex, there will always be a place for the former, but we will need a lot more of the latter.

From our perspective (paraphrasing Aristotle's), this "(unfortunate but fascinating) imprecision in the class of (political) things" should make students of politics wary of applying the exacting standards of the natural sciences to their research. Bismarck famously described politics as "the art of the possible" - ergo not "the science of the probable or of the inevitable."12 We must confess that we have never considered ourselves primarily as scientists. Our experience has been closer to that of artists. ${ }^{13}$ Scientists are confident that their observations are accurate, valid and definitive, in conformity with reality, and conclusive in the sense that other scientists gathering and manipulating data on the same subject would always arrive at similar (if not identical) conclusions. We have never had that sort of confidence in what we have contributed. An artist is always aware that he or she can never completely grasp and represent reality least of all, condense it into a parsimonious formula, measure it numerically and calculate the significance of its relationships. ${ }^{14}$ And we have never believed

11 First, the replication crisis in the social sciences (and even medicine) calls the whole enterprise profoundly into question. But even setting that aside, the "external validity" of such experiments can be called into question in two senses: (1) Would the findings also be valid for a random sample from a culturally, economically or socially different population in a different political unit?; and (2) Would they remain valid if the individuals involved were gathered into political groups of a larger and larger scale? The first is known in the jargon of the social sciences as the "problem of generalizability"; the second as the "fallacy of aggregation." In other words, transferring the laboratory to another country (or even another unit within the original country) is very likely to result in different (but equally "scientific") results.

12 Every department, institute or faculty specializing in the study of politics should have (symbolically) chiseled above its entry the Latin phrase: Quis custodiet ipsos custodies: Dependet ("Who Guards the Guardians: It Depends") to remind those who enter the discipline that whatever they find out about the exercise of power, it will be contingent, spatially and temporally, on factors that they may or may not have considered. Nothing is likely to be true always and everywhere, and it is one of the researcher's tasks to extend his or her purview laterally to take these contextual limitations into consideration.

13 When Blecher's department changed its name from "Government" 25 years ago, it specifically rejected "Political Science" on the grounds that the discipline and its subject matter are arts as well. He recalls a slogan on a lapel button he received from one of his students who attended Cornell (where it's still "Government"): "Don't Confuse Politics with Government."

14 Although we must confess to having gathered quantitative data, crunched numbers and estimated the magnitude and significance of correlations from time to time. Schmitter 
in, used or sought to develop universally generalizable laws or even tendencies. $A u$ contraire, we have always, perhaps a bit perversely, found ourselves far more intrigued by "outliers." 15 The best one can do is to produce an approximation or impression of what is an inevitably complex and contingent process of action and reaction whose results are always ephemeral and, then, to attempt to communicate this to others in the form of words which are also only imperfect approximations of reality. ${ }^{16}$ An artist also tends to produce corrections to what he or she has written (or painted or said), and that we have been frequently compelled to do. ${ }^{17}$ As self-serving as it may sound, we believe that the study of contemporary politics has too many aspiring scientists and not enough aspiring artists. As an academic profession, it is unfortunately rigged to reward the former and to discredit the latter. It needs both.

This may explain our predilection for the (over-?)use of "ideal" types in this essay. It constitutes our recognition (however imperfect) that political reality is composed of complex relationships and institutions that can only be captured

even taught Blecher in a course on "Aggregate Data Analysis." This is (unfortunately) still a professional imperative in order to be taken seriously as a "card-carrying" political scientist, though we like to believe that we have done so for better reasons having to do with the value and validity of such methods to attack certain kinds of questions, especially where a particularly interesting trove of data presented itself. We have even done this recently: Carsten Schneider and Philippe C. Schmitter, "Liberalization, Transition and Consolidation: Measuring the Components of Democratization," Democratization 11, no. 5 (2004): 59-90; and Philippe C. Schmitter (with Arpad Todor), "Varieties of Capitalism and Types of Democracy," unpublished essay, (forthcoming); Marc Blecher and Daniel Zipp, "Migrants and Mobilization: Sectoral Patterns in China, 2010-2013," Global Labour Journal VI, no. 1 (January 2015): 116-126.

15 In Schmitter's aforementioned course on aggregate data analysis, he once sketched a scattergram and its regression line on the blackboard and asked the class to reflect on its usefulness. After Blecher and the other eager graduate students flailed around for a while, Schmitter circled a dot way off in the corner. "That's the one to write your dissertation on!"

16 This reminds Schmitter of an incident at a conference in São Paulo during the very lengthy transition of Brazil from autocracy to democracy. He was asked by an impudent student in the audience: "How would we Brazilians know when our democracy has been consolidated?" After some embarrassing hesitation, Schmitter replied: "When your politics becomes boring!" Some six months later, when participating in a seminar in Santiago, he saw a headline in El Mercurio: "Elecciones Municipales: Casi Aburridas!" - the local elections were "almost boring" because they had turned out more or less as predicted. His immediate reaction was "Chile has made it! And so much faster and less ambiguously than Brazil!"

17 Looking back at what we have written, we discovered our frequent (some will say, excessive) use of dialectics as a rhetorical and even analytical device. We have repeatedly placed two (or more) concepts in juxtaposition to each other with the implication that they constitute a dilemma, i.e., that they are in conflict and that political agents will have to choose between them or come up with solution that includes some of both. We also discovered that we are addicted to the use of parentheses (parenthicitis?) and overly long sentences with multiple subordinate clauses to supplement or qualify our arguments. We leave it to the reader to decide whether these are accurate reflections of the nature of the subject matter or just stylistic quirks on our part. 
with concepts composed of a multitude of (presumably) covariant conditions. A student once complained to Schmitter that his definition of corporatism contained no less than 14 variables! He was a bit embarrassed by this revelation until he discovered Austria, which almost perfectly fit his ideal-type. All of the other so-called "neo-corporatist" systems of interest intermediation in Western and Southern Europe lacked one or more of its conditions. The definitions of other key concepts in this essay may be somewhat less prolix, but they do represent our effort at trying to seize the complexity of contemporary politics - with all of the attendant problems of comprehension and measurement.

Reflecting in a concerted and cumulative way on the nature of politics, as distinct from merely recording the content of its laws or relating the feats of its leaders, started under very peculiar circumstances in a very specific setting and we are still indebted to this effort by our Greek predecessors. From its heartlands in Western Europe and North America, politology has subsequently spread to virtually all corners of the Earth. New ideas, concepts, methods and even basic assumptions are now coming from a much wider range of sources and sites. Political scientists are also being employed in a much greater variety of places outside of academe.

What has politology contributed to the practice of politics? It certainly is not the case that the former has been uniformly successful in improving the quality of the latter. But it has made some observable improvement in some cases $^{18}$ although it would be an exaggeration to claim that politicians who have been trained as political scientists have done a better job at practicing politics than others. The best one can expect is that politologists will be able to describe accurately and explain convincingly what has happened in the past, estimate the probable occurrences and outcomes that are happening in the present, and, maybe, imagine or, if we are lucky, occasionally project (if not predict) what could happen in the future, at least for the benefit of the citizens/subjects striving to live within, endure, understand and even participate in politics, and perhaps also for those who strive to lead them.

It has been a privilege to have played a modest role in this reflexive process. More than occasionally, it has even been very good fun and downright exciting. And as the pace of political change is accelerating and entering ever more uncharted territory, politology seems set to become even more exhilarating and absorbing.

18 At a seminar at Wits University in Johannesburg, Schmitter was approached by a representative of the African National Congress (ANC) who explained that he had been asked by Nelson Mandela to thank him and his co-author, Guillermo O'Donnell, for their "little green book" which apparently had been smuggled into his cell on Robbin Island. He claimed that it helped to convince him that a peaceful and negotiated transition from autocracy to democracy was possible. 


\section{REFERENCES}

N.a. "Laughing at Power." The Economist (October 22, 2014). https://www.economist. com/prospero/2014/10/22/laughing-at-power; accessed November 29, 2018.

Almond, Gabriel and Sidney Verba. The Civic Culture: Political Attitudes and Democracy in Five Nations. Princeton, NJ: Princeton University Press, 1963.

Aristotle. The Nichomachean Ethics. Translated by W. D. Ross. Lawrence: Digireads, 2009.

Armony, Ariel. The Dubious Link: Civic Engagement and Democratization. Stanford, CA: Stanford University Press, 2004.

Bachrach, Peter and Morton S. Baratz. "Two Faces of Power." American Political Science Review 56, no. 4 (December 1962): 947-952.

Bartels, Larry. Unequal Democracy: The Political Economy of the New Gilded Age, 2nd ed. Princeton, NJ: Princeton University Press, 2016.

Bartolini, Stefano. The Political. London: ECPR Press/Rowman and Littlefield International, 2018.

Benton, Meghan. "The Problem of Denizenship: A Non-Domination Framework." Critical Review of International Social and Political Philosophy 17, no. 1 (January 2014): 46-69.

Berlin, Isaiah. The Hedgehog and the Fox. London: Weidenfeld and Nicolson, 1933.

Berman, Sheri. The Social Democratic Moment: Ideas and Politics in the Making of Interwar Europe. Cambridge, MA: Harvard University Press, 1998.

Blecher, Marc. "What - and How - Have Tianjin Workers Been Thinking?" Journal of Chinese Political Studies 13, no. 3 (October 2008): 249-267.

Blecher, Marc and Daniel Zipp. "Migrants and Mobilization: Sectoral Patterns in China, 2010-2013.” Global Labour Journal 6, no. 1 (January 2015): 116-126.

Bromwich, David. "The Fastidious President." London Review of Books 32, no. 22 (18 November 2010): 3-6.

. "The World's Most Important Spectator." London Review of Books 36, no. 13 (3 July 2014): 3-6. 
Bull, Hedley. The Anarchical Society: A Study of Order in World Politics. London: Macmillan, 1977.

Cai, Yongshun. "Power Structure and Regime Resilience: Contentious Politics in China." British Journal of Political Science 38, no. 3 (July 2008): 411-432.

Cohen, Roberta. "Integrating Human Rights in US Foreign Politics: The History, the Challenges and the Criteria for an Effective Policy." Brookings InstitutionUniversity of Bern Project on International Displacement, 2008. https://www. brookings.edu/wp-content/uploads/2016/06/04_human_rights_cohen.pdf

Collier, Ruth Berins and David Collier. Shaping the Political Arena: Critical Junctures, the Labor Movement, and Regime Dynamics in Latin America. South Bend, IN: University of Notre Dame Press, 2002.

Crozier, Michel and Erhard Friedberg. L'acteur et le système. Paris: Seuil, 1977.

della Porta, Donatella and Michael Keating, eds. Approaches and Methods in the Social Sciences. Cambridge: Cambridge University Press, 2008.

Digeser, Peter. "The Fourth Face of Power." Journal of Politics 54, no. 4 (November 1992): 977-1007.

Dryzek, John S. and Jeffrey Berejikian. "Reconstructive Democratic Theory." American Political Science Review 87, no. 1 (March 1993): 48-60.

Duverger, Maurice. Les Partis Politiques. Paris: Armand Colin, 1951.

Easton, David. A Framework for Political Analysis. Englewood Cliffs, NJ: Prentice-Hall, 1965.

Fact/Myth. April 26, 2017. http://factmyth.com/factoids/thomas-jefferson-called-forrebellion-and-revolution/; accessed November 29, 2018.

Ferguson, Adam. An Essay on the History of Civil Society. London: T. Cadell, 1782.

Friedman, Eli. Insurgency Trap: Labor Politics in Post-Socialist China. Ithaca, NY: ILR Press, 2014.

Fukuyama, Francis. The End of History and the Last Man. New York: Avon, 1992.

. The Demand for Dignity and the Politics of Resentment. New York: Farrar, Straus and Giroux, 2018.

Gandhi, Jennifer. Political Institutions under Dictatorship. New York: Cambridge University Press, 2008.

Gehlen, Arnold. Der Mensch: Seine Natur und seine Stellung in der Welt. Edited by Karl-Siegbert Rehberg. Frankfurt: Verlag Vittorio Klosterman, 2016.

Ginsburg, Tom and Tamir Moustafa. Rule by Law: The Politics of Courts in Authoritarian Régimes. New York: Cambridge University Press, 2008.

Gramsci, Antonio. Selections from the Prison Notebooks. Edited by Quintin Hoare and Geoffrey Nowell Smith. New York: International Publishers, 1971.

Guilhot, Nicholas. The Democracy Makers: Human Rights and the Politics of Global Order. New York: Columbia University Press, 2005.

Haggard, Stephan and Robert R. Kaufman. The Political Economy of Democratic Transitions. Princeton, NJ: Princeton University Press, 1995.

Hamilton, Alexander and James Madison. The Federalist Papers. New York: Penguin Classics, 1987.

Herrenstein, Richard and Charles Murray. The Bell Curve: Intelligence and Class Structure in American Life. New York: Free Press, 1994.

Hirschman, Albert O. Exit, Voice and Loyalty. Cambridge, MA: Harvard University Press, 1970.

Huntington, Samuel P. Political Order in Changing Societies. New Haven, CT: Yale University Press, 1968. 
Isocrates II. On the Peace. Areopagiticus. Against the Sophists. Antidosis. Panathenaicus. Translated by George Norlin. Cambridge, MA: Harvard University Press, 1929.

Kaplan, Abraham. The Conduct of Inquiry: Methodology for Behavioral Science. San Francisco, CA: Chandler Publishing Co., 1964.

Karl, Terry Lynn. "The Hybrid Regimes of Central America." Journal of Democracy VI, no. 3 (July 1995): 72-86.

Keating, Joshua. Invisible Countries. New Haven, CT: Yale University Press, 2018.

Khaldûn, Ibn. The Muqaddimah: An Introduction to History. Translated by Franz Rosenthal and edited by N. J. Dawood. Princeton, NJ: Princeton University Press, 1994.

King, Gary, Robert Keohane and Sidney Verba. Designing Social Inquiry: Scientific Inference in Qualitative Research. Princeton, NJ: Princeton University Press, 1994.

Kuntz, Phillip and Mark R. Thompson. "More than Just the Final Straw: Stolen Elections as Revolutionary Triggers." Comparative Politics 41, no. 3 (2009): 253-272.

di Lampedusa, Giuseppe Tomasi. The Leopard. Translated by Archibald Colquhoun. New York: Knopf Everyman, 1991.

Lasswell, Harold. Politics: Who Gets What, When, How. New York: McGraw Hill, 1936.

Lebow, Richard Ned. A Cultural Theory of International Relations. Cambridge: Cambridge University Press, 2009.

Lechner, Norbert. "El (maldito) factor tiempo." Espacios 5 (1995): 66-71.

- Obras escogidas de Norbert Lechner: volume II. Santiago: LOM Ediciones, 2007.

Lenin, Vladimir. “The State and Revolution.” In Robert Tucker, ed., The Lenin Anthology. New York: Norton, 1975: 344.

Levitsky, Steven and Daniel Ziblatt. How Democracies Die. New York: Crown, 2016.

Li Cheng. "The End of the CCP's Resilient Authoritarianism? A Tripartite Assessment of Shifting Power in China." China Quarterly 211 (September 2012): 595-623.

Linz, Juan. "An Authoritarian Régime: Spain." In E. Allardt and Y. Littunen, eds. Cleavages, Ideologies and Party Systems: Contributions to Comparative Political Sociology. Helsinki: Transactions of the Westermarck Society, 1964: 291-341.

Lowi, Theodore. "American Business: Public Policy, Case Studies, and Political Theory." World Politics XVI, no. 4 (1964): 677-715.

Lukes, Steven. Power: A Radical View. New York: Macmillan, 1973.

Machiavelli, Niccolò. The Prince. Edited and translated by David Wooton. Indianapolis, IN: Hackett, 1995.

Marx, Karl. Capital: A Critique of Political Economy, Volume 1. Edited by Ernest Mandel and translated by Ben Fowkes. New York: Penguin, 2004.

Mearsheimer, John. The Tragedy of Great Power Politics. New York: Norton, 2001.

Morgenthau, Hans. Politics among Nations: The Struggle for Power and Peace. New York: Knopf, 1948.

Munck, Gerardo and Richard Snyder. Passion, Craft, and Method in Comparative Politics. Baltimore, MD: Johns Hopkins University Press, 2007.

Nathan, Andrew. "Authoritarian Resilience." Journal of Democracy 14, no. 1 (January 2003): 6-17.

Nussbaum, Martha. Political Emotions: Why Love Matters for Justice. Cambridge, MA: Harvard University Press, 2013.

O'Donnell, Guillermo and Philippe C. Schmitter. Transitions from Authoritarian Rule: Tentative Conclusions about Uncertain Democracies. Baltimore, MD: Johns Hopkins University Press, 1986.

Olson, Mancur. The Logic of Collective Action: Public Goods and the Theory of Groups. Cambridge, MA: Harvard University Press, 1971. 
Oxford English Dictionary. https://www.oed.com.

Pitkin, Hannah Fenichel. The Concept of Representation. Berkeley: University of California Press, 1972.

Pierson, Paul. Politics in Time: History, Institutions, and Social Analysis. Princeton, NJ: Princeton University Press, 2004.

Pierson, Paul and Jacob Hacker. Off Center: The Republican Revolution and the Erosion of American Democracy. New Haven, CT: Yale University Press, 2006.

Plato. The Republic. Translated by G. M. A. Grube. Indianapolis, IN: Hackett, 1992.

Popper, Karl. "Des nuages et des horloges. Une approche du problème de la rationalité et de la liberté humaine." La connaissance objective. Paris: Aubier, 1991: 319-382.

Putnam, Robert and Lewis Feldstein, with Donald Cohen. Better Together: Restoring the American Community. New York: Simon and Schuster, 2005.

Putnam, Robert, Robert Leonardi and Raffaella Nanetti. Making Democracy Work: Civic Traditions in Modern Italy. Princeton, NJ: Princeton University Press, 1993.

Ramzy, Austin. "China Environmental Protests Gather Force." Time, November 23, 2009.

Rieff, David. "Multiculturalism's Silent Partner: It's the Newly Globalized Consumer Economy, Stupid." Harpers (August 1993): 62-72.

Sandel, Michael. Democracy's Discontent: America in Search of a Public Philosophy. Cambridge, MA: Belknap Press, 1996.

Sartori, Giovanni. "Concept Misformation in Comparative Politics." American Political Science Review 64, no. 4 (December 1970): 1033-1053.

Schaffer, Frederic C. Elucidating Social Science Concepts: An Interpretivist Guide. New York and London: Routledge, 2016.

Scharpf, Fritz W. "Problem-Solving Effectiveness and Democratic Accountability in the EU." Max Planck Institute for the Study of Societies Working Paper 03/1, February 2003.

Schatz, Edward, ed. Political Ethnography: What Immersion Contributes to the Study of Power. Chicago, IL: University of Chicago Press, 2009.

Schelling, Thomas. The Strategy of Conflict. Cambridge, MA: Harvard University Press, 1960.

Schiff, Jade. Burdens of Political Responsibility: Narrative and the Cultivation of Responsiveness. Cambridge: Cambridge University Press, 2014.

Schmitter, Philippe C. "Crisis and Transition, but not Decline." Journal of Democracy 26, no. 1 (January 2015): 32-44.

Schmitter, Philippe C. with Arpad Todor. "Varieties of Capitalism and Types of Democracy." forthcoming.

Schneider, Carsten and Philippe C. Schmitter. "Liberalization, Transition and Consolidation: Measuring the Components of Democratization." Democratization 11, no. 5 (2004): 59-90.

Schwartz-Shea, Peregrine and Dvorah Yanow. Interpretive Research Design: Concepts and Processes. New York: Routledge, 2012.

Shapiro, Ian and Donald Green. Pathologies of Rational Choice Theory: A Critique of Applications in Political Science. New Haven, CT: Yale University Press, 1994.

Spanakos, Anthony P. "Conceptualising Comparative Politics: A Framework." In Anthony P. Spanakos and Francisco Panizza, eds. Conceptualising Comparative Politics. New York: Routledge, 2015: 1-14.

Streeck, Wolfgang. "How Will Capitalism End?” New Left Review 87 (May-June 2014): 35-64. 
Suny, Ronald Grigor. The Revenge of the Past: Nationalism, Revolution, and the Collapse of the Soviet Union. Stanford, CA: Stanford University Press, 1993.

de Tocqueville, Alexis. Democracy in America. New York: J. and H. G. Langley, 1841.

Tomba, Luigi. The Government Next Door: Neighborhood Politics in Urban China. Ithaca, NY: Cornell University Press, 2014.

Weber, Max. From Max Weber. Translated and edited by H. H. Gerth and C. Wright Mills. New York: Oxford University Press, 1946.

White, Gordon, Jude Howell and Shang Xiaoyuan. In Search of Civil Society. Oxford: Clarendon Press, 1996.

Whyte, Martin King. The Myth of the Social Volcano: Perceptions of Inequality and Distributive Justice in China. Stanford, CA: Stanford University Press, 2010.

Young, Iris M. Justice and the Politics of Difference. Princeton, NJ: Princeton University Press, 1990.

Žižek, Slavoj. In Defense of Lost Causes. London: Verso, 2017. 

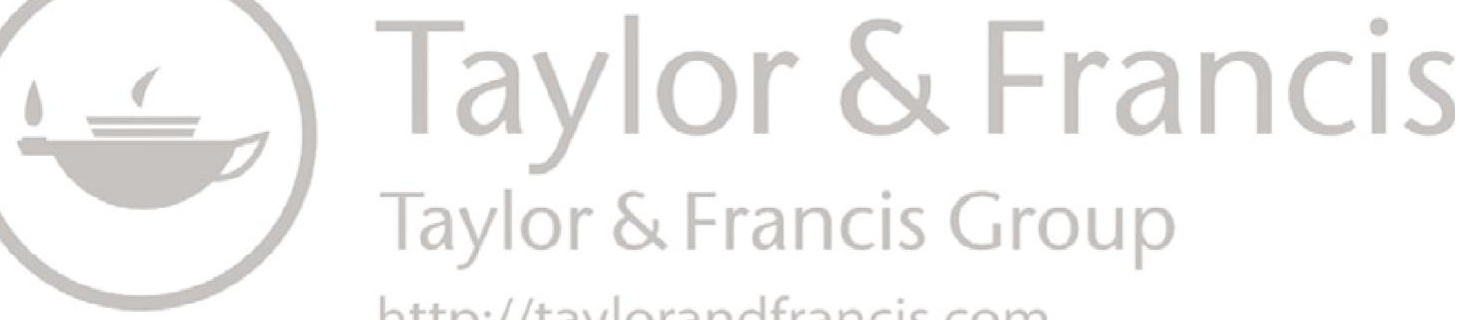

http://taylorandfrancis.com 


\section{INDEX}

Note: Italic page numbers refer to figures and page numbers followed by " $n$ " denote endnotes.

abnormal politics $15,16 \mathrm{n} 6,17$

accountability 60

acquiesce 48

African National Congress (ANC) 126n18 agency $15 \mathrm{n} 4,22-23,40$

agents 3-4, 3n6, 14, 17, 77, 120; civil

societies 28, 35-37; collectivities 27-30,

33; elaborations and qualifications

23-24; individual and autonomous human beings 25 ; interest association 33-34, 56-57; loyalists and sufferancers 24-25; past/present actions 23; political parties 30-33; preferences and political agency 26; rational choices 27 ; real-existing democracies $24,27,29$; reflexivity 23 ; re-presenting ideas 29; social movement 34-35; theories of "iterative games" 27

All But Dissertations (ABDs) 112n20

American Bar Association 78n33

Amnesty International 78n33

anti-corruption campaigns, South Korea 30n 49

Anti-Vietnam War 30n49

Arab Spring 30n48, 86n14

archeo democracies 116

argument 95

Aristotle 15, 56, 67; "master science" 8 ; politics, imprecision and indeterminacy 15 authoritarianism 59n110

authoritarian régimes 59

authoritarian resilience $21 \mathrm{n} 24,51,118$

autocracies 77; dichotomies 61-62;

self-referential $60 \mathrm{n} 114$

autocratic régimes $49,50 \mathrm{n} 88,59-60$

autonomous human beings 25

balance of power 73

barefoot empiricism 87n21

Bartolini, Stefano 2

behavioral economics $116 \mathrm{n} 3$

behaviorists $23 \mathrm{n} 31$

Bentham, Jeremy 102

Bismarck 124

Blecher, Marc 10n25-26, 62, 71n12, 109n17, 123n7-8

Bobbio, Norberto 22n30

Bolsonaro, Brazil 50n89

Brexit, UK 50n89, 54n103, 57n107, 86n14

Bromwich, David 6n13

Cameron, David 54n103

capital 69n7

capitalism 11, 64; and democracy 65n125, 84n8; Marxian historical materialism 37; and socialism $20 \mathrm{n} 23$

Carter, Jimmy: foreign policy $50 \mathrm{n} 88$

case selection 100; area studies 98; committing counter-factualism 101; 
configurations of variables 99; data gathering 97; inferences, descriptive or causal 99, 101; paired comparison design 98; quantity of variables 97,98 ; quasi-experiments 101; real-existing societies and polities 101-102; reductio ad absurdum strategy 99; thought experiments 101; topic, selection 97-98 causal/directional analytical modeling 123 causal inference: climate research 108-109;

Covering Law 111; critical ones 110; data exploitation 109; generalizability 109-110; numerical and narrative 108; researcher bias 110; strategy of case selection 110; Type One Confirmation Bias 110-111

"cause and effect" 87n21

centrifugal politics 39

centripetal politics 39

centrist parties 117

Chinese Communist Party 28n42

Chinese Cultural Revolution of 1966 $92 \mathrm{n} 3$

Chinese Great Leap Forward 7n18

Chinese Revolution 6n16

citizens/subjects 3n4, 30, 49, 60, 115

civil-military relations $69 \mathrm{n} 7$

Civil Rights 30n49

civil societies 28,118 ; autocracies 36 , 37; definition 35; democratic or participatory politics 36 ; institutions 36n60; intermediate bodies 36

civil wars $17 \mathrm{n} 12$

class: politics $72 \mathrm{n} 18$; and voting behavior, relationship between $95 \mathrm{n} 6$

cleavages 14, 17, 121; between Communist

Party leaders $32 \mathrm{n} 52$; context of

contingent events 41 ; cumulative

macro-structure 39; and factions,

distinguish between 37-38, 40;

state socialist régimes 40 ; structural

changes 40

coalition politics $63 \mathrm{n} 122$

coercion 47,57

collective action $8-9$ n22

collectivities 27

Collier, David 52

Collier, Ruth 52

collusion 46-47

colored revolutions 30n48, 40n70, 44n77

communism 5n11, 77, 115

comparative method 91

compete 46

competition 44,57 complex interdependence $122 \mathrm{n} 6$

compromise 48

concepts 17, 120; formation of 19-20;

ideal types 20; phenomenon or process

20; phenotypes and genotypes 21;

problem with 22

conceptualists $19 \mathrm{n} 19$

conceptualization 20-21n24; operative and inoperative 95; pre-conceptualized 94;

the state of theory 95; variables 94-96

conflict 45, 46

conformity $30,47,61,74,76,80,103,124$

consent 48-49, 68

consequences 14, 18, 122; collective

human existence 67 ; externalities

73-74; legitimacy 74-78; order 68-69;

production and distribution $70-71$;

recognition and respect $71-73$

constants 96

constitutionalize 68

contemporary politics 73

contingency $15 \mathrm{n} 4,89 \mathrm{n} 24$

contingent 41

convergence 115

convictions 41-42, 44n77, 57

Coolidge, Calvin $24 \mathrm{n} 38$

cooperation $45,46,57$

cooptation 47,57

corporatism $21 \mathrm{n} 26$

corporatist $33,110 \mathrm{n} 19$

counter factualism 101

credibility 30 iníí

crises 13

critical elections 89

critical junctures, concept of 52n95

Crozier, Michel 54

cultural homogeneity 75

Cultural Revolution 40n69, 62, 69n8

culture wars 73 n19

cyclones, political 52

Czech rising, 1968 92n3

data-gathering 85

dèmokratía 64

de-legitimation 76

democracies $24 \mathrm{n} 35$; other-referential

60n114; sub-types 61

democraduras 62, 65, 117

democratic régimes 59

democratizations, Brazil 60n113

denizens $71 \mathrm{n} 15$

"Departments of Government" 60n115

dependent variable 86

determinists $23 \mathrm{n} 31$ 
de Tocqueville, Alex 35

development (modernization) theory 88

dictablandas 62

differences 14, 17

direction 107

discovery 96

distribution 122

divergences 114

domestic politics 89

Durkheim, Emile 20

Duverger, Maurice 18n17

Easton, David 67n1

Elster, Jon 102

empathy 6,7

empires 57

endogeneity problem $87 \mathrm{n} 18$

entropy 64

equifinality 5

equity $70 \mathrm{n} 10$

essentialism $45 \mathrm{n} 80$

estimation 121

European Union (EU) 31

evaluation of results 111

exercise 17 ; of power 9-12

exit 23

explicanda 15,40

explicandum 86, 87, 95, 98

explicans 15, 86, 87, 95, 98

externalities 73-74, 122

external validity 124

factions 37

failed states7 17, 116

"fallacy of aggregation" $124 \mathrm{n} 11$

family socialization, notions of 75

far-right movements, US 30n49

fascism 115

Fascist Parties 36n60

fear 43-44, 52, 119

Ferguson, Adam 35

foreign democracy promotion programs 50

fortuna 14, 15, 119, 122

fragmented authoritarianism 21n24, 118

Friedberg, Erhard 54

frozen conflicts 73

functional international organizations and agreements 74

futurologists 86 n14

Gehlen, Arnold 3n6

generalizability $109,124 \mathrm{n} 11$

genotypes 21
German Nazism 49

globalization $122 \mathrm{n} 6$

governance $19 \mathrm{n} 20$

"government-organized non-government organization" (GONGO) 118

governments 19n20, 60, 121, 124n13;

British 54n103; liberal/illiberal 61;

tyrannical/institutional 61

Gramsci, Antonio 2n3, 43

Green, Donald 25n39

guardian institutions 78n33

Habermas, Jürgen 102

habit 42-43

hegemony 57

Herrenstein, Richard 11n25

Hirschman, Albert 23

historicity 51; Chinese structural reforms $51 \mathrm{n} 93$

Hobbes, Thomas 41n73, 68n2

homo sapiens $5,7 \mathrm{n} 20,9$

Hungarian Uprising, 1956 92n3

Huntington, Samuel 12n28, 22n30

hybrid régime $59 \mathrm{n} 112$

hybrids 59

idea 90

idealists 85

"ideal-not-yet-existing democracy" 64

ideals 81

ideal types 20,125

imperialism $73 \mathrm{n} 20$

independence movement, Taiwan 30n49

independent variable 86

Indian National Congress 31n51

individual 25

inoperatives 95-96

inputs 120

institutionalization: and politics $44 \mathrm{n} 78$

institutions 11,12

interest 42, 43n77

interest association 33-34

interest intermediation 34

interests 41

international advocacy groups 50

International Labor Organization 78n33

International Monetary Fund (IMF) 31, 57

international régimes 73

Inter-Ocular Impact Test 107n15

intra-party pluralism 118

irrelevant variables 96

1978 Islamist Uprising, Iran 30n48

Israel-Palestine 56n106

Italian Fascism 49 
Japanese Liberal Democratic Party 38n64 Jaruzelski, Wojciech 70n11

\section{Karl, Terry 59n112}

Kremlinology 92n3

labor $69 \mathrm{n} 7$

ladder of abstraction, level of generality $22 \mathrm{n} 29$

Lasswell, Harold 67n1

Lechner, Norbert 4, 52

legal-formal 76n23

legitimacy $12,77,122$; definition 74-76; input and output $76 \mathrm{n} 23$; politics and legitimacy forms 74 ; and power 74

legitimate 11

legitimation strategies $78 \mathrm{n} 31$

liberal bias $82-85$

liberal democracies 24n35, 26n40, 51

liberalism 77

liberalizing autocrats 65

Lieberman, Joseph 6n13

Linz, Juan 59n110

Llosa, Mario Vargas 68n 4

London Review of Books (Bromwich) 6n13

loyalty 23,42

Machiavelli, Niccolò 15, 41n73, 114n1, 119; abnormal (female times) politics 16n6; normal (male times) politics 16n6; politicians (Princes) 16n7; Type One politics 52-53; Type Two politics 53

Madison, James 38-39; argument for pluralism 39

Mair, Peter 31, 32

Mandela, Nelson 126n18

manipulation 57

Mao Zedong 6n16, 40n69, 62, 69n8

Marxists 23n31

Marx, Karl 11n25, 20, 45n80, 102; historical materialism 37

mass organizations 34

measurement: course corrections 106; internal quality control 105; learning from research process 106; quantitative and qualitative indicators 105-106

mechanisms 14, 17, 121; coercion 47, 49; cooptation 47, 49; hegemony 48, 49; manipulation 47-48, 49

modernization theory 26n40, 50, 66 monist 34

moral sentiment 75

motives 14, 17, 121; autocracies 43; convictions $41-42$; loyalty 42 ; out of fear 42n75, 43; out of habit 42-43;

passions 41; power-holder 44;

self-regarding interests 41

multi-nationalism 77

Murray, Charles 11n25

\section{NAFTA 57n107}

nation 56, 58n109

nationalism 78n31; in East Asia 78n31

nation-states $16,17 \mathrm{n} 12,27$

Nazi 36n60

necessità 14, 15, 119

neo-corporatist systems 126

neo democracies 116

new authoritarianism, theory of $22 \mathrm{n} 30$

Nixon, Richard 24n38

non-government organizations

(NGOs) 118

non-revolutionary transition 89

normal politics $15,16 \mathrm{n} 6,17$

normative political theory 86

norms 10

null hypothesis $87 \mathrm{n} 20$

Nussbaum, Martha 25n39; emotions $25 n 39$

Obama, Barack 6n13

O'Donnell, Guillermo 18n18, 62

ontology 19n21

operationalization of variables 103-105

operative variables 95, 104

order 122; democratic régimes 68 ; domestication of power 68,69 ; value order 69; violent revolutionaries 69 outputs 120

"Pareto Optimal" 2

parties: "those of movement" (the Left)

18n17; "those of stasis" (the Right)

$18 \mathrm{n} 17$

passions 41, 42, 44n77, 57

path dependence 106, 111

path-independence 89

Pekingology 92n3

phenotypes 21

pluralism 39, 110n19, 121n4

pluralist 33

police violence $77 \mathrm{n} 26$

policies $122 \mathrm{n} 5$

Polish Solidarność 92n3

political activists $3 \mathrm{n} 4$

political agents 8

political culture $76 \mathrm{n} 24$

political parties 30-33 
political radicalism $65 \mathrm{n} 126$

political science 9n23, 114n2

political sociology $92 \mathrm{n} 3$

political violence: private 7

politics 1-2; abnormal 15, 17; autocratic

political régimes 6 ; causality and

consequence 5 ; centrifugal 39 ;

centripetal 39; citizens/subjects 3 n 4 ,

$30,49,60,115$; communication $6-7,8$; comparative $21 \mathrm{n} 24$; conservatives 4,11 , 24n37; domestic 17n13, 89; genotypes and phenotypes, problem of $3 n 4$; international 17n13; "the Leftward Bias" 18n17; liberal democracies 18; micro- (o meso-) foundations 14-15, 17, 25; normal 15, 17; open systems 9; of progressives 4, 11, 24n 37 ; quality of 10; rational choice 115-116; real-existing democracies $2 \mathrm{n} 2,10 \mathrm{n} 24$; realistic science of 8 ; as science 119, 120; sphere of human activity, characteristics 8; telos of 18; Type One politics 15-16, 17; Type Two politics $15,16,17$

polities, sub- or supra-national 75 politokratía, 64

politologists $3 n 4,21$; of ethnographic methods 22n27; Median Voter, notion of 39n68; theoretical pre-disposition 19; X-Y relationship 87-88, 89

politology 9, 16; International (or inter-state) relations 16 polyfinality 5

Popper, Karl 52

populist parties 116, 117

post-World War II East Asia 65

potential risks and benefits 121

power 2, 9, 14, 17; crises 13; definition

$2 \mathrm{n} 2$; incumbency $12-13$; inequality of 29; logic of action-reaction 12; resources 78; structural or functional 89 ; voluntaristic 89

practices 10

private rating agencies $72 \mathrm{n} 17$

processes 14, 17, 121; collusion 46; competition 44; conflict 46; cooperation 45-46; of electoral competition in REDs 45; power resources, use of 44-45

production 70-71, 122

Progressive Movement 115

project 90

projections 94

proof 96 proposal writing: argument, normative or logical consistency 102-103; research funding 103; strategic choices 103

puzzles 94

Qualitative Comparative Analysis (QCA) 86 n16

Rawls, John 102

real-existing democracies (REDs) 24, 27, 31-32, 49-50, 55, 64, 77n25, 78, 115,117

real-existing politics 122

realism 82

realists $16 \mathrm{n} 9,85-86,88$

recognition 122; existence of differences 71; leaders and citizens/subjects 73; memberships and identities 72

régimes $11,12,14,16,18,27,57,121$; accountability 60 ; by agents, processes and mechanisms 58-59; autocracy 64-65; democracy 63-64; democratic, totalitarian and autocratic 59-60, 61; dictablandas and democraduras 62; differences between USSR and China 62 ; generic types 60 ; institutional 60; into micro-foundations 63 ; organizational structures 60-61; producing governments 60

replication crisis $124 \mathrm{n} 11$

representation 29

reproduction 122

research cycle 93

research design 90; area specialists 92; causal inference 108-111; comparative 91; conceptualization 94-96; evaluation of results 111; formation of hypotheses 96-97; "the Logic of Discovery" 112; "Logic of Explication" 112; measurement 105-106; operationalization of variables 103-105; point of departure 11; political research cycle 91, 92; predicting/estimating outcomes $91 \mathrm{n} 2$; process of translation 90; professionalization 92; proposal writing 102-103; selection of cases 97-102; survey research 90-91; test for association 106-108

respect $71-73,122$

responsibly 31

responsive 31

reunification of Germany

86 n14 
Romo, Mishella 17n13, 18n18, 20, 25n39, 59n112

rules 10

Scharpf, Fritz 76n23

Schmitter, Philippe 6n12, 21n26, 38n66, 59n111, 62, 69n6, 77n25, 119, 125n15-16, 126n18, 901

secondary citizens/subjects 30 secularism 77

self-declared politicians $3 \mathrm{n} 4$

sequence 107

Shapiro, Ian 25n39

significance 107

skepticism, intrinsic $22 \mathrm{n} 28$

social credit $72 \mathrm{n} 17$

Social Darwinism 11n25

social movement 34-35

Solidarity Movement 36n61

sovereignty $16-17,58$

Soviet Union, collapse of $86 \mathrm{n} 14$

Spanakos, Tony 8n21

Spencer, Herbert 10n25

stability 68

Stalinist USSR 65

state $56,58 \mathrm{n} 109$

state corporatism $34 \mathrm{n} 56$

state socialism 5, 5n11,36n61, 115

state socialist régimes $59 \mathrm{n} 111$, 60n117, 93n4

Streeck, Wolfgang 65

strength 107

structure $15 \mathrm{n} 4,40$

sub national units 57

sufferance 24

Suny, Ronald: collapse of USSR 32n52, $57 \mathrm{n} 108$

supra national institutions 57

sur-idealists 85,86

surrealists 85,86

telos 18

temporalities 14, 17-18, 121; autocracies

55, 60n114; chronological time 51-52,

53 n 100 ; contemporary politics $52-53$;

national identity 55 ; political timing

$53-56$; rules of the régime 54

test for association: data gathering

106-107; narration 108; niche players

108; quantitative data 107-108;

recipients of scores 107; variables 107 theoretic trajectory $79-82$

there is no single best strategy or set of strategies 91

Thermodynamics, First and Second

Laws of 4

third parties $78 \mathrm{n} 33$

Third Wave of democratization, Latin America and East Asia 30n48

throughputs 120

time 107; chronological 51-52, 53n100; political 53-56; reckoning and constructing 57

time-tested scientific formula 123

timing 107

Tönnies, Ferdinand 20

topic 90

totalitarian régimes 29, 59

Trans-Pacific Partnership 57n107

Trump, Donald 11n26, 50n89; “Trump moment" 55n105

trust $46,47 \mathrm{n} 83$

Type One politics $15-16,17,52-53,74$, 89,122

Type Two politics $15,16,17,53$, 73,89

unit 14,17, 27, 121; domestication of conflict 56 ; functioning units $56-57$; nation-state 56 ; sovereignty 58 ; sub-national units 57

validity $88 \mathrm{n} 22$

variables 86,94 ; operationalization of 101-103

Vietnam War 51n93

violence: avoidance of 70; domesticating use of 115 ; individual or collective 10

virtù $14,15,119,122$

voice 23

Washington consensus 50

Weber, Max 7, 20, 34n56, 76n23

words 94

World Trade Organization (WTO) 57

Xi Jinping: corruption in Chinese Communist Party 33n54

Žižek, Slavoj 24n37

zoon politikon (political animals) 3n6 